PFC/RR-90-10

\title{
Fatigue, Fracture, and Life Prediction Criteria for Composite Materials in Magnets
}

\author{
F.M.G. Wong \\ Plasma Fusion Center \\ Massachusetts Institute of Technology \\ Cambridge, MA 02139
}

June 1990

\section{DISCLAIMER}

\begin{abstract}
This report was prepared as an account of work sponsored by an agency of the United States Government. Neither the United States Government nor any agency thereof, nor any of their employees, makes any warranty, express or implied, or assumes any legal liability or responsibility for the accuracy, completeness, or usefulness of any information, apparatus, product, or process aisclosed, or represents that its use would not infringe privately owned rights. Reference herein to any specific commercial product, process, or service by trade name, trademark, manufacturer, or otherwise does not necessarily constitute or imply its endorsement, recommendation, or favoring by the United States Government or any agency thereof. The views and opinions of authors expressed herein do not necessarily state or reflect those of the United States Government or any agency thereof.
\end{abstract}

This work was supported by the U. S. Department of Energy Contract No. DE-AC0278ET51013. Reproduction, translation, publication, use and disposal, ip whole or in part by or for the United States government is permitted. 


\section{FATIGUE, FRACTURE, AND LIFE PREDICTION CRITERIA FOR COMPOSITE MATERIALS IN MAGNETS}

by

FRANK MICHAEL GERARD WONG

S.B., Nuclear Engineering
Massachusetts Institute of Technology (1984)
and
S.M., Nuclear Engineering
Massachusetts Institute of Technology (1984)

Submitted to the Department of Nuclear Engineering in partial fulfillment of the requirements for the degree of

DOCTOR OF PHILOSOPHY

at the

MASSACHUSETTS INSTITUTE OF TECHNOLOGY

May 1990

(C) Massachusetts Institute of Technology 1990

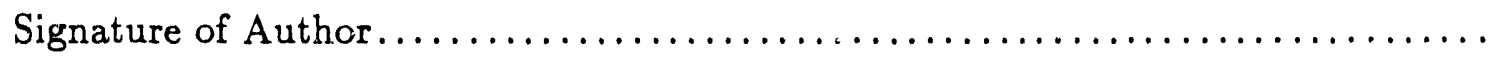

Department of Nuclear Engineering Maj 18, 1990

Certified by

Dr. Ronald G. Ballinger

Thesis Superviscr

Accepted by

Dr. Allan F. Henry

Chairman, Departmental Committee on Graduate Students 


\title{
FATIGUE, FRACTURE, AND LIFE PREDICTION CRITERIA FOR COMPOSITE MATERIALS IN MAGNETS
}

\author{
by \\ FRANK MICHAEL GERARD WONG
Submitted to the Department of Nuclear Engineering on May 18, 1990, in partial fulfillment of the requirements for the degree of Doctor of Philosophy in Nuclear Engineering

\begin{abstract}
An explosively-bonded copper/Inconel 718/copper laminate conductor was proposed to withstand the severe face compression stresses in the central core of the Alcator C-MOD tukamak toroidal field (TF) magnet. Due to the severe duty of the TF magnet, it is critical that an accurate estimate of useful life be determined. As part of the effort to formulate an appropriate life prediction, fatigue crack growth experiments were performed on the laminate as well as its components. Crack growth experiments were done at room temperature and $77^{\circ} \mathrm{K}$. A switched D.C. potential drop methnd was used to measure crack length. Metallographic evaluation of the laminate interface revealed many shear bands in the Inconel 718. Shear bands and shear banc' cracks were produced in the Inconel 718 as a result of the explosion bonding process. These shear bands were shown to have a detrimental effect on the crack growth behavior of the laminate, by significantly reducing the load carrying capability of the reinforcement layer and providing for easy crack propagation paths.

Fatigue crack growth rate was found not only to be dependent on temperature but also on crientation. Fatigue cracks grew faster in directions which contained shear bands in the plane of the propagating crack.

Fractography showeci crack advancement by fatigue cracking in the Inconel 718 ani ductile tearing of the copper at the interface. However, further away from the interfaces, the copper exh:bited fatigue striations indicating that cracks were now propagating by fatigue.

Taminite life prediction results showed a strong dependence on shear band orientation, and exhibited little variation between room temperature and $77^{\circ} \mathrm{K}$. Predicted life of $i$ is laminate was lower when the crack propagation was along a
\end{abstract}


shear band than when crack propagation was across the shear bands. Shear bands appear to have a dominating effect on crack growth behavior. The life prediction presented may be unconservative in the case where crack propagation is along a shear band, but conservative when crack propagation is across the shear bands.

Thesis Supervisor: Ronald G. Ballinger

Title: Associate Professor of Nuclear Engineering and Materials Science and Engineering 


\section{Dedication}

3

To my mother Shirley

For all the years of generous

care and love 


\section{Acknowledgments}

Many people have provided me with much help and assistance in my research. I would like to take this opportunity to thank them.

First, I would like to acknowledge the members of my Ph.D. committee. I am particularly grateful to Prof. Ronald Ballinger, my thesis advisor, who over the years has provided much invaluable expertise, insight, and guidance during my graduate studies. I am also grateful to Drs. Herbert Becker and David Gwinn, my thesis readers, who have taught me much engineering design and analysis over the years. Hopefully, some of their engineering intuition has rubbed off on me. I would like to thank Prof. John Meyer, my undergraduate and Masters thesis advisor, whose advice and guidance over the years is much appreciated. I would also like to thank Prof. Ian Hutchinson, who is one of the best teachers I have had.

Second, I am very grateful for the invaluable assistance of the Alcator technical staff: Frank Silva, Bill Byford, Mark Iverson, Bob Childs, Bill Parkin, Bill Beck, Steve Tambini, Richie Danforth, Peter Desjardins, Joe Daigle, Cees Holtjer and Ralph Griffith. Their consultation, expertise, and workmanship were truly more than anyone could ask for.

Third, I would like to thank scientists and fellow students in the Materials Lab and the Plasma Fusion Center for the generous assistance, invaluable suggestions, creative insight, infinite discussions, on everything from fracture mechanics to life in general : Dr. Ilsoon Hwang, Marty Morra, Prof. Regis Pelloux, Dr. Glenn Romanowski, Rui Vieira, Dr. Jun Feng, Pete Stahle, John Murphy, David Humphreys, Marie Oshima, and Samuel Tsui.

Finally, I would like acknowledge my family: my mother Shirley, my sisters Cathy and Mary Anne, my brother Tim, and my maternal grandparents Dr. and Mrs. Richard K. Chun, who all have given much love and support throughout my 
academic career. None of this would be have been possible without them. Although my grandfather Dr. Richard K. Chun could not be here to see the completion of this research, he is certainly here in spirit. 


\section{Contents}

$\begin{array}{ll}\text { Abstract } & 2\end{array}$

Dedication $\quad 4$

Acknowledgments $\quad 5$

$\begin{array}{ll}\text { Table of Contents } & 7\end{array}$

$\begin{array}{ll}\text { List of Figures } & 11\end{array}$

$\begin{array}{ll}\text { List of Tables } & 15\end{array}$

$\begin{array}{lll}1 \text { Introduction } & 17\end{array}$

1.1 Alcator C-MOD Toroidal Field Magnet System . . . . . . . . 21

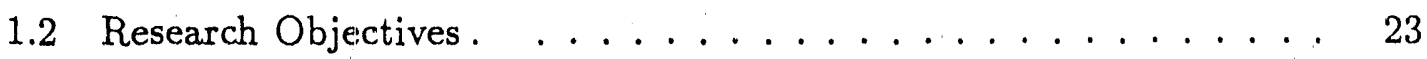

1.3 Organization of the Thesis $\ldots \ldots \ldots \ldots \ldots \ldots$

2 Literature Review $\quad 25$ 
2.1 Explosion Bonding Mechanics ... . . . . . . . . . 25

2.1.1 Background Theory ................. 25

2.1.2 Explosion Bonding Mechanics ............. 27

2.1.3 Jetting Phenomenon ............... 30

2.1.4 Bond Characteristics ............... 33

2.1.5 Mechanical Properties . . . . . . . . . . 37

2.1.6 Explosion Bonding of the Alcator C-MOD Laminate . . . 38

2.2 Copper $107 \ldots \ldots \ldots \ldots$. . . . . . . . . . . . . . . 40

2.3 Inconel $718 \ldots \ldots \ldots \ldots \ldots$

2.4 Fatigue and Fracture ..................... 45

2.5 Stress Intensity Factors . . . . . . . . . . . . . . . . . . 48

2.5.1 Crack Tip Plasticity ................. 51

2.5.2 Plane Stress and Plane Strain ............. 53

2.6 D.C. Potential Drop Crack Monitoring Technique . . . . . . . . 57

2.7 Life Prediction $\ldots \ldots \ldots \ldots 6$

3 Experimental Setup, Specimen Design, and Procedures 64

3.1 Experimental Setup . . . . . . . . . . . . . . 64

3.1.1 DC Potential Drop Crack Measurement System . . . . . . 65

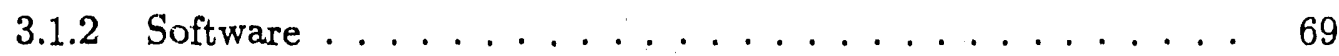

3.1.3 Cryogenic System . . . . . . . . . . . . . 71

3.2 Specimen Design . . . . . . . . . . . . . . . . 79

3.2.1 Tensile Test Specimens . . . . . . . . . . . . . 81 
3.2.2 Center Cracked Tension Panel . . . . . . . . . . . 81

3.2 .3 Grip Design . . . . . . . . . . . . 85

3.2.4 Specimen Machining Techniques . . . . . . . . . 87

3.3 Experimental Procedures . . . . . . . . . . . . . . . 91

3.3 .1 Tensile Tests $\ldots \ldots \ldots \ldots$. . . . . . . . . . . . 91

3.3.2 Fatigue Crack Growth Tests . . . . . . . . . . . . . 91

3.3.3 Simulation of Alcator C-MOD TF Core Loading . . . . . . . 94

3.3.4 Experiment Operating Parameters . . . . . . . . . 97

3.3.5 Analysis Procedures ... . . . . . . . . . . . 98

4 Materials Characterization $\quad 100$

4.1 Metallography .................... 100

4.2 Tensile Results . . . . . . . . . . . . . . . 107

5 Results 111

5.1 Fatigue Crack Growth Results . . . . . . . . . . . . . . . 111

5.1.1 Comparison of Crack Growth Rates . . . . . . . . . . 112

5.2 Fractography ........................ 126

6 Discussion $\quad \mathbf{1 3 2}$

6.1 Crack Advancement . . . . . . . . . . . . . . . . 132

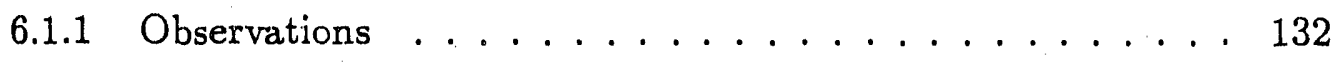

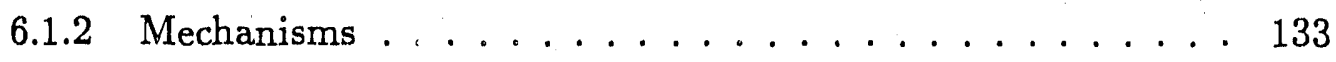

6.1 .3 Morphology .................... 133 
6.2 Application to Life Prediction . . . . . . . . . . . . . 146

6.2 .1 Assumptions . . . . . . . . . . . 146

6.2.2 Definition of Failure: Determination of Critical Crack Size . 146

6.2.3 Life Prediction Analysis . . . . . . . . . . . . 149

6.3 Applicability of Life Prediction Criteria to Alcator C-MOD TF Core 152

6.4 Implications for TF Core Service . . . . . . . . . . . . . . . . . 154

7 Summary, Conclusions, and Recommendations for Future Work 156

7.1 Summary and Conclusions . . . . . . . . . . . . 156

7.2 Recommendations for Future Work . . . . . . . . . . 158

A Stresses in C-MOD Laminate Conductor $\quad 160$

A.1 Determination of In-Plane Stresses Due to Face Compression Under Elastic Conditions . . . . . . . . . . . . . . . . . . . . . . .

A.2 Determination of Stress in Inconel 718 When The Applied Tresca Stress Exceeds The Copper Yield Strength . . . . . . . . . . . . 163

B Calculation of Stress Intensity Factors in Inconel 718 and Copper 107 Based on Equal CTOD

C D.C. Potential Drop Crack Measurement Calibration 


\section{List of Figures}

1.1 Alcator C-MOD Central Column of the Toroidal Field Magnet System 19

1.2 Isolated View of One TF Central Core Plate . . . . . . . . . . . 20

1.3 Alcator C-MOD Toroidal Field Coil . . . . . . . . . . . . . 22

2.1 Explosion Bonding Process Schematic (From Explosive Fabricators

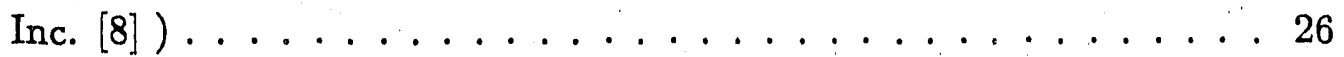

2.2 Attached Shock Waves When Collision Velocity $\gg$ Sonic Velocity . 28

2.3 Detached shock waves when collision velocity $>$ sonic velocity . . . 28

2.4 Pressure distribution created by a subsonic collision velocity . . . . 29

2.5 High velocity jet emanating from the collision point because of upstream pressure. From Reference $[3] \ldots . . . . . . . . . . . .32$

2.6 Mechanism for jetting away the surface layer from the parent metal. From Reference $[7] \ldots \ldots 32$

2.7 $\mathrm{Cu}-\mathrm{Ni}$ bond showing continuous layer bond zone, $\mathrm{X}$ 100. From Reference $[3] \ldots \ldots \ldots \ldots \ldots$

2.8 $\mathrm{Cu}-\mathrm{Ni}$ bond with a wavy interface. X 50. From Reference [3] . . . 35

2.9 Shear Bands in Inconel 718 at a Wavy Interface . . . . . . . . . 36

2.10 Typical da/dn versus $\Delta \mathrm{K}$ Curve. From [55] . . . . . . . . . . 47 
2.11 Crack Tip Coordinate System. From $[57] \ldots \ldots$. . . . . 50

2.12 Irwin's Correction for the Crack Tip Plastic Zone. From [58] . . . 52

2.13 Contraction Due to Transverse Strain in Front of a Crack Tip. From

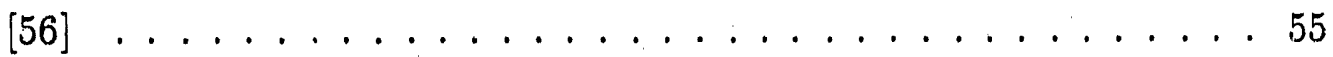

2.14 The Concepts of Plane Strain and Plane Stress. From [56] . . . . 56

2.15 D.C. Potential Drop Crack Measurement Calibration for Inconel $718 \quad 59$

2.16 D.C. Potential Drop Crack Measurement Calibration for Copper 10760

2.17 D.C. Potential Drop Crack Measurement Calibration for Laminate Longitudinal . . . . . . . . . . . . . . . . 61

2.18 D.C. Potential Drop Crack Measurement Calibration for Laminate Transverse . . . . . . . . . . . . . . . . . . . . .62

3.1 DC Potential Drop Crack Measurernent System Layout . . . . . . 68

3.2 The Closed Loop Servohydraulic Fatigue Testing Machine _ . . . 72

3.3 Schematic of the Cryogenic Dewar . . . . . . . . . . . . . 75

3.4 Cryogenic Dewar with Specimen and D.C. Potential Drop Crack Mea. surement Cables in Place $\ldots \ldots \ldots \ldots \ldots \ldots$

3.5 Liquid Nitrogen Filling Cryogenic Dewar with Laminate CCT Specimen 77

3.6 Cryogenic Fatigue Testing System After Four Days of Continuous Operation ...................... . . 78

3.7 Longitudinal and Transverse Specimen Orientations in the Explosion Bonded Laminate Plates . . . . . . . . . . . . . . . . . . 80

3.8 Tensile Test Specimen Design $\ldots \ldots \ldots \ldots$

3.9 Center Cracked Tension (CCT) Specimen Design $\ldots \ldots \ldots \ldots$ 
3.10 Normalized Size Requirements for a 3.0 inch wide CCT Fatigue Crack Growth Specimen . . . . . . . . . . . . . . . 84

3.11 Specimen Grip Assembly . . . . . . . . . . . . . . . 86

3.12 Schematic of Electric Discharge Machining (EDM) Process. From

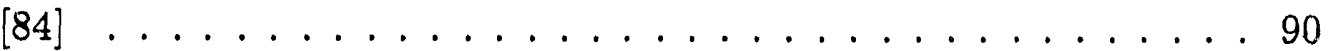

3.13 Probe Hole Locations for D.C. Potential Drop Crack Measurement

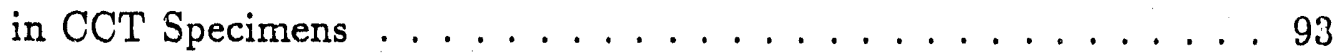

3.14 Alcator C-MOD Loading - Time History For The TF Core. From

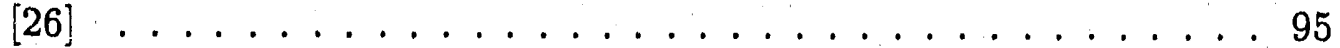

4.1 Shear Crack in Inconel 718 at Wavy Interface Prior to Etching . . . 102

4.2 Severe Plastic Deformation in Copper 107 at Wavy Interface . . . . 103

4.3 Variation of Microhardness Across Laminate Cross Section . . . . . 106

5.1 Comparison of Fracture Surfaces at Room Temperature and $77^{\circ} \mathrm{K} . \quad 114$

5.2 Incond $718 \mathrm{da} / \mathrm{dN}$ vs. $\Delta \mathrm{K}$ at Room Temperature . . . . . . . 116

5.3 Copper $107 \mathrm{da} / \mathrm{dN}$ vs. $\Delta \mathrm{K}$ at Room Temperature . . . . . . . . 117

5.4 Laminate Longitudinal da/dN vs. $\Delta \mathrm{K}$ at Room Temperature . . . 118

5.5 Laminate Transverse da/dN vs. $\Delta \mathrm{K}$ at Room Temperature . . . . 119

5.6 Copper 107 Longitudinal da/dN vs. $\Delta \mathrm{K} 77^{\circ} \mathrm{K} \ldots \ldots \ldots$

5.7 Copper 107 Transverse da/dN vs. $\Delta \mathrm{K} 77^{\circ} \mathrm{K} \ldots \ldots \ldots 121$

5.8 Laminate Longitudinal Specimen No. $23 \mathrm{da} / \mathrm{dN}$ vs. $\Delta \mathrm{K}$ at $77^{\circ} \mathrm{K}$. 122

5.9 Laminate Longitudinal Specimen No. $24 \mathrm{da} / \mathrm{dN}$ vs. $\Delta \mathrm{K}$ at $77^{\circ} \mathrm{K} \quad 123$

5.10 Laminate Transverse Specimen No. $32 \mathrm{da} / \mathrm{dN}$ vs. $\Delta \mathrm{K}$ at $77^{\circ} \mathrm{K}$. . 124

5.11 Laminate Transverse Specimen No. $33 \mathrm{da} / \mathrm{dN}$ vs. $\Delta \mathrm{K}$ at $77^{\circ} \mathrm{K}$. . 125 
5.12 Shear Cracks at the Ripple Interface $\ldots \ldots \ldots \ldots \ldots \ldots$

5.13 Inner Region of a Shear Crack at Higher Magnification . . . . . 128

5.14 Shear Cracks with Ductile Failure in Adjacent Regions . . . . . 129

5.15 Shear Cracks Present Along the Flat Interface . . . . . . . . 130

5.16 Transverse Laminate Tensile Test Specimen Interface . . . . . . 131

6.1 Schematic Showing Specimen Orientation, Explosion Direction, and Direction of Crack Propagation . . . . . . . . . . . 136

6.2 Crack Front Shapes in Longitudinal and Transverse Orientations . . 137

6.3 Ductile Tearing of Copper 107 at the Ripple Interface . . . . . . 138

6.4 Ductile Tearing of Copper at the Flat Interface . . . . . . . . 139

6.5 Fatigue Striations in Copper 107 Far From the Ripple Interface . . 140

6.6 Line of Cracks Within a Shear Band in a Transverse Specimen . . . 141

6.7 Shear Band Length and Shear Band Crack Length as Functions of Ripple Thickness (From [11] ). . . . . . . . . . . . . . 145

A.1 Stresses On An Element of Laminate Conductor . . . . . . . . . . 165

A.2 Definition of In-plane and Out-of-Plane Directions $\ldots \ldots \ldots 166$ 


\section{List of Tables}

2.1 Summary of Tensile Test Data Ranges for Copper C107 at Room Temperature, Reference $[40] \ldots \ldots \ldots$. . . . . 42

2.2 Inconel 718 Limiting Chemical Composition, Reference [28] $\ldots .44$

2.3 Inconel 718 Direct Age Process Specifications, Reference [29] . . . 44

2.4 Summary of Tensile Test Data Ranges for Inconel 718 at room temperature, Reference $[38]$. . . . . . . . . . . . . . . . 44

3.1 Alcator C-MOD Peak Stress Summary for Central Column During Flat-top Portion of a Full Field Pulse $\ldots \ldots \ldots \ldots$

3.2 In-Plane Stress Summary Due to Face Compression and Vertical Tension on Laminate Plates of the TF Core. . . . . . . . . . . . . 96

3.3 Testing Matrix Showing All Specimens Tested _ . . . . . . . . . 99

3.4 Fatigue Crack Growth Test Operating Parameters . . . . . . . . . 99

3.5 Fatigue Crack Growth Tests: Crack Length and Current Values . . 99

4.1 Metallographically Determined Explosion Bonding Interface Parameters . . . . . . . . . . . . . . . . . . . . . . . 104

4.2 Shear Band Angle and Density _. . . . . . . . . . . 104

4.3 Room Temperature Tensile Test Summary . . . . . . . . . . . 109 
$4.477^{\circ} \mathrm{K}$ Tensile Test Summary _ . . . . . . . . . . . . . 109

4.5 Inconel 718 Elongation Comparison: Before and After Bonding . . . 110

5.1 Experimentally Derived Crack Growth Equations Constants .... 115

5.2 Comparison of $\mathrm{da} / \mathrm{dN}$ for All Materials at Specified Values of $\Delta \mathrm{K}$. 115

6.1 Laminate Critical Crack Size $\mathrm{a}_{\text {crit }}$ as a Function of Location . . . 148

6.2 Laminate Life as a Function of Orientation, Temperature, and Location 151

A.1 Alcator C-MOD Stress Summary for Central Column . . . . . . 167

A.2 In-Plane Stress Summary Due to Face Compression and Vertical Ten-

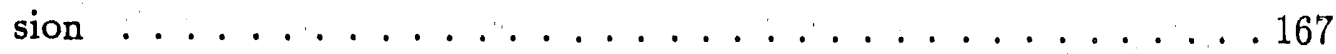

C.1 D.C. Potential Drop Calibration Least Squares Polynomial Statistics 172

C.2 Verification of :) C Potential Crack Measurement with Optical Measurement . . . . . . . . . . . . . . . . . . 172

C.3 Verification of DC Potential Crack Measurement with ASTM E64786 a Standard . . . . . . . . . . . . . . . . . . . 172 


\section{Chapter 1}

\section{Introduction}

The success of the Alcator $\mathrm{C}$ tokamak in fusion research at MIT has reinforced the merits of the high-field, high-density tokarnak. As a next step in fusion research, MIT has decided to build a new high-field compact tokamak named Alcator CMOD. Alcator C-MOD will have the same major radius as Alcator $\mathrm{C}$, but it will have a 2:1 plasma elongation, a divertor, and higher plasma current. It is designed to be heated by ion cyclotron range of frequencies (ICRF) and to be prototypical of an ignition machine, the proposed Compact Ignition Tokamak (CIT).

As a result of the high magnetic fields of Alcator C-MOD tokamak, high stresses are generated in the magnets that provide the toroidal magnetic field, the toroidal field (TF) magnets. In order to alleviate some of the engineering difficulties in TF magnets, MIT has chosen to use demountable TF coils with slip joints at all four corners of the magnet. The arguments for choosing demountable TF coils is basically twofold. Due to space limitations, demountable TF magnets will allow the ohmic transformer and poloidal field (PF) magnets to be located inside the TF magnets. Demountable TF coils will also allow easier access to the vacuum vessel. Due to the use of sliding joints at all four corners of the coil and also the use of an external frame superstructure supporting the TF magnet system, all inplane and 
out-of-plane loads on the top, bottom, and out-board legs are supported. However, on the inner leg, the inplane radial compression must be carried by wedging, and the out-of-plane loads must be taken by shear between the vertical plates that comprise the core. The use of sliding joints also alleviates much of the vertical tension usually found in the inner leg of a continious TF coil. Thus, with this magnet design, the most severe stresses are due to the compression loads at the inner leg.

In order to construct a dernountable TF coil that will withstand the severe stresses, MIT originally decided to use a copper C10700 / Inconel 718 / copper 10700 composite in the inner leg of the TF coil. The inner leg is shown in Figure 1.1. This composite is explosively bonded. The decision to use such a composite in the inner leg was based on strength and conductivity considerations. The severe stresses encountered are too great for pure copper to support by itself. Although copper alloys would provide higher strength than pure copper, the conductivity degrades with increasing strength, and as a result, since there is a larger temperature increase during operation, more energy is needed to cool the magnet. Thus, with Inconel 718 providing high strength and oxygen-free copper 107 providing good conductivity, the copper / Inconel 718 / copper composite was chosen. In each of the core plates. of the TF magnet, the thickness of Inconel 718 is $2.3 \mathrm{~mm}$. The cross sectional thickness of the composite varies from $5 \mathrm{~mm}$ at the bore to $15 \mathrm{~mm}$ at the outer surface. An view of one TF central core plate is shown in Figure 1.2. 


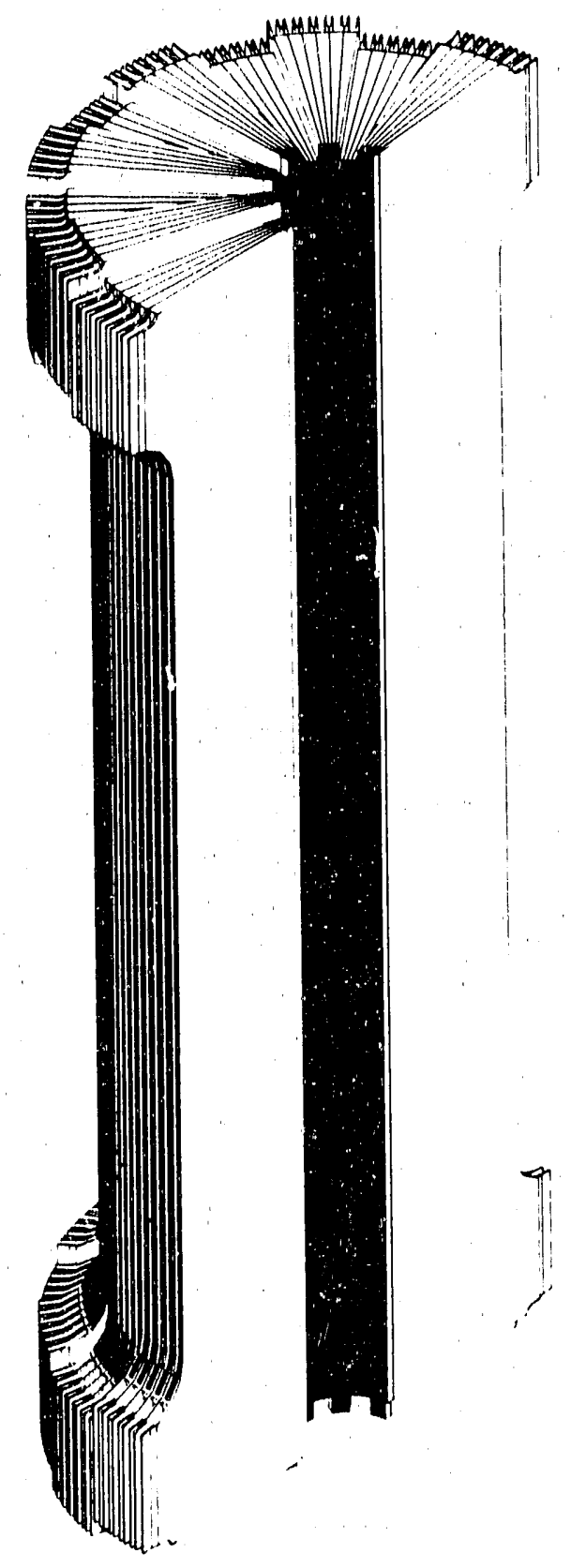

Figure 1.1: Alcator C-MOD Central Column of the Toroidal Field Magnet System 


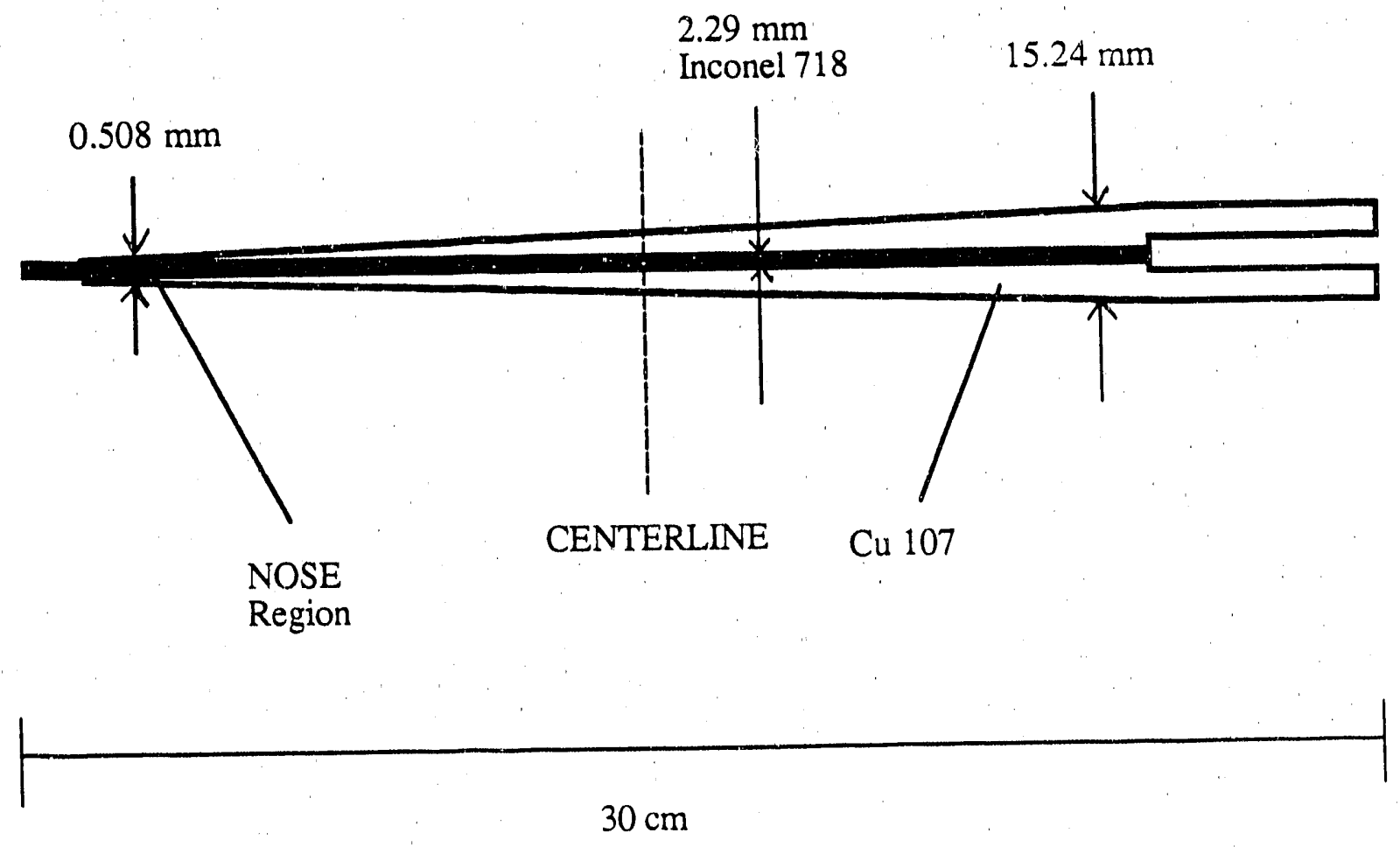

Figure 1.2: Isolated View of One TF Central Core Plate 


\subsection{Alcator C-MOD Toroidal Field Magnet Sys- tem}

The basic configuration of the Alcator C-MOD toroidal field coil is shown in Figure 1.3. The TF coil has a picture frame geometry with sliding joints at the four corners. Only the inboard legs were to be made of the explosion-bonded laminate. The two horizontal arms and the outboard leg are made of copper C10700. The outer TF magnet consists of 20 bundles of 6 plates each for a total of 120 turns. The magnet field strength on axis is designed to be $9 \mathrm{~T}$ for 50,000 full field pulses of approximately 5 seccids duration [25]. The entire TF magnet is cooled with liquid nitrogen prior to plasma startup. The magnet temperature does not remain at $77^{\circ}$ $\mathrm{K}$ during plasma operation, but rises to approximately $200^{\circ} \mathrm{K}$ near the end of each full field pulse [25]. Because the TF magnet must be cooled back to $77^{\circ} \mathrm{K}$ after every plasma, the minimum time between plasmas is approximately 20 minutes.

The TF central core is fabricated from the tapered laminate plates with thin sheets of polyimide / fiberglass insulation between them. The TF core measures $190 \mathrm{~cm}$. high and $30 \mathrm{~cm}$. in radius. 
1

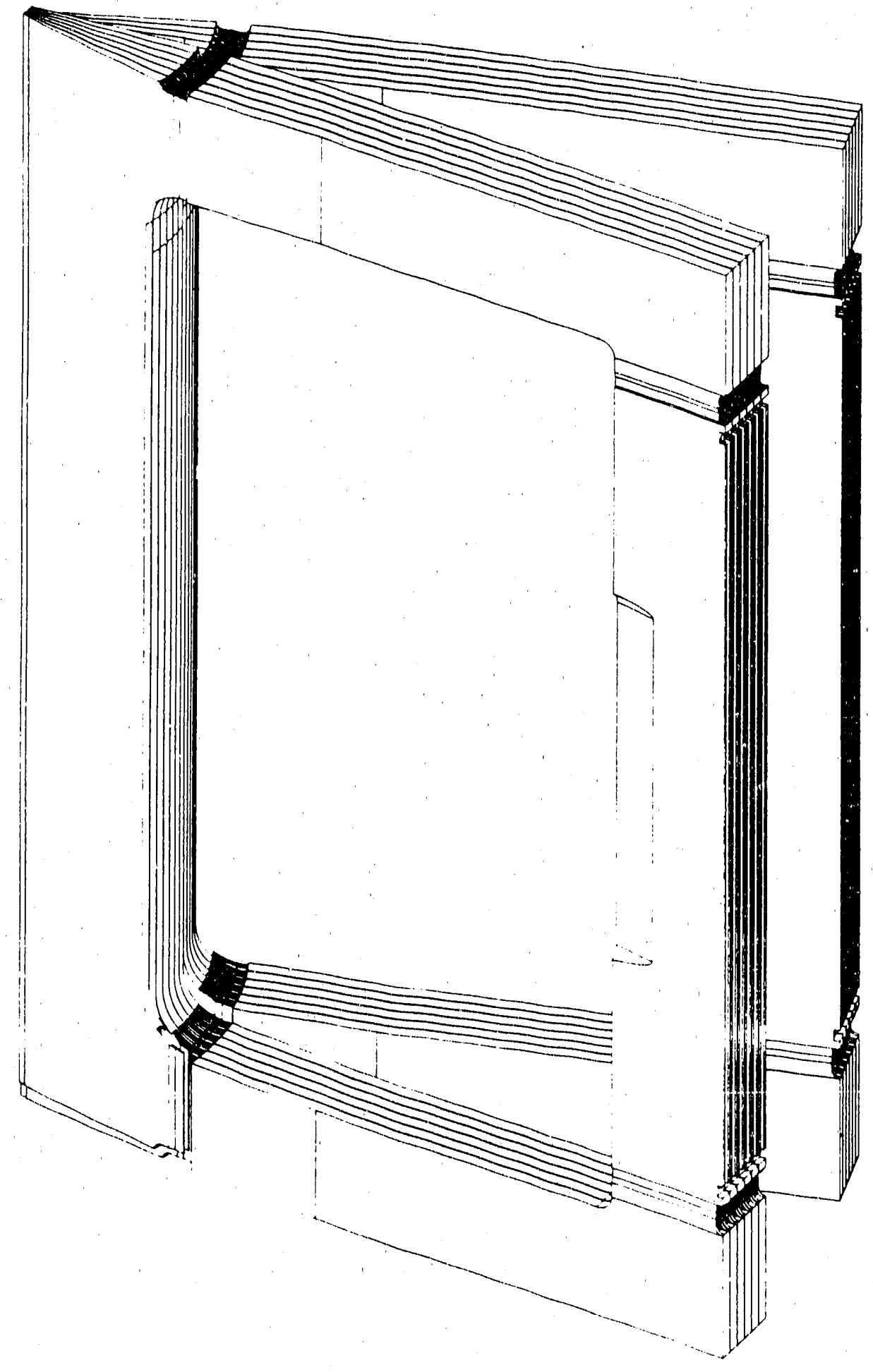

Figure 1.3: Alcator C-MOD Toroidal Field Coil 


\subsection{Research Objectives}

In order to formulate an appropriate life prediction for the composite materials in magnets, the fatigue and fracture characteristics of these materials must be investigated.

A coherent program of experinental testing is designed to investigate appropriately the fatigue and fracture characteristics of the composite materials. There is very littile fatigue and fracture data on these composites. No data exists on the fatigue and fracture properties at liquid nitrogen temperatures. It is also widely documented that in terision and shear tests, the explosively bonded interface is stronger than the weaker component. However, the fracture and fatigne properties of this interface have not been investigated. It also appears that explosion bonding alters the material significantly so that that predicting the b-havior of the laminate is not necessarily an interpolation based on its components. Clearly at this time, most the effective method of investigating the fatigue crack propagation behavior of this laminate is through an experimental approach.

The research objectives of this thesis may be described as follows:

- To understand the effects of the explosion bonding process on fatigue crack growth.

- To correlate these effects on crack growth with microstructural or mechanical behavior.

- To formulate an appropriate life prediction for this laminate. 


\subsection{Organization of the Thesis}

The thesis is organized as follows. Chapter 2 consists of a literature review which reviews the process and mechanics of explosion bonding, the mechanical properties of copper 10700 and Inconel 718, the essential concepts of fatigue and fracture mechanics, the concepts of D.C. potential drop crack measurement, the ideas associated with life prediction. Chapter 3 describes the experimental setup which includes mechanical and electrical systems, the specimen design for tensile and fatigue crack growth testing, and the experimental procedures used in performing the experiments. Chapter 4 describes the characterization of the laminate through metallography, microhardness, and tensile properties. Chapter 5 presents the results of the fatigue crack growth experiments and the associated fractography. Chapter 6 discusses these results in terms of microstructural and mechanical behavior and formulates a life prediction for the laminate. Chapter 7 presents conclusions and recommendations for future work. Appendix A details the analysis of determining the resulting in-plane stresses due to face compression and vertical tension stresses in the laminate. Appendix B details the analysis of determining the stress intensity factors in the copper and Inconel 718 with the equal crack opening displacement (CTOD) constraint. Appendix C describes the calibration of the D.C. potential drop crack measurement system. 


\section{Chapter 2}

\section{Literature Review}

\subsection{Explosion Bonding Mechanics}

In this section, the process of explosion bonding is reviewed and the effects on mechanical properties is examined

\subsubsection{Background Theory}

A schematic diagram of the explosion bonding proces 3 is illustrated in Figure 2.1. A layer of explosive is positioned above the cladding material, which is positioned a small distance above the parent material. The explosive is designed such that it detonates at constant velocity. With the detonation front moving parallel to the interface, the two materials are bought together under high rressure which produces a metallurgical bond. A detailed treatment of the theory of explosion bonding is given by Holtzman [3]. Only the major features of this treatment will be discussed here. 


\section{BASIC PROCESS SCHEMATIC}

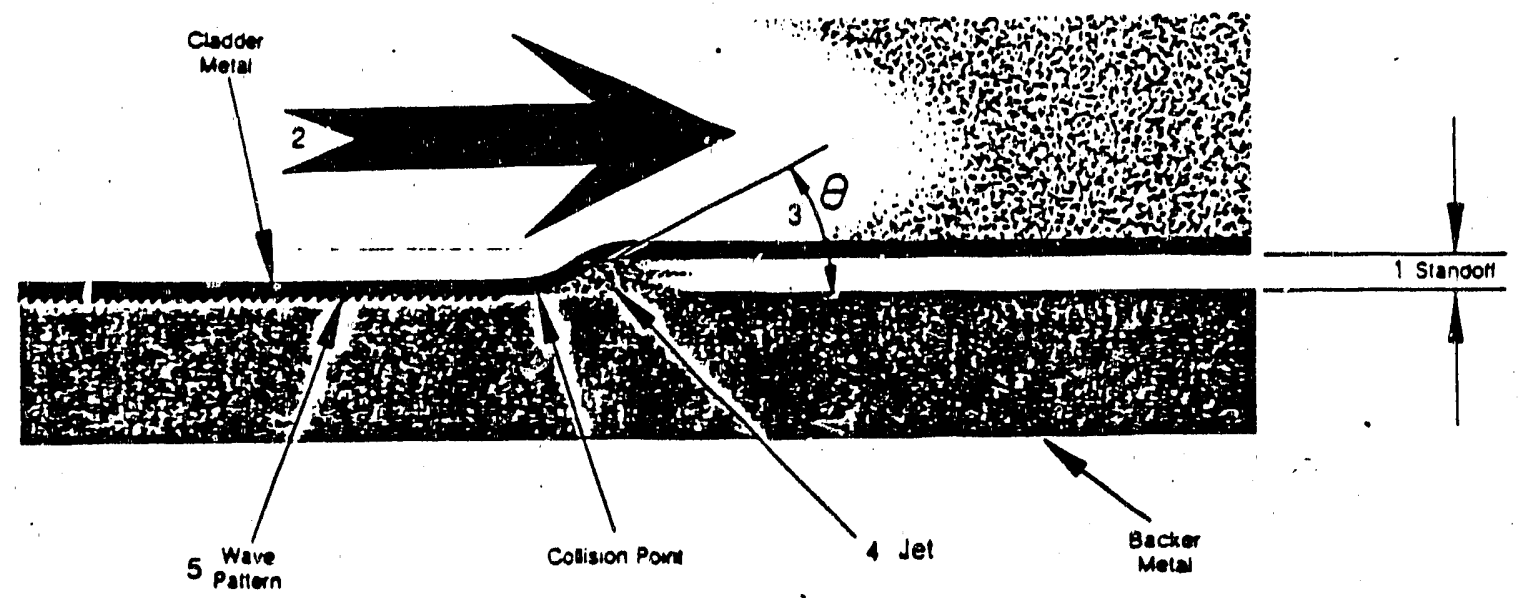

The above schematic of DYNACLAD" Explosion Cladding Process iltustrates the main features of the process.

1. A specific standoff between the cladder metal and the backer mitral.

2. Progressive detonation of the exptosive over the metal to be explosion itad or welded

3. A specific bend angle by the cladder metal as it is torced to weld to the backer metal.

4. The formation of a jet within the included angle belween the cladder melal and the backer metal.

The explosion pressure causes the surface metal between the cladder and backer to behave as a

fluid. These surfaces are scoured clean by the jet.

5. A characteristic (and visible) wave pattern at the weld interface caused by the lurbulent plastic inetal flow after collision.

Figure 2.1: Explosion Bonding Process Schematic (From Explosive Fabricators Inc. [8]) 


\subsubsection{Explosion Bonding Mechanics}

Pressure disturbances, which are generated in a metal that is in direct contact with a detonating explosive, are created by the action of explosively propelled colliding plates. In explosive bonding, a plate is accelerated by a detonating explosive to a high plate velocity, $V_{p}$, toward a stationary plate (Figure 2.2). Pressure disturbances produced by the collision are generated in both plates. The type of pressure disturbance that forms depends on the velocity with which the collision travels along the plate $V_{c}$ and the transverse plate velocity $V_{p}$

When the collision velocity $V_{c}$ is well abo ce the sonic velocity of the metal, attached shock waves are formed at the collision point (Figure 2.2). These shock waves move with the collision point and subject the atoms in each metal to very high instantaneous applied pressure. The magnitude of this pressure depends on plate velocity $V_{p}$ and the densities of the metals. For example, high velocity impacts of dense metals will generate high pressures.

When the collision velocity just slightly exceeds the sonic velocity in the metal, detached shock waves are created. These detached shocks are located at a position slightly upstream from the collision point as shown in Figure 2.3.

When the collision velocity is less than the the sonic velocity, no shock waves are created since the pressure can be spread out ahead of the collision, as shown in Figure 2.4. 


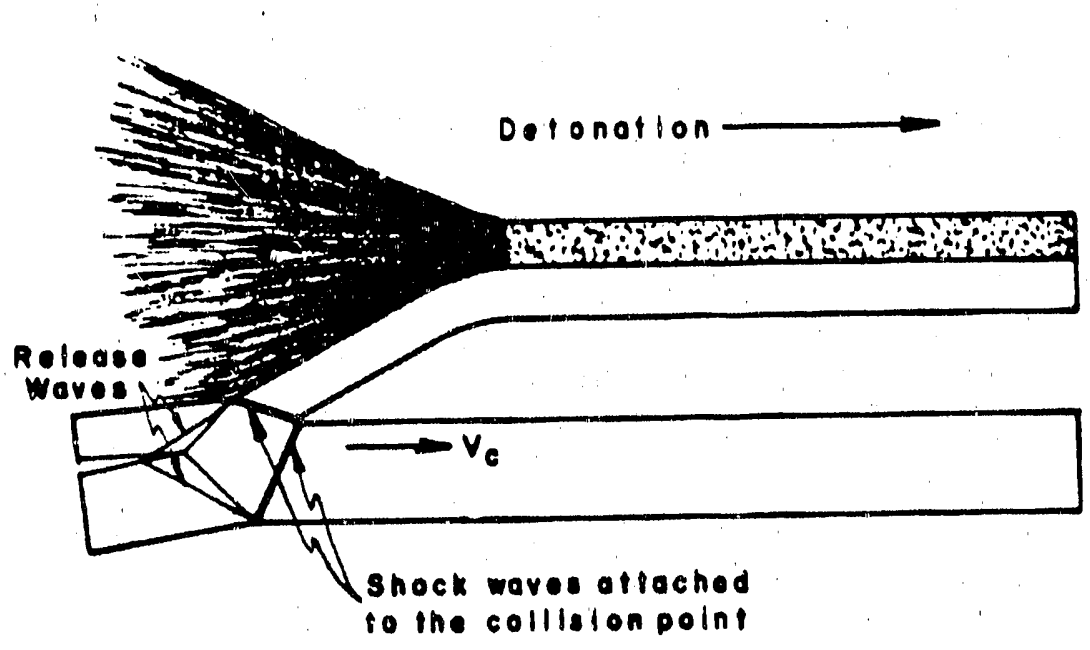

Figure 2.2: Attached Shock Waves Formed When The Collision Velocity Substantially Exceeds The Sonic Velocity Of The Metals. From Reference [3].

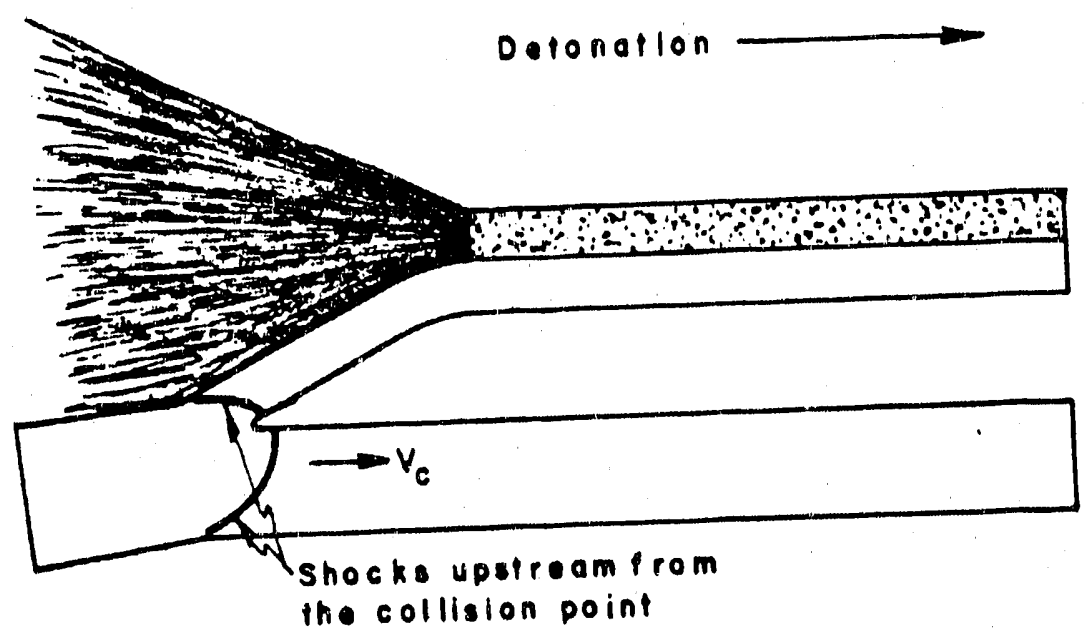

Figure 2.3: Detached shock waves formed when the collision velocity slightly exceeds the sonic velocity of the metals. The pressure acting ahead of the collision causes the free surfaces to deflect, thereby leading to the configuration shown in Figure 2.5. From Reference [3]. 


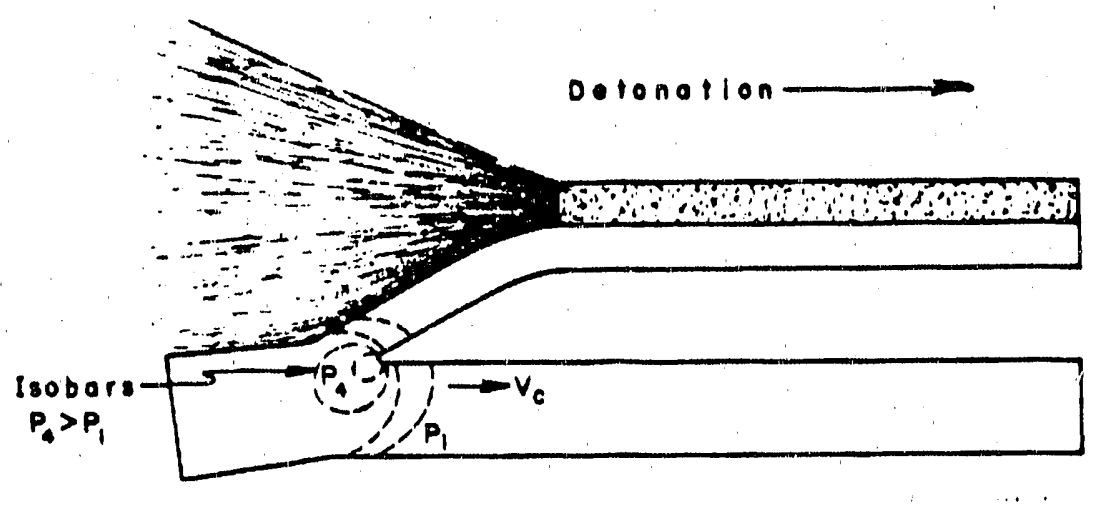

Figure 2.4: Pressure distribution created by a subsonic collision velocity. The pressure acting ahead of the collision causes the free surfaces to deflect, thereby leading to the configuration shown in Figure 2.5. From Reference [3]. 


\subsubsection{Jetting Phenomenon}

In the detached shock and nonshock cases, pressure is generated just ahead of the collision point. If this pressure is large enough, the free surfaces of the metals will plastically deform and flow into the space between the plates. This flow is in the form of a high velocity jet, which is illustrated schematically in Figure 2.5. This jet does not form when attached shock waves are produced or when the upstrearn pressure is too low to plastically deform the free surface of the metals. Thus, the critical parameters which affect the jet formation are plate velocity $V_{p}$, collision velocity $V_{c}$, and the collision angle which in turn depends on the standoff distance between the plate.

The formation of the jet is a vital aspect in the production of a successful bond. By scouring off and ejecting the surface layers immediately ahead of the collision point, the jet provides a cleansing action which removes any surface contaminants that be detrimental to bonding. As a result, a direct metal-to-metal bond may be formed because these cleaned surfaces are under extreme pressure and in intimate contact immediately behind the collision point. [5].

Since the pressure in the parent metals at, and downstream from, the collision point (sometimes called the stagnation point) is xtremely high and the shear strength of the metal surfaces is quite small by comparison, the metals behave as fluids of low viscosity. The result of using low or high velocity explosives is the formation of laminar or turbulent flow in theses "metal fluids" as they flow past the collision point (Figure 2.6). Using a low detonation velocity creates laminar conditions, and the interface between the clad metals will be essentially straight. Using a high detonation velocity creates turbulent conditions and produces a wavy interface. However, if the detonation velocity is too high, secondary turbulence will be caused, and the wavy bond interface will have small eddies on the primary waves. Since the eddies are caused by excessive collisional energy, they usually appear as 
pockets where melting occurs during wave formation. The ideal explosion bond interface morphology is characterized by uniform waves with little or no secondary waves or melt pockets on the waves [7]. 


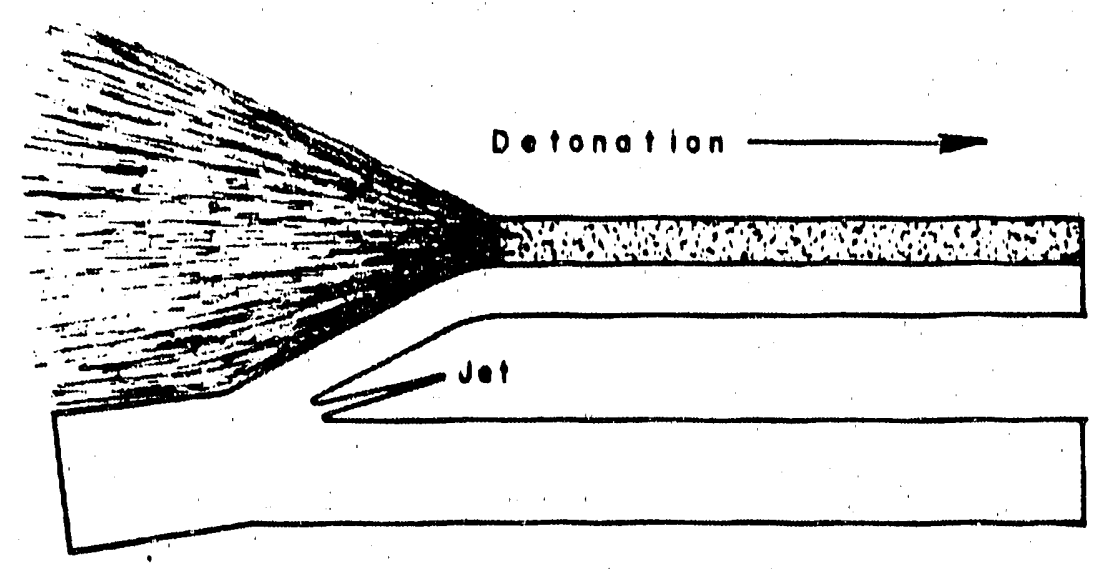

Figure 2.5: High velocity jet emanating from the collision point because of upstream pressure. From Reference [3].

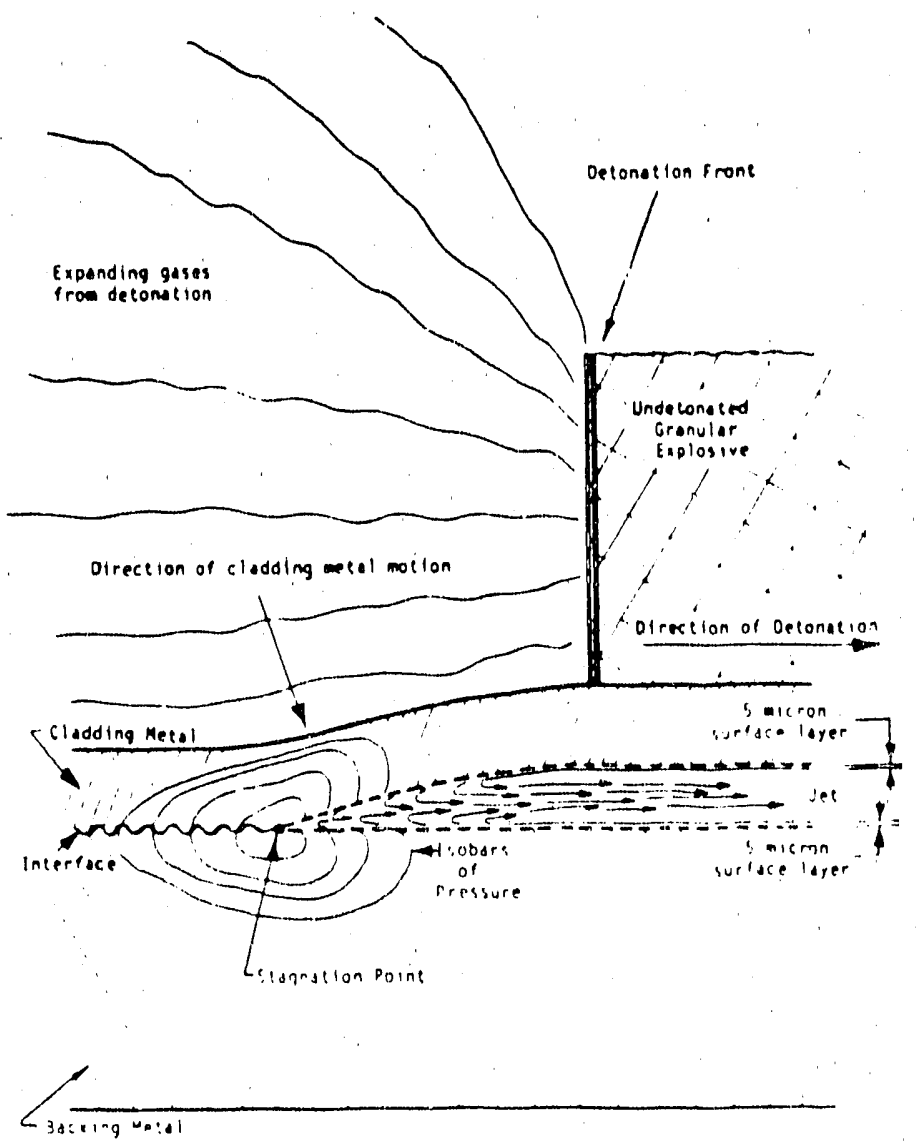

Figure 2.6: Mechanism for jetting away the surface layer from the parent metal. From Reference [7]. 


\subsubsection{Bond Characteristics}

In addition to the direct metal-to-metal bond which is formed when the jet completely escapes, other types of bond zones may be formed. When the jet does not completely escape from between the plates, but is partially trapped between them, the formation of a continuous layer results. This continuous layer is unally of uniform thickness. Such a bond between copper and nickel is shown in Figure 2.7. The thickness of the continuous layer is a function of the nature and geometry of the explosion. A thickness range of 0.5 to 100 microns has been observed for these layers. Various experimental studies have concluded that the uniform layer between the plates is a melted and resolidified zone [3]. The studies point out that the relative constancy of the microhardness across the zone is an indication of the uniform chemical composition of the layer.

When the collision region is unstable and oscillates, a wavy bond interface is created between the two metals (Figure 2.8). A detailed treatment of the wavy bond interface is given by Cowan [2]. Only a few highlights shall be noted here. The wavy bond zone in explosion bonding is analogous to the formation of an oscillating wake and vortex street in fluid flow past an obstacle. The transition from a smooth to a wavy bond zone with increasing collision velocity can be predicted quantitatively from a critical value of a Reynolds number $R_{T}$, which is defined in terms of average density and hardness of the two metals [2].

$$
R_{T}=\frac{\left(\rho_{1}+\rho_{2}\right) V_{T}^{2}}{2\left(H_{1}+H_{2}\right)}
$$

where $\rho_{1}, \rho_{2}$ are the material densities, $H_{1}, H_{2}$ are the diamond pyramid hardnesses, and $V_{T}$ is the collision velocity where the transition occurs. The experimetally observed value of $R_{T}$ was 10.6 [2]. It was also observed that at very high collision velocities, pockets of solidified melt began to appear in the eddy regions. The size of the melt pockets increases sharply with increases in collision velocity. 
In some metals such as Inconel 718, when a wavy interface is formed by explosion bonding, shear bands are formed as a result of shearing due to local vortex formation at the wavy interface. Figure 2.9 shows the presence of shear bands in Inconel 718. It was observed in thesis no shear bands were evident at a relatively flat interface. Shear bands will be discussed in depth later. 


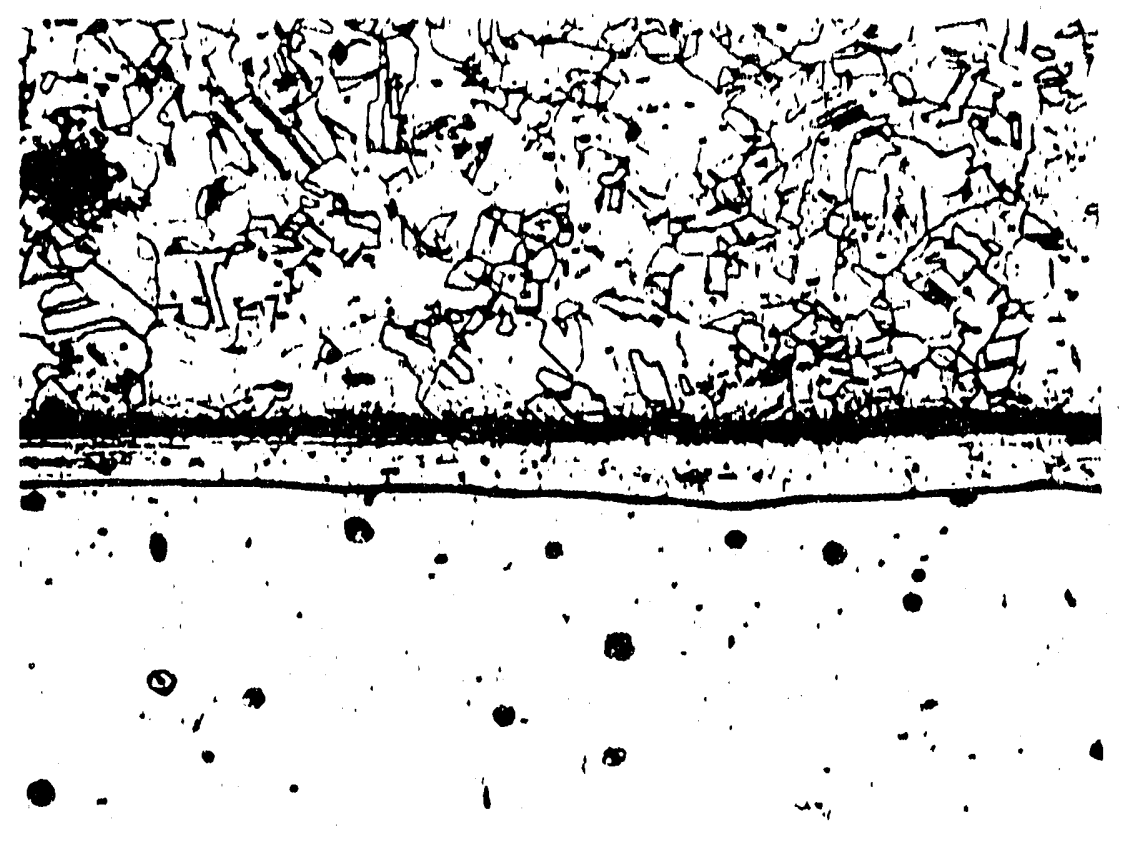

Figure 2.7: $\mathrm{Cu}-\mathrm{Ni}$ bond showing continuous layer bond zone, $\mathrm{X}$ 100. From Reference [3].

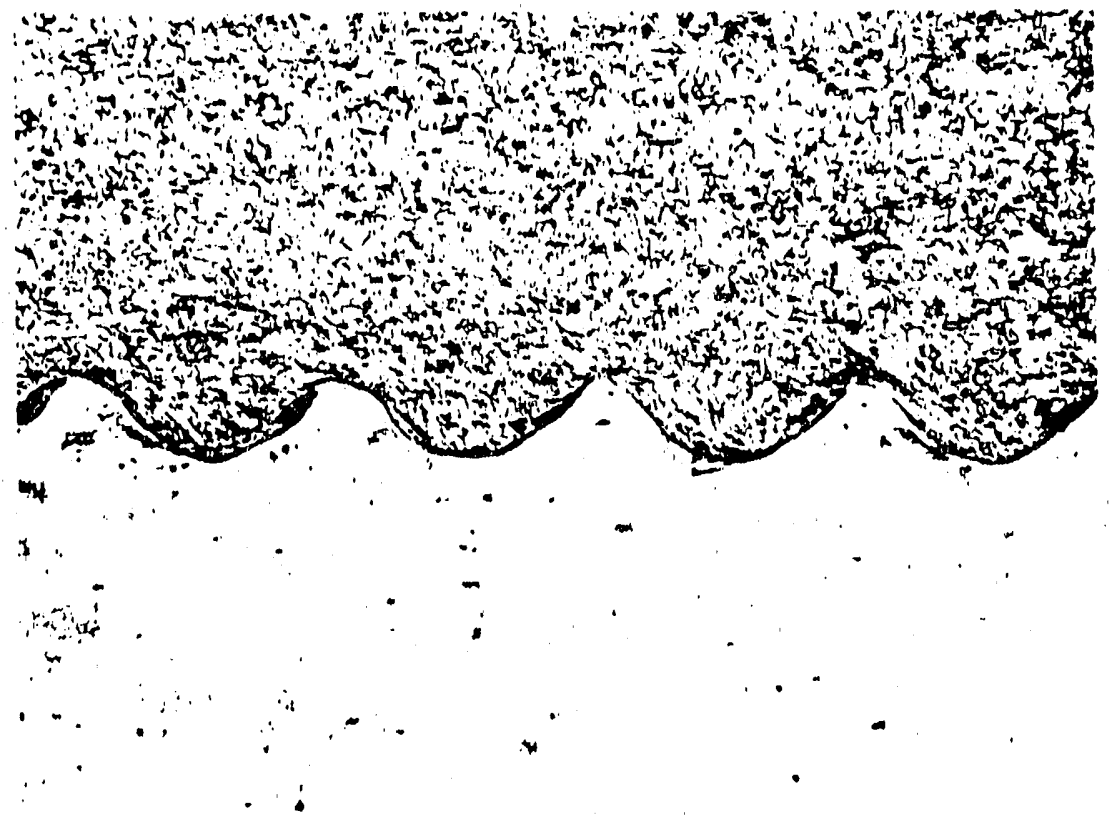

Figure 2.8: Cu-Ni bond with a wavy interface. X 50. From Reference [3]. 

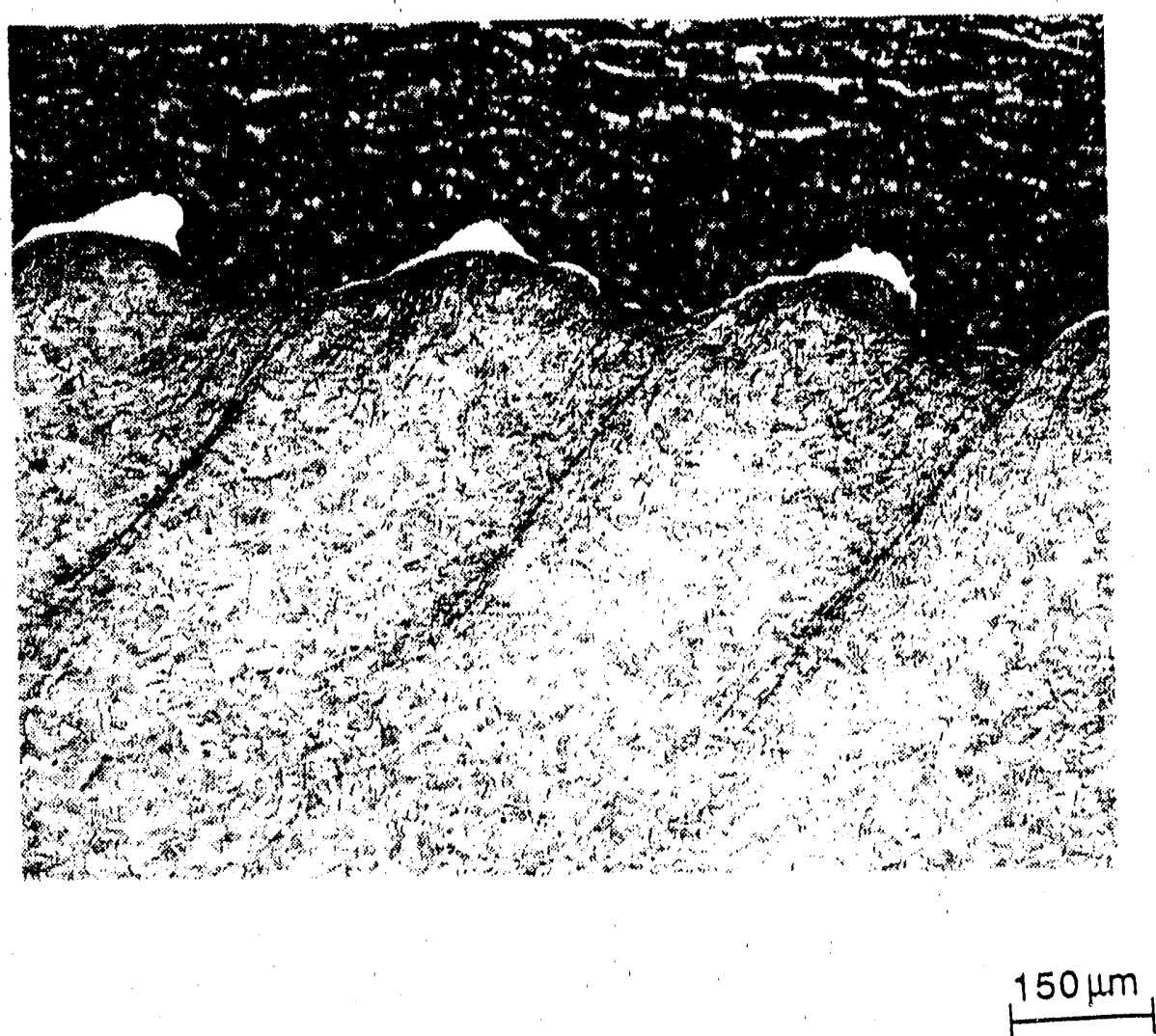

Explosion Direction

Figure 2.9: Shear Bands in Inconel 718 at a Wavy Interface. Etched with Kalling's etchant $(100 \mathrm{ml} \mathrm{HCl}+100 \mathrm{ml}$ Ethanol $+5 \mathrm{gm} \mathrm{CuCl} 2)$. Shear bands emanate from the valleys of the ripple. 


\subsubsection{Mechanical Properties}

From a practical engineering perspective, the most important aspect of any bonding process is the mechanical properties of the bond and the effects of the process on the mechanical properties of the joined metals. Two important aspects of explosive bonding influence the properties of the resulting bond: (1) the cold or room temperature nature of the process, and (2) the severe material flow which occurs near the bond interface. The mechanical properties of this bond interface are treated extensively in [3] and Linse [4]. A few notable points shall be discussed here.

Hardness. In general, microhardness traverses made across explosion bonds show an increase in the overall level of hardness of the metals after bonding. Hardening is somewhat greater immediately adjacent to the irterface where the collision and jetting action has produced high pressure. The magnitude of hardening depends on the hardening characteristics of the metals. For example, becalse stainless steel has a greater work-hardening rate than aluminum, the bardness increase in the steel is somewhat greater. Post-cladding heat treatment may remove the cold working that has been introduced by the explosion bonding process.

Heat-affected Zone. In most cases, microstructural examination reveals negligible heat-affected zones other than the actual melted regions at the interface. For example, in a copper-to-copper bond extensively worked regions of the direct metal-to-metal bonds have not experienced heat-affected microstructural changes. Steel clads similarly show the lack of heat-affected zone even immediately adjacent to the interface [3].

Shear Strength. Experimental studies that measure the shear strength of the bond according to the ASTM specification A264-44T [3]. It was usually observed that fracture did not occur in the bond zone, but rather in the weaker metal of the composite. This increased bond shear strength may be attributed to the localized increase in hardness adjacent to the bond zone. Thus, these shear strength tests 
support the statement that "an explosion bond is stronger than the weakest material in the combination."

Tensile Properties. Tensile properties paralle? the shear properties. A slight increase is observed in yield and ultimate strength with an associated decrease in elongation when compared with unbonded base metals. It was also shown that an appropriate amount of heat treatment restores the properties to pre-clad values.

Fatigue Testing. Unfortunately, there is a very scarce amount of fatigue data, either thermal or mechanical, for explosively bonded composites [4]. It is essential that more thorough fatigue data be generated for explosively bonded composites.

Impact Resistance. Some Charpy V-rotch impact resistance data have been compiled for stainless steel and titanium-to-steel clads. Preliminary indications show a small decrease in impact resistance, which is consistent with the cold-working effect on the metals. The full impact resistance of the steel appears to be restored with heat treatment.

Thus, although explosion bonding seems to affect the mechanical properties in a non-detrimental manner, more extensive testing is needed, especially in fatigue, to assess fully the effects on mechanical properties from explosion bonding.

\subsubsection{Explosion Bonding of the Alcator C-MOD Laminate}

The Alcator C-MOD explosively bonded laminate consisted of $91 \mathrm{~cm}$. by $244 \mathrm{~cm}$. plates of copper 10700 / Inconel 718 / copper 10700. The thickness of each copper plate is $10.4 \mathrm{~mm}$, and the thickness of the Inconel plate is $2.3 \mathrm{~mm}$ The plates are stacked on a bed of plywood and sand on the floor of a mine, Balsa spacers are used to create the standoff distance between the plates. The plates are bonded with an explosion from one side, and approximately $227 \mathrm{~kg}$. of granular explosives are used per laminate. The detonation velocity and collision energy are estimated to 
be $2412 \mathrm{~m} / \mathrm{s}$ and $660 \mathrm{~kJ}$ per plate. 


\subsection{Copper 107}

Copper $\mathrm{C} 10700$ is an oxygen-free silver-bearing copper. Its chemical composition is $99.95 \mathrm{~min} \mathrm{Cu}$ and $0.085 \mathrm{~min} \mathrm{Ag}$ [39] and electrical conductivity is essentially the same as copper C10200. This copper has many uses because of its good creep strength at elevated temperatures and high softening temperature. Other applications include bus bars, conductivity wire, and commutator segments.

The Alcator C-MOD Copper Core Specification [42] precisely defined the materials ma facturing requirements for the copper C107. The applicable items are noted here.

- Plate dimensions are $9.1 \mathrm{~cm} \times 244 \mathrm{~cm} \times 10.4 \mathrm{~mm}$

- The plate gauge tolerance is $-0 \%$ and $+0.030 \%$.

- The plates were cold reduced in order to achieve a longitudinal $0.2 \%$ offset yield strength of $310 \mathrm{MPa}$. minimum and a transverse yield strength of 21 MPa. less.

- The conductivity measured at room temperature must be greater than $96 \%$ IACS for the finished product.

- A $100 \%$ dye penetrant test was performed on both sides of each plate.

The finished copper 107 plates had been cold-rolled $50 \%$ prior to bonding [40]. Mechanical Properties of Copper C107

As required by the materials specification, Revere Copper Products Inc. performed 150 longitudinal and 150 transverse tensile tests at room temperature on the copper 107 plates for the TF core. A summary of the the $0.2 \%$ offset yield stress, ultimate tensile stress, and elongation ranges is given in Table 2.1. The material 
that was used in manufacturing the TF core passed all concitions stipulated in the materials specification. 


\begin{tabular}{|l|c|c|}
\hline & Longitudinal & Transverse \\
\hline$\sigma_{0.2 \%}$ & $294-354 \mathrm{MPa}$ & $316-346 \mathrm{MPa}$. \\
\hline$\sigma_{U T S}$ & $315-357 \mathrm{MPa}$. & $327-360 \mathrm{MPa}$. \\
\hline $\begin{array}{l}\text { Elongation for } \\
\text { 2" Gage Length }\end{array}$ & $17-29 \%$ & $12-23 \%$ \\
\hline
\end{tabular}

Table 2.1: Summary of Tensile Test Data Ranges for Copper C107 at Room Temperature, Reference [40] 


\section{$2.3 \quad$ Inconel 718}

Inconel 718 is a nickel-iron-based super alloy which is used at $-423^{\circ}$ to $1300^{\circ} \mathrm{F}$ [28]. Its composition is given in Table 2.2. Inconel 718 is an age hardenable, high tensile strength, corrosion resistant material which has no ductile-to-brittle transition temperature. As a result of its favorable properties, Inconel 718 has seen a wide range of applications which include components and parts for liquid rockets, aircraft turbine engines, and cryogenic tankage [28].

The Alcator C-M.OD Inconel 718 Specification [43] precisely defined the manufacturing requirements for the Inconel 718 . The applicable items are noted here.

- Plate dimensions are $91 \mathrm{~cm} . \times 244 \mathrm{~cm} . \times 2.3 \mathrm{~mm}$.

- The plates must have a minimum $0.2 \%$ offset yield strength of $1138 \mathrm{MPa}$. and a maximum of $1344 \mathrm{MPa}$.

- The direct aging heat treatment must conform to AMS 5596E [29]. This direct aging process is shown in Table 2.3.

- The finished plates were bright annealed, solution treated and cold worked if necessary to achieve the above specified yield strength range.

- A $100 \%$ dye penetrant test was performed on both sides of each plate.

The finished plates that were furnished to MIT had successfully passed the criteria stipulated in the materials specification.

Mechanical Properties of Inconel 718

Upon delivery of the Inconel 718 plates to MIT prior to bonding, 17 longitudinal and 14 transverse tensile tests at room temperature were performed by Vieira [38]. Table 2.4 summarizes the tensile test data ranges that were obtained. 


\begin{tabular}{|lc|lc|}
\hline Nickel (plus Cobalt) & $50.00-55.00$ & Cobalt & 1.00 max. \\
Chromium & $17.00-21.00$ & Carbon & 0.08 max. \\
Iron & Bal. & Manganese & 0.35 max. \\
Columbium (plus Tantalum) & $4.75-5.50$ & Silicon & 0.35 max. \\
Molybdenum & $2.80-3.30$ & Phosphorous & 0.015 max. \\
Titanium & $0.65-1.15$ & Sulfur & 0.015 max. \\
Aluminum & $0.20-0.80$ & Boron & 0.006 max. \\
& & Copper & 0.30 max. \\
\hline
\end{tabular}

Table 2.2: Inconel 718 Limiting Chemical Composition, Reference [28]

\begin{tabular}{|l|l|}
\hline Heat to $1325^{\circ} \mathrm{F} \pm 15\left(720^{\circ} \mathrm{C} \pm 8\right)$ and hold & $8 \mathrm{hr} \pm 0.5$ \\
Cool to $1150^{\circ} \mathrm{F} \pm 15\left(620^{\circ} \mathrm{C} \pm 8\right)$ & $100^{\circ} \mathrm{F}\left(55^{\circ} \mathrm{C} \pm 8\right)$ deg per hr \\
Hold at $1150^{\circ} \mathrm{F} \pm 15\left(620^{\circ} \mathrm{C} \pm 8\right)$ & $8 \mathrm{hr} \pm 0.5$ \\
Air Cooling & \\
\hline
\end{tabular}

Table 2.3: Inconel 718 Direct Age Process Specifications, Reference [29]

\begin{tabular}{|l|c|c|}
\hline & Longitudinal & Transverse \\
\hline$\sigma_{0.2 \%}$ & $1234-1310 \mathrm{MPa}$. & $1241-1310 \mathrm{MPa}$. \\
\hline$\sigma_{U T} S$ & $1420-1489 \mathrm{MPa}$. & $1393-1469 \mathrm{MPa}$. \\
\hline $\begin{array}{l}\text { Elongation for } \\
2 " \text { Gage Length }\end{array}$ & $15.1-17.0 \%$ & $13.5-15.8 \%$ \\
\hline
\end{tabular}

Table 2.4: Summary of Tensile Test Data Ranges for Inconel 718 at room temperature, Reference [38] 


\subsection{Fatigue and Fracture}

Since Alcator C-MOD is designed to operate in a pulsed fashion, the severe stresses encountered in the TF magnet are cyclic in nature. These cyclic stresses are due to both the mechanical and thermal loadings imposed on the composite conductor. As a result, the entire toroidal field magnet system is designed to avoid fatigue failures. Understanding of fatigue, fracture, and crack propagation in this laminate conductor is imperative. In this section, the essentials of fatigue and fracture mechanics are reviewed. Perhaps, the most important quantity in fracture mechanics is the stress intensity factor $K$. A treatment in depth of the stress intensity factor is given in the next section.

Because fatigue involves cyclic loading, the following quantities are usually encountered when characterizing fatigue.

- $\Delta \sigma$ is the alternating stress amplitude, equal to $\sigma_{\max }-\sigma_{\min }$

- $\sigma_{m e a n}$ is the mean stress level, equal to $\frac{\sigma_{\max }-\sigma_{\min }}{2}$

- $R$ is the ratio of minimum stress(or load) to maximum stress (or load)

In crack growth experiments and data, the following quantities are usually encountered:

- $K$ which denotes the stress intensity factor. It is usually of the form $K=$ $Q \sigma \sqrt{\pi a}$, where $\sigma$ is the applied stress, $a$ is crack length, and $Q$ is a function $a$ and dependent on specimen geometry. $\Delta K=K_{\max }-K_{\min }$ can be thought of as the driving force behind a crack. See next section.

- $\mathrm{da} / \mathrm{dN}$ is the crack growth rate which is expressed as crack extension per unit cycle. 
Crack growth is usually displayed in graphical form as a curve that relates $\mathrm{da} / \mathrm{dN}$ to $\Delta \mathrm{K}$. A typical da/dN versus $\Delta \mathrm{K}$ curve is shown in Figure 2.10. The curve usually is divisible into three regions according to curve shape, crack growth mechanisms, and various environmental and material factors. These factors are summarized by Ewalds and annotated in Figure 2.10. In region I, a threshold value, $\Delta K_{t h}$, exists below which there is no measurable crack growth. In region II, there is usually a linear $\log -\log$ relationship between $\mathrm{da} / \mathrm{dN}$ and $\Delta \mathrm{K}$. In region III, the $\mathrm{da} / \mathrm{dN}-\Delta \mathrm{K}$ curve approaches an asymptote where the maximum stress intensity factor, $K_{\text {max }}$, in the fatigue cycle becomes equal to the critical stress intensity factor, $K_{\mathrm{c}}$, and fracture finally occurs.

Many closed-form expressions have been formulated to describe the $\mathrm{da} / \mathrm{dn}$-$\Delta K$ fatigue crack growth rate curve [55]. These crack growth expressions are usually developed by semi or wholly empirical means. The most widely used expressions for the $\mathrm{da} / \mathrm{dN}-\Delta \mathrm{K}$ curve are:

The Paris equation [64]:

$$
\frac{d a}{d N}=C(\Delta K)^{m}
$$

The Forman equation [65]:

$$
\frac{d a}{d N}=\frac{C(\Delta K)^{m}}{(1-R) K_{c}-\Delta K}
$$

The Paris' equation is only applicable in the linear log-log (region II) section of the $\mathrm{da} / \mathrm{dN}-\Delta \mathrm{K}$ curve, where the Forman equation is applicable in both regions II and III. 


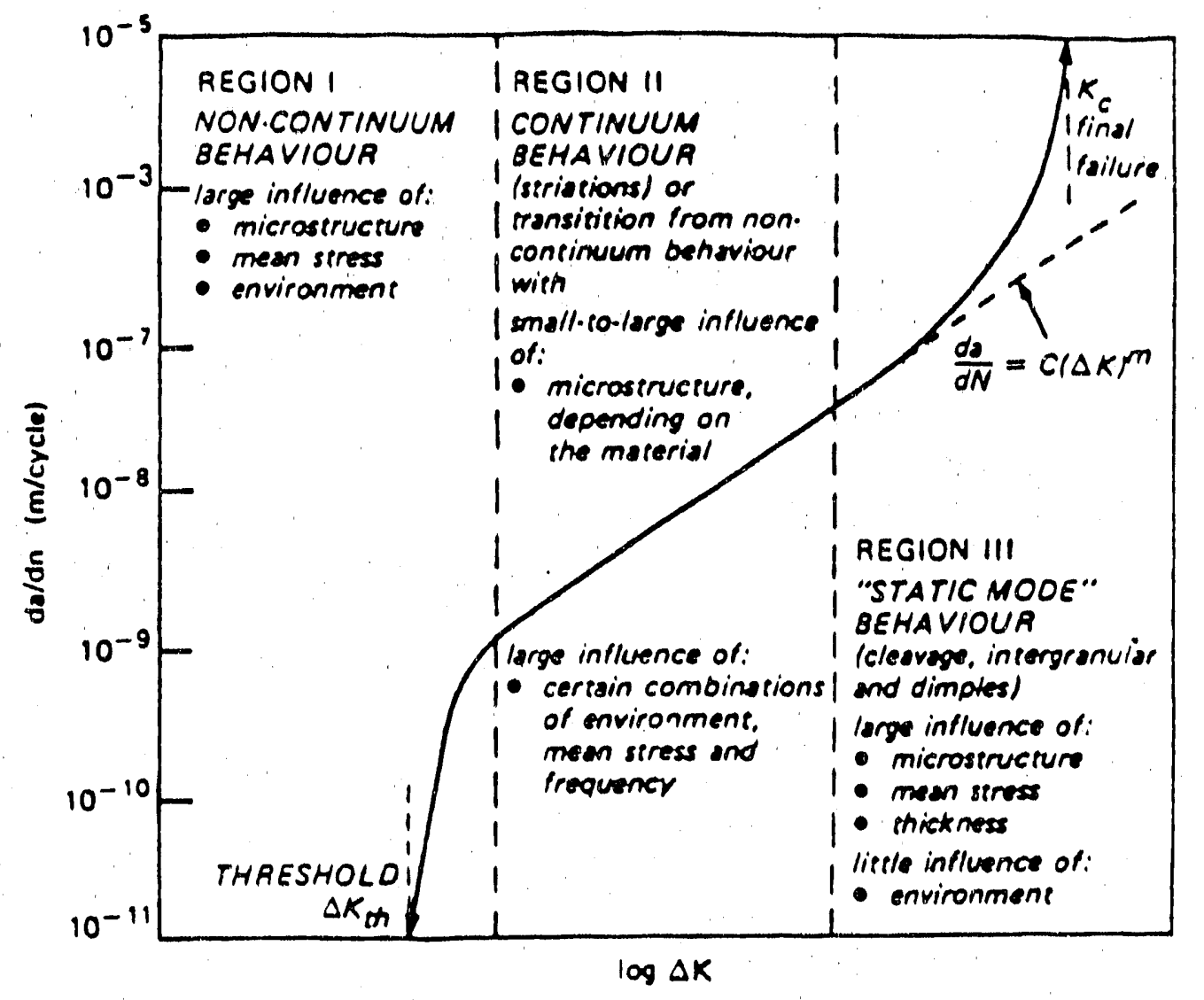

Figure 2.10: Typical da/dn versus $\Delta \mathrm{K}$ Curve. From [55] 


\subsection{Stress Intensity Factors}

The stress distribution at the crack tip in a thin elastic plate for the coordinate system shown in Figure 2.11 is given by (valid for $a>r>\rho$ ) [58]:

$$
\begin{aligned}
& \sigma_{\text {w }}=\sigma\left(\frac{a}{2 r}\right)^{1 / 2}\left[\cos \frac{\theta}{2}\left(1-\sin \frac{\theta}{2} \sin \frac{3 \theta}{2}\right)\right] \\
& \sigma_{y}=\sigma\left(\frac{a}{2 r}\right)^{1 / 2}\left[\cos \frac{\theta}{2}\left(1+\sin \frac{\theta}{2} \sin \frac{3 \theta}{2}\right)\right] \\
& \tau_{\text {xy }}=\sigma\left(\frac{a}{2 r}\right)^{1 / 2}\left[\sin \frac{\theta}{2} \cos \frac{\theta}{2} \cos \frac{3 \theta}{2}\right]
\end{aligned}
$$

Irwin noted that the local stresses near a crack are a function of the product of nominal stress $\sigma$ and the square root of the half-flaw length. He defined this quantity as the stress intensity factor K. For a sharp elastic crack in an infinitely wide plat $K=\sigma \sqrt{\pi a}$. Using this definition, the stress distribution equations at a crack tip can be re-written as;

$$
\begin{aligned}
\sigma_{x} & =\sigma \frac{K}{\sqrt{2 \pi r}}\left[\cos \frac{\theta}{2}\left(1-\sin \frac{\theta}{2} \sin \frac{3 \theta}{2}\right)\right] \\
\sigma_{y} & =\sigma \frac{K}{\sqrt{2 \pi r}}\left[\cos \frac{\theta}{2}\left(1+\sin \frac{\theta}{2} \sin \frac{3 \theta}{2}\right)\right] \\
\tau_{x y} & =\sigma \frac{K}{\sqrt{2 \pi r}}\left[\sin \frac{\theta}{2} \cos \frac{\theta}{2} \cos \frac{3 \theta}{2}\right]
\end{aligned}
$$

The definition of $K$ as $\sqrt{\pi a}$ is only valid for an infinite plate. In a finite width specimen, geometry has an effect on the stress distribution at a crack tip. As a result, the expressions for stress intensity factors are modified with the addition of correction factors for different specimen and crack geometries. A general form of a modified stress intensity factor is: [55]

$$
K=C \sigma \sqrt{\pi a} F\left(\frac{a}{W}\right)
$$


where $\mathrm{C}$ and $\mathrm{F}\left(\frac{a}{W}\right)$ are determined by stress analysis.

For a center cracked tension (CCT) panel, many $\mathrm{K}$ solutions have been formulated. Many of the $\mathrm{K}$ solutions are derived from empirical means. Ewalds [55] reviews the most common stress intensity solutions for a CCT. A brief summary of these stress intensity expressions for a CCT specimen is given here.

Ishida [77] obtained a numerical solution for the geometrical correction factor $\mathrm{F}\left(\frac{a}{W}\right)$ which was expressed as a 36 term power series. Brown, however, formulated a four term power series expression which has a $0.5 \%$ accuracy for a/W $\leq 0.35$ :

$$
F\left(\frac{a}{W}\right)=1+0.256\left(\frac{a}{W}\right)-1.152\left(\frac{a}{W}\right)^{2}+12.200\left(\frac{a}{W}\right)^{3}
$$

Feddersen [78] formulated another purely empirical correction factor as an approximation to Ishida's expression:

$$
K=\sigma \sqrt{\pi a} \sqrt{\sec \left(\frac{\pi a}{W}\right)}
$$

Feddersen's solution is accurate to within $0.3 \%$ for a/W $\leq 0.35$

Dixon has recently introduced a correction factor which is often used:

$$
K=\sigma \sqrt{\pi a} \frac{1}{\sqrt{1-\left(\frac{2 a}{W}\right)^{2}}}
$$

In order to comply with ASTM fatigue crack growth test procedures [67], the Feddersen stress intensity expression (Equation 2.4) is used for the CCT fatigue crack growth specimens. The Feddersen solution is valid for $2 \mathrm{a} / \mathrm{W} \leq 0.95$. 


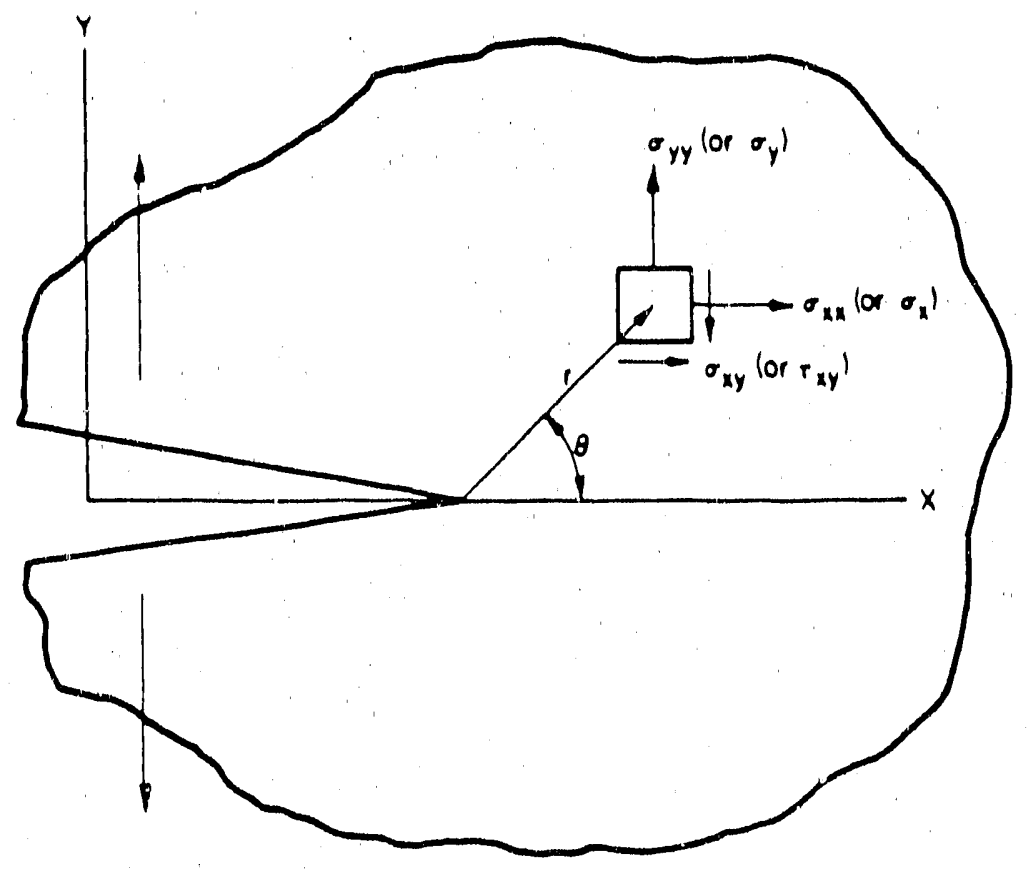

Figure 2.11: Crack Tip Coordinate System. From [57] 


\subsubsection{Crack Tip Plasticity}

Because structural materials deform plastically at stress values above the yield stress of the material, in actuality a plastic zone surrounding the crack tip will be created. The fleld of Linear Elastic Fracture Mechanics (LEFM) assumes that the plastic zone is small compared to crack size and that the cracked material still behaves elastically. If this is not the case, then the problem must be treated with ElasticPlastic Fracture Mechanics (EPFM) which is not so well developed as LEFM theory $[55]$.

Irwin formulated that a circular plastic zone exists at the crack tip under tensile loading, and he showed that the circular plastic zone has radius $r_{p}$. This circular plastic zone and crack tip are shown in Figure 2.12. Irwin's expressions for the radius of the plastic zone are [55]:

For plane stress:

$$
r_{p}=\frac{1}{2 \pi}\left(\frac{K_{I}}{\sigma_{y}}\right)^{2}
$$

For plane strain:

$$
r_{p}=\frac{1}{2 \pi}\left(\frac{K_{I}}{C \sigma_{y}}\right)^{2}
$$

where $C$ is usually about 1.7. The basic notion of crack tip plasticity is that the presence of such plasticity corresponds to an apparent increase in elastic crack length in a material of an increment equal to $r_{p}$. 


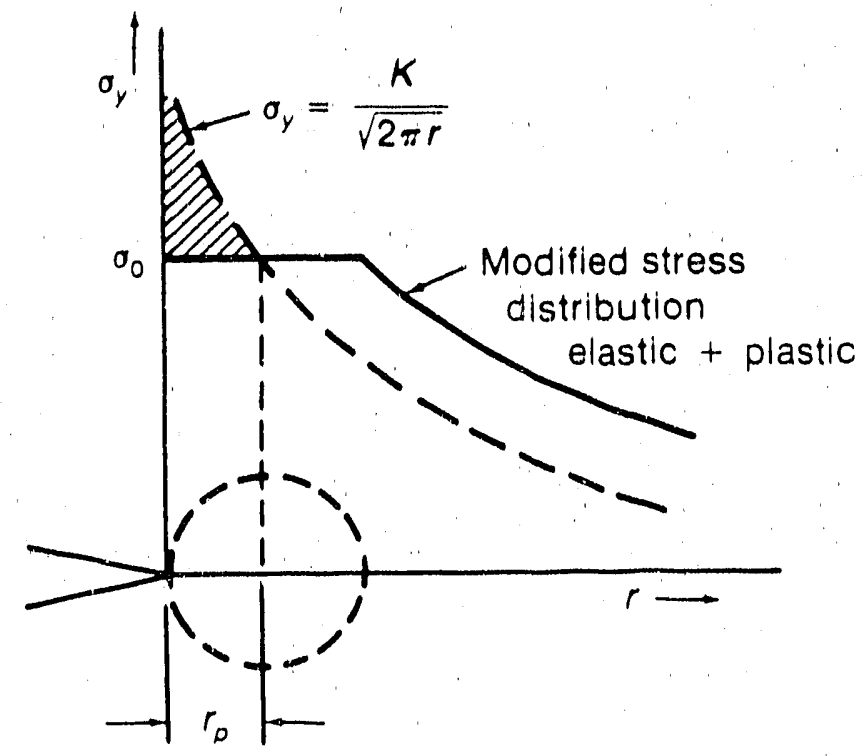

Figure 2.12: Irwin's Correction for the Crack Tip Plastic Zone. From [58] 


\subsubsection{Plane Stress and Plane Strain}

Two important concepts related to crack tip plasticity are plane strain and plane stress. A detailed treatment of these concepts is given by Broek [57,56]. A brief summary of this treatment of plane strain and plane stress is given here.

When a bar of material is subject to a high axial tensile stress, it will strain in the axial direction. However, due to the Poisson effect, this axial strain will also lead to a transverse strain or contraction as the bar becomes thinner. Stresses at the crack tip are locally very high, and as a result, the material immediately in front of the crack tip, particularly the plastic zone, experiences a large transverse strain. The material immediately behind the crack tip at the crack faces is stress free, and thus, it does not experience any transverse strain. At locations further away from the crack tip, the stresses are much lower and the transverse strains are much less. This contraction at in front of the crack tip is shown in Figure 2.13.

A thin roll of material immediately in front of the crack tip wants to contract, due to this large transverse strain. However, the bulk material around this thin roll prevents it from contracting. As a result, the transverse strain is completely constrained and remains zero. Thus, in the transverse $\mathrm{Z}-$ direction, $\epsilon_{z}=0$. For the transverse strain to be constrained, the surrounding material must exert a transverse tensile stress on the thin roll, $\sigma_{z}$. If $\epsilon_{z}=0$, then only the in-plane strains are nonzero. This condition is known as plane strain.

If the conditions in the material is such that the thin roll of material immediately in front of the crack tip is allowed to contract, then the transverse strain $\epsilon_{z} \neq 0$, and the transverse stress $\sigma_{z}=0$. Thus, now only the in-plane stresses are non-zero. This condition is known as plane stress. The conditions of plane strain and plane stress are illustrated in Figure 2.14.

The factors that determine whether the material is in plane strain or plane stress, are the plate thickness (the roll length) and plastic zone size (the roll diam- 
eter). For example, in two plates of different thicknesses but with the same crack size and applied stress, the thicker plate will be in plane strain and the thinner plate will be in plane stress. 


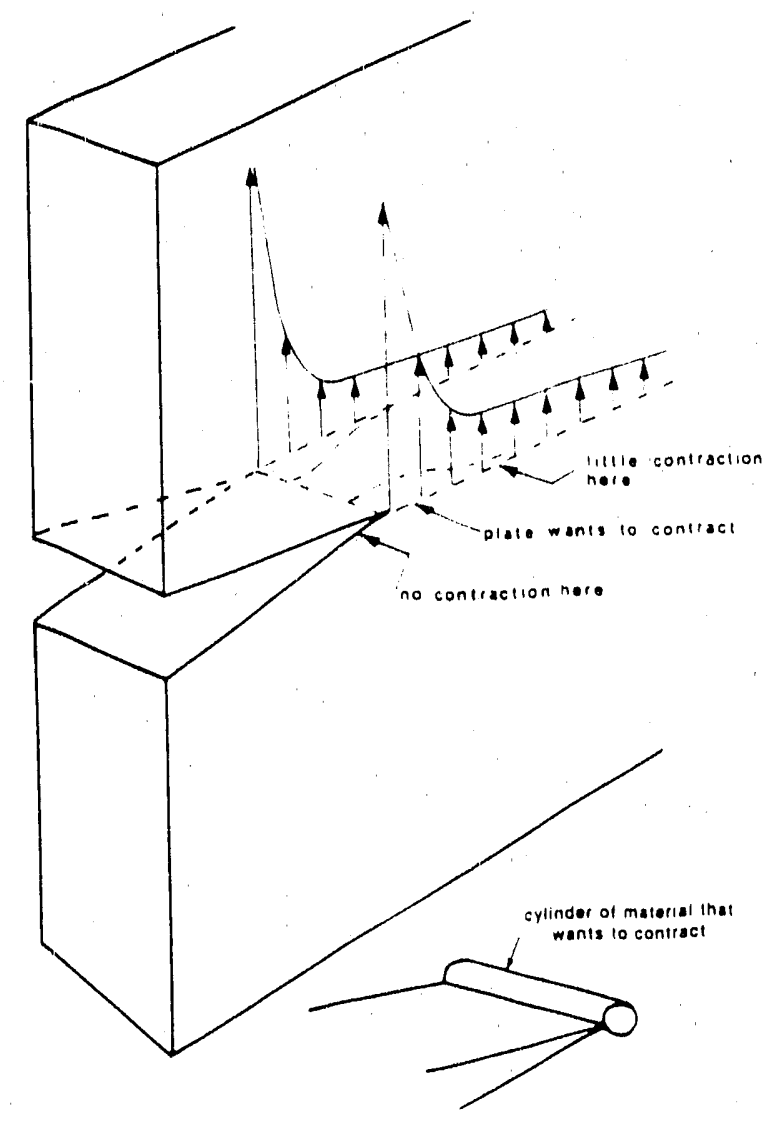

Figure 2.13: Contraction Due to Transverse Strain in Front of a Crack Tip. From $[56]$ 


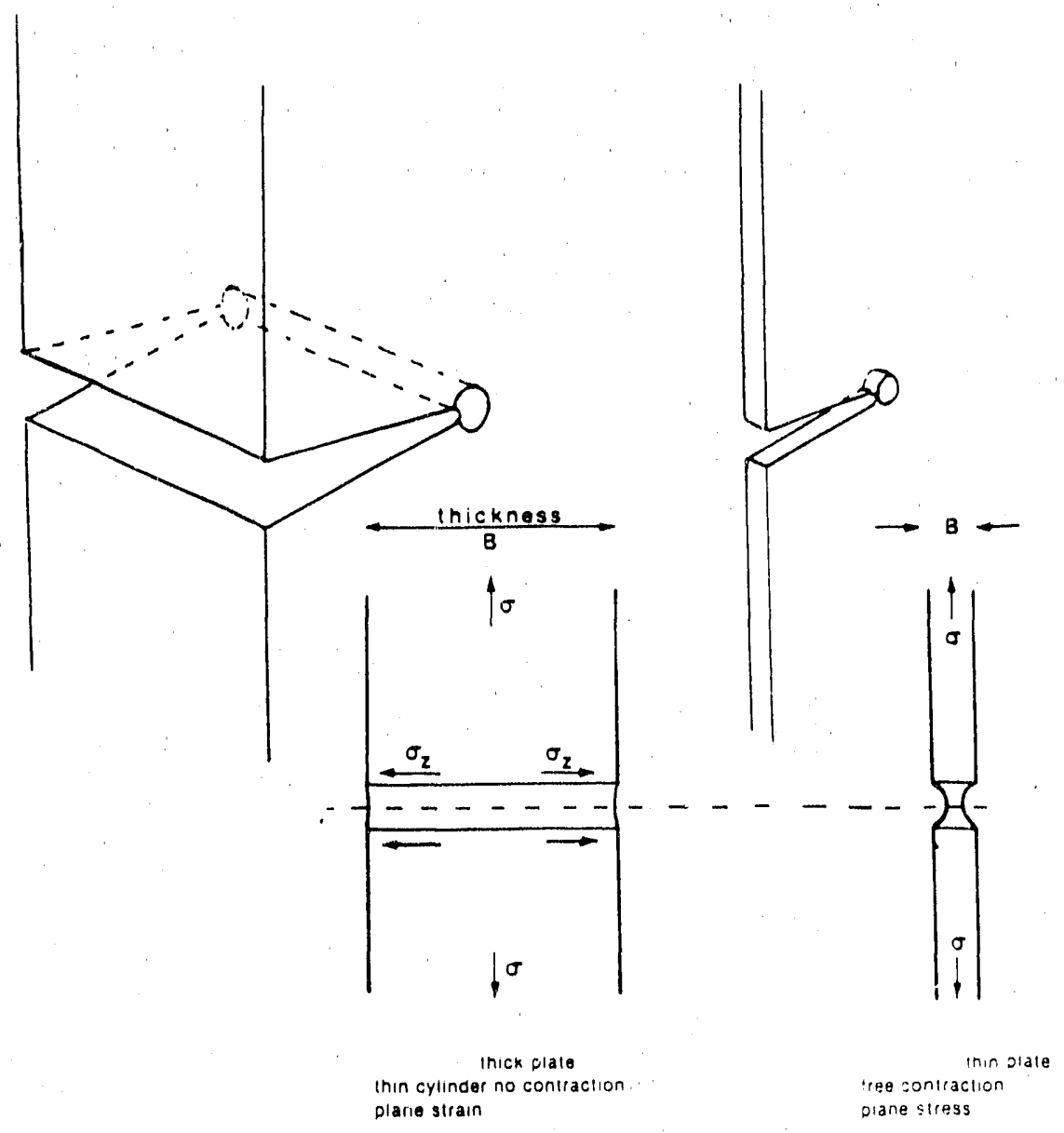

Figure 2.14: The Concepts of Plane Strain and Plane Stress. From [56] 


\subsection{D.C. Potential Drop Crack Monitoring Tech- nique}

The D.C. potential drop method is a well understood, documented, and widely applied technique for measuring crack length in metallic fatigue and fracture specimens $[44,45,47,48,49,50,51,52,46]$. The use of the DC potential drop method is based on the fact that at constant current the electrical resistance of a specimen increases with crack extension. The increase in electrical resistance is a result of a decrease in specimen cross sectional area in which the current flows. The measurement of specimen resistance is typically done by measuring the voltage across the crack and dividing by the applied current.

The potential drop technique has many advantages over conventional optical crack measurements. Because potential drop does not require visual accessibility, it is well suited for crack measurement applications in sealed or cryogenic environments. With potential drop measurement, total crack measurement is obtained inclusive of crack front curvature. Since no human intervention is required for crack measurement, the potential drop technique may also be incorporated into a fullyautomated crack growth experiment.

Experimental calibration is usually use to calibrate specimens of complex geometry. A second method of crack measurement is used to determine the crack length at a corresponding resistance. Two measurement methods which are usually used to calibrate D.C. potential drop are visual and compliance techniques. Once crack length associated resistance data have been obtained, a calibration expression which relates resistance to crack length is formulated, usually by least squares regression analysis. In the crack growth experiments performed in this thesis, the D.C. potential drop system is calibrated by visual inspection of the crack length by using a travelling microscope. 
The elimination of extraneous noise in the D.C. potential drop system is imperative. An efficient method for eliminating noise in a D.C. potential drop system was proposed by Andresen [46] and is known as switched D.C. potential drop. The switched D.C. potential drop method consists of taking two voltage readings, one at positive current and one at negative current, to measure the crack length. These voltage reading pairs are then subtracted and divided by two to obtain a "true" voltage reading. This method subtracts out the thermal emfs inherently present in the system. The switched D.C. potential drop method eliminates the need for reference probes to be present on the specimen. However, this method requires a way to switch the polarity of the D.C. output current, which is usually done by a relay.

The details of the D.C. potential drop crack measurement system are given in Appendix C. The calibration curves for the Inconel 718, copper 107, and laminate specimens are shown in Figures $2.15-2.18$. 


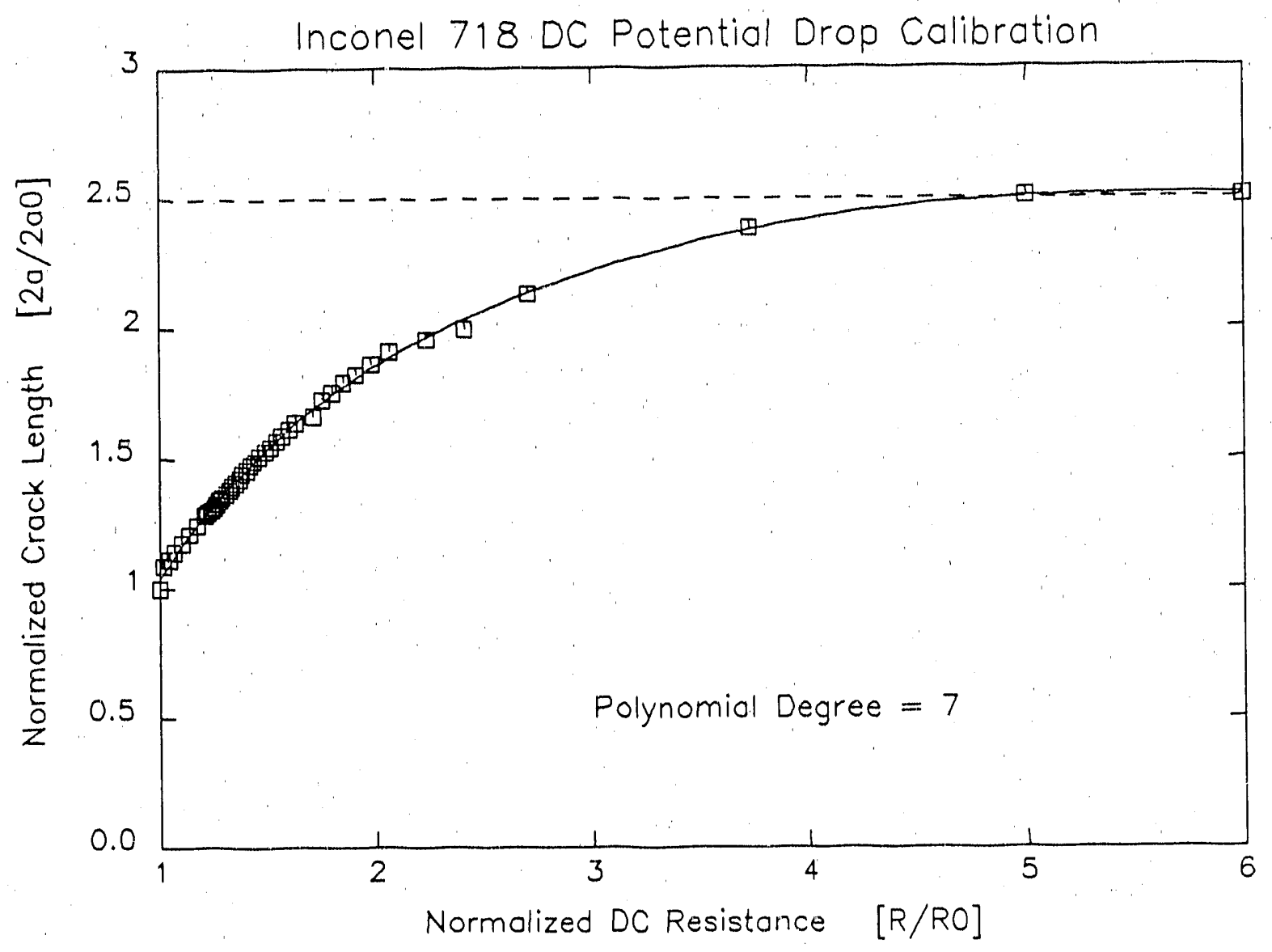

Figure 2.15: D.C. Potential Drop Crack Measurement Calibration for Inconel 718 


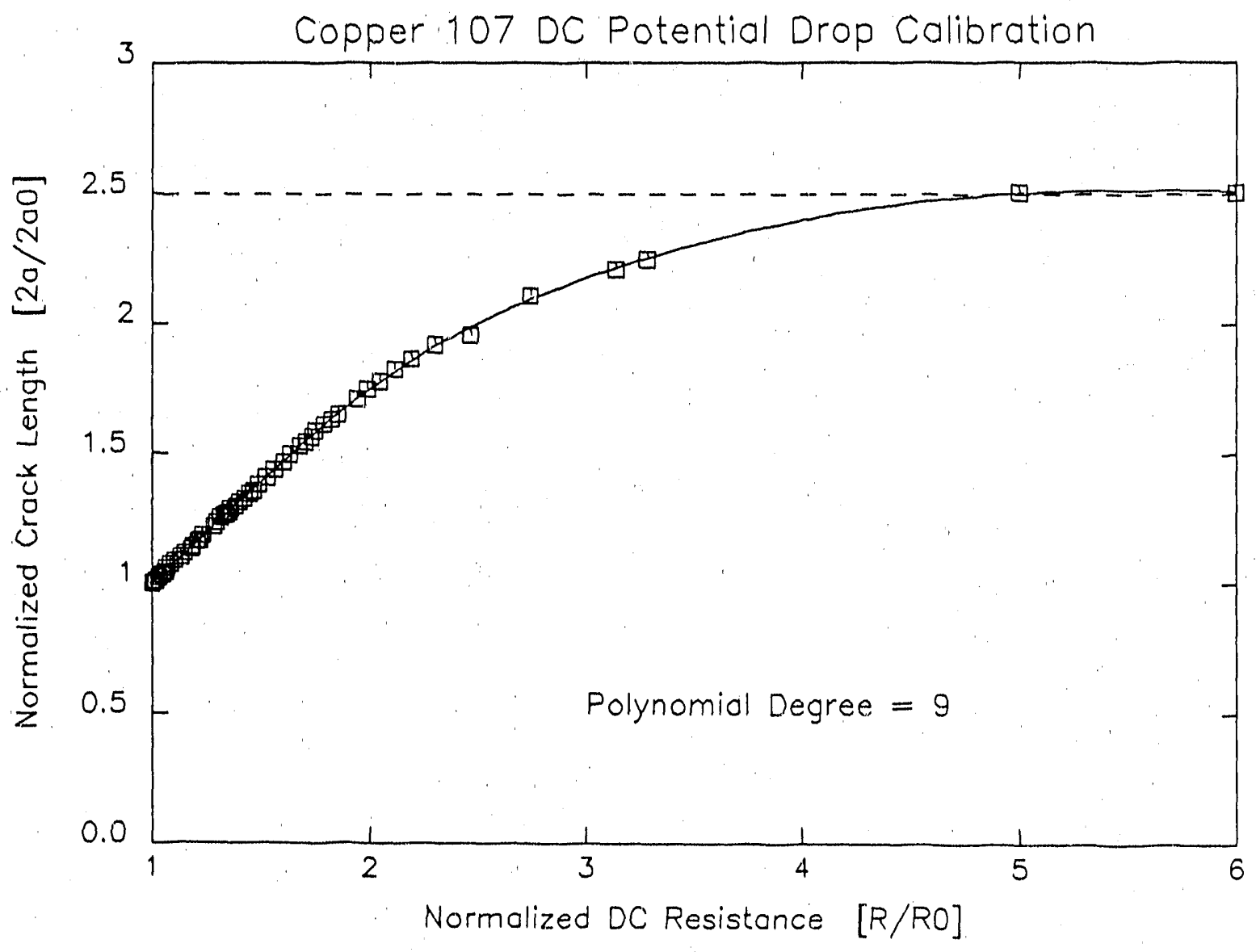

Figure 2.16: D.C. Potential Drop Crack Measurement Calibration for Copper 107 


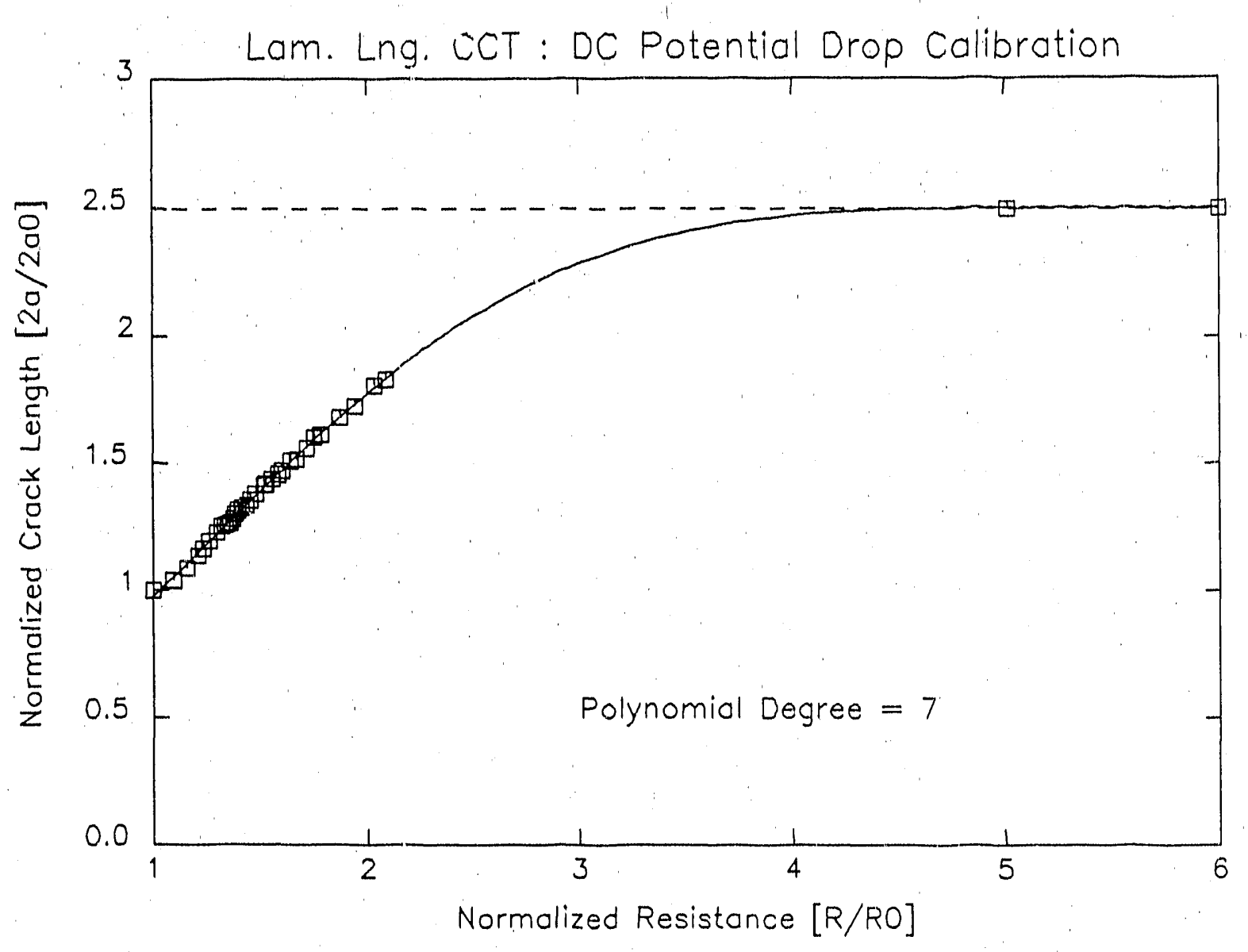

Figure 2.17: D.C. Potential Drop Crack Measurement Calibration for Laminate Longitudinal 


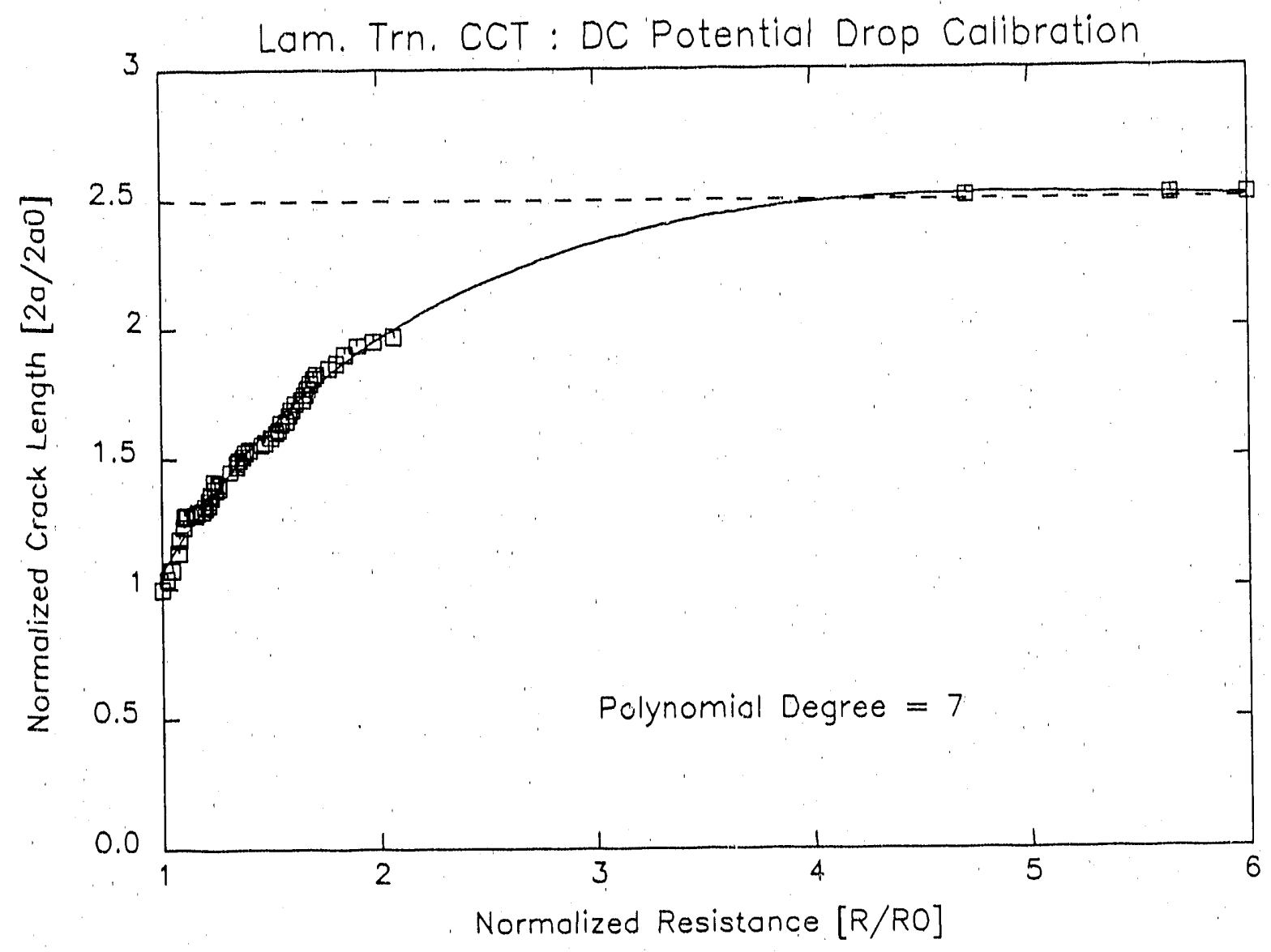

Figure 2.18: D.C. Potential Drop Crack Measurement Calibration for Laminate Transverse 


\subsection{Life Prediction}

There are many established methods of life prediction which include fatigue life, cumulative damage, and fatigue crack propagation $[58,55,59,57,56,60]$. However, since this thesis concerns fatigue crack in an explosively bonded laminate, the discussion here will focus on the fatigue crack propagation method of life prediction.

As discussed in Section 2.4, there are many closed-form expressions for the fatigue crack growth curve, which are useful because they can be integrated analytically to yield an expression for life, $N$. One of the most widely used expressions for the fatigue crack growth curve is the Paris equation, $d a / d N=C \Delta K^{m}$. If a wide plate is assumed, then the following expression for $\Delta K$ may be used.

$$
\Delta K=Q \Delta \sigma \sqrt{\pi a}
$$

If this equation is substituted into the Paris equation, a familiar expression relating life $N$, number of cycles, to crack length $a$ results:

$$
N=\frac{1}{(C \Delta \sigma \sqrt{\pi} Q)^{m}} \frac{1}{\left(\frac{m}{2}-1\right)}\left(\frac{1}{a_{o}^{\frac{m}{2}-1}}-\frac{1}{a_{f}^{\frac{m}{2}-1}}\right)
$$

where $C$ and $m$ are constants, $\Delta \sigma$ is the applied stress range, $a_{o}$ is initial crack length, and $a_{f}$ is final crack length. If the expressions for $\Delta K$ are complex, then the analytical integration may becomes difficult, and as a result, numerical integration techniques are usually used [55].

Fatigue crack growth techniques can be used to predict the life of a component as long as an expression that relates crack length $a$ and $\Delta K$ is known. However, in some applications, it is this expression for $\Delta K$ which may be quite difficult to accurately determine because of complexities of crack geometry. 


\section{Chapter 3}

\section{Experimental Setup, Specimen Design, and Procedures}

\subsection{Experimental Setup}

Mechanical tests were performed using a closed-loop servohydraulic fatigue machine, which is shown in Figure 3.2. The servohydraulic fatigue machine which was used to perform the tensile and crack growth experiments was a hybrid system which employed components from the MTS and Instron Corporations. The fatigue frame, servohydraulic systems, and associated transducers (load cell, LVDT, and extensometers) were MTS equipment. The MTS load frame and servohydraulic actuator have a maximum fatigue load capacity of $22,650 \mathrm{~N}$.

The servohydraulic controller was the Instron 8500 Series controller. All experiments were performed under computer control using a Hewlett Packard (HP) 350 workstation that was connected to the Instron 8500 via a GPIB (General Purpose Interface Bus, IEEE-488). The initial software was supplied by Instron but substantially modified and enhanced by the author to meet testing requirements. 
In the three types of mechanical tests (tensile, crack growth, and fatigue), an Instron 8500 Series controller was used for instrumentation control and data acquisition. In all tests, the Instron 8500 was operated in remote mode and all control functions, data acquisitions, and data logging were initiated by the HP 350 Workstation via communication through a GPIB.

The significant features of the 8500 controller are highlighted below.

- Dedicated Motorola 68000 microprocessors running at $12.5 \mathrm{MHz}$ are employed for each control channel.

- The 68000 and a TMS-320 digital signal processor performs high speed control loop functions and waveform generation:

- 32-bit waveform generation

- Multiple 16-bit Analog-to-Digital converters for each transducer channel

- Programmable limit detectors, event detectors, and digital I/O lines

When testing at frequencies higher than $5 \mathrm{~Hz}$, amplitude control is necessary to ensure accurate stabilization of the mean and span of the desired waveform. Although the Instron 8500 has amplitude control circuits in resident, only the waveform span is stabilized. As a result, when running crack growth experiments, amplitude control was accomplished by software routines in the HP 350. These amplitude control routines stabilized both waveform mean and span.

\subsubsection{Potential Drop Crack Measurement System}

Figure 3.1 shows the layout of DC potential drop crack measurement system. In order to employ DC potential drop crack measurement techniques, the following hardware in conjunction with the Instron 8500, MTS Load Frame, and HP 350 workstation were used: 
- EMHP 600 Amp Power Supply and Transformer. This power supply was operated in constant current mode.

- 6000 Amp Air-Driven Pnuematic Relay. This relay was used to switch the current polarity in the specimen. A solid-state relay interface was built to allow the Instron 8500 to switch the pnuematic relay via its digital output lines.

- $1000 \mathrm{Amp} / 100 \mathrm{mV}$ Shunt to read the current in the specimen.

- FLUKE $8840 \mathrm{~A}$ Multimeter. The Fluke $8840 \mathrm{~A}$ wis used to read the voltage across the current shunt. The HP 350 obtained this voltage reading through the HP-IB and converted it into a current reading.

- KEITHLEY 155 Microvoltmerer. The Keithley 155 measured the voltage across crack from probes that were either soldered or spot-welded to the CCT. specimen. This voltage was then scaled as an output voltage from 0 to 1 Volt and digitized by an HP digital multimeter (DMM).

- HP 3478A Multimeter. The HP 3478A was used to digitize the scaled output voltage on the Keithley. The HP 350 obtained this scaled voltage reading through the HP-IB and converted it into a voltage reading.

- 1000 Amp Rated Braided Copper Cables. These cables were used to connect the power supply, relay, and specimen. Wherever possible, the cables were twisted to aid in minimizing electromagnetic noise.

As with conventional power supplies, the mode of control, current or voltage, of the EMHP power supply is determined by the load resistance value which is given by [53] :

$$
\text { Load Resistance (Ohms) }=\frac{\text { Voltage Control Setting(Volts) }}{\text { Current Control Setting (Amperes) }}
$$


For high liad resistance values, the power supply operates in voltage control mode. However, for low load resistance values, the power supply operates in current control mode. Thus, an automatic safety feature is inherently provided. When the fatigue crack is growing during a test, the power supply is operating in constant current mode. When the specimen completely fractures, the load resistance will. become very high. As a result, the power supply automatically switches over to constant voltage control mode and hold. Switching and holding in constant voltage control mode ensures that the specimen or testing equipment will not be damaged after the specimen fractures.

The calibration procedures associated with this D.C. potential drop crack measurement system are described in Appendix C. 


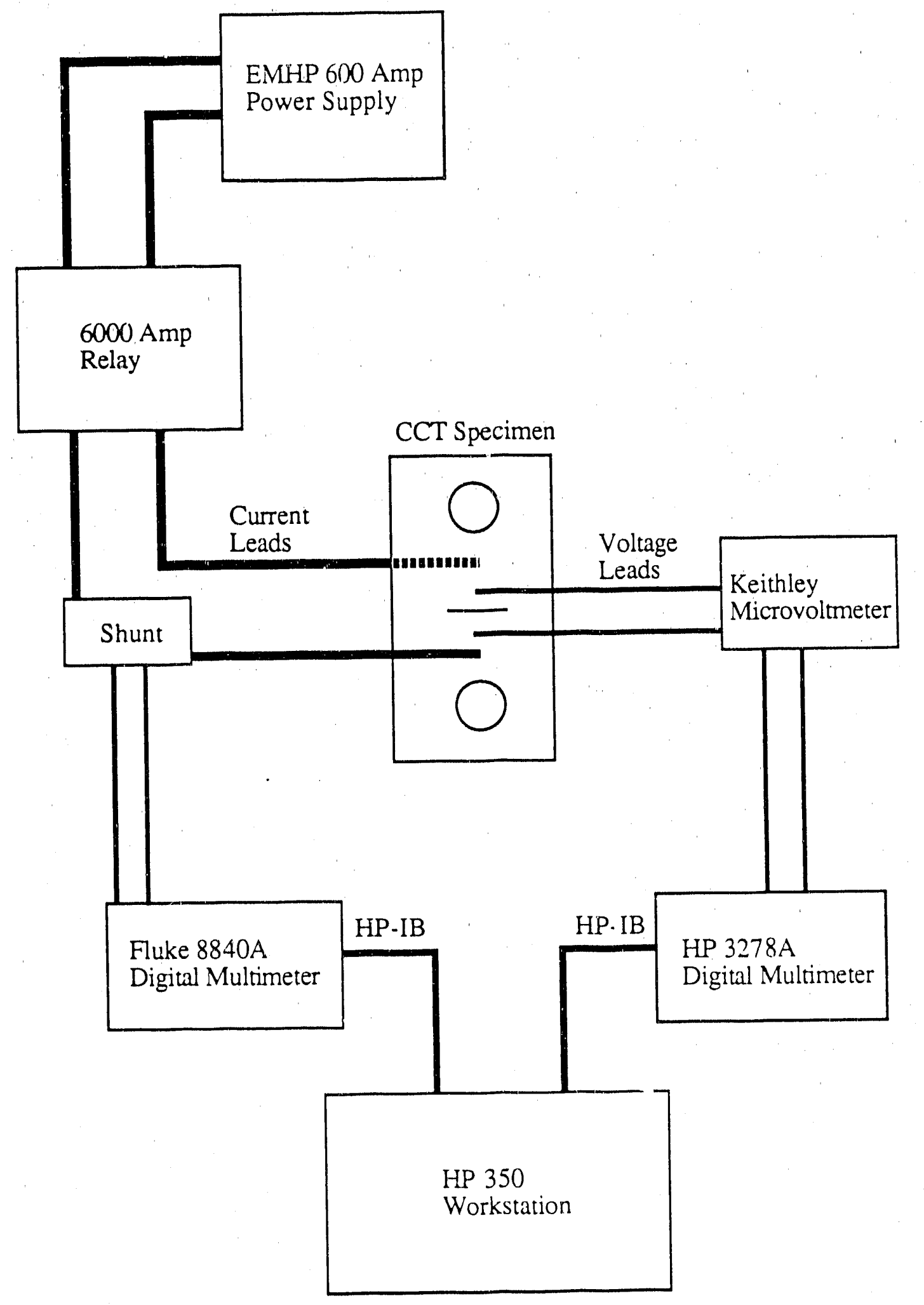

Figure 3.1: DC Potential Drop Crack Measurement System Layout 


\subsubsection{Software}

All software was programmed in HP BASIC 5.0 on an HP 350 Workstation. Two programs were used: a fatigue crack growth program, DADNFW, and a tensile test program, PROOF2. Complete listings of these programs can be found in Appendix B. Since all tests were performed in computer control, the HP 350 workstation constructed and monitored the servohydraulic testing waveforms, performed the data acquisition, and checked the operational status of all system components. Of the two programs, the crack growth program underwent the most modifications and enhancements, and some of the more significant features are briefly discussed here. The final version of the crack growth program was fully-automated and ran for several days without any human intervention.

After extensive modifications to the supplied testing software, the fatigue crack growth program was expanded to include the following additional capabilities:

- Calculation of the stress intensity factor $K$ for a center cracked tension specimen.

- Ability to hold the test at a pre-specified cycle intervals

- Ability to input crack length readings from a travelling microscope

- Ability to determine crack length from a switched D.C. potential drop crack measurement system

- Ability to hold the test at after a pre-determined crack length has been achieved

- Immediate logging of data to the hard disk which would protect against possible data loss in the event of power failure

- Real-time plotting of $2 \mathrm{a} / \mathrm{W}$ versus number of cycles on the test screen 
The most difficult software feature to be developed was the inclusion of the D.C. potential drop crack measurement system. A brief description of the software for this system is given here.

The software developed for the D.C. potential drop crack measurement system was responsible for interfacing with the DMMs, which measured current in the specimen and potential across the fatigue crack, and instructed the 6000 amp relay to switch the polarity of the current into the specimen. Switching this relay involved toggling a digital output line of the Instron 8500 controller which in turn established power to the relay via a custom interface box. Forty readings of voltage and current were acquired and averaged to obtain one resistance value that was correlated with a crack length. More specifically, 10 pairs of voltage and current readings (10 positive and 10 negative) were taken. Prior to switching, two readings at each polarity were taken and averaged to give the 10 pairs of readings. Each of these 10 pairs of readings were averaged to give 10 values of resistance, which were then averaged to give the single reading of resistance that was used to compute crack length. All D.C. potential drop data acquisition was performed while the test was held at the mean load. After D.C. potential drop data acquisition was complete, the crack growth test resumed normal operation. 


\subsubsection{Cryogenic System}

In order to perform tensile and fatigue crack growth tests in liquid nitrogen, a cryogenic system was constructed for the servohydraulic fatigue frame, which is shown in Figures $3.3-3.5$. The same cryogenic system was used in both the tensile and crack growth experiments. The cryogenic system consisted of an insulated 304 stainless steel dewar, a liquid nitrogen level controller, and a heater for the load cell. The cryogenic system had to be designed so that the existing. DC potential drop system could be used. The requirements on dewar design became quite specific: the dewar had to allow adequate space for the DC potential current and probe leads, enclose most of the load train in order to minimize nitrogen losses, and ensure correct specimen and probe alignment. Due to these specific requirements, the dewar is made as two halves which are clamped into position once the specimen, cables, and probes are in place. The dewar measures $36 \mathrm{~cm}$. inches in diameter. and $71 \mathrm{~cm}$. high. It is shown in Figure 3.3. This dewar is designed to be clamped around the lower $7.6 \mathrm{~cm}$. clevis grip.

Sealing the dewar once it was in place proved to be a formidable task. GORETEX Joint Sealant is a sealing material which survives at $77^{\circ} \mathrm{K}$. Silicon rubber was first tried but only has a minimum temperature rating of $-45^{\circ} \mathrm{C}$, and it becomes brittle and cracks at $77^{\circ} \mathrm{K}$. A GORE-TEX gasket is constructed along the outer flanges of the dewar. Additional GORE-TEX is used around the lower clevis grip to ensure good seal around the grip. The dewar is clamped and held in place by two hose clamps around the lower cylindrical section and $18 \mathrm{C}$-clamps along the outer flanges.

The dewar is designed to only clamp on to the lower clevis grip. As a result, it is completely extraneous to the load train. Thus with this design, there is no need to account for dewar and liquid nitrogen weight. The only effect of dewar and liquid nitrogen weight is to increase the inertia of the actuator. An increase in actuator 


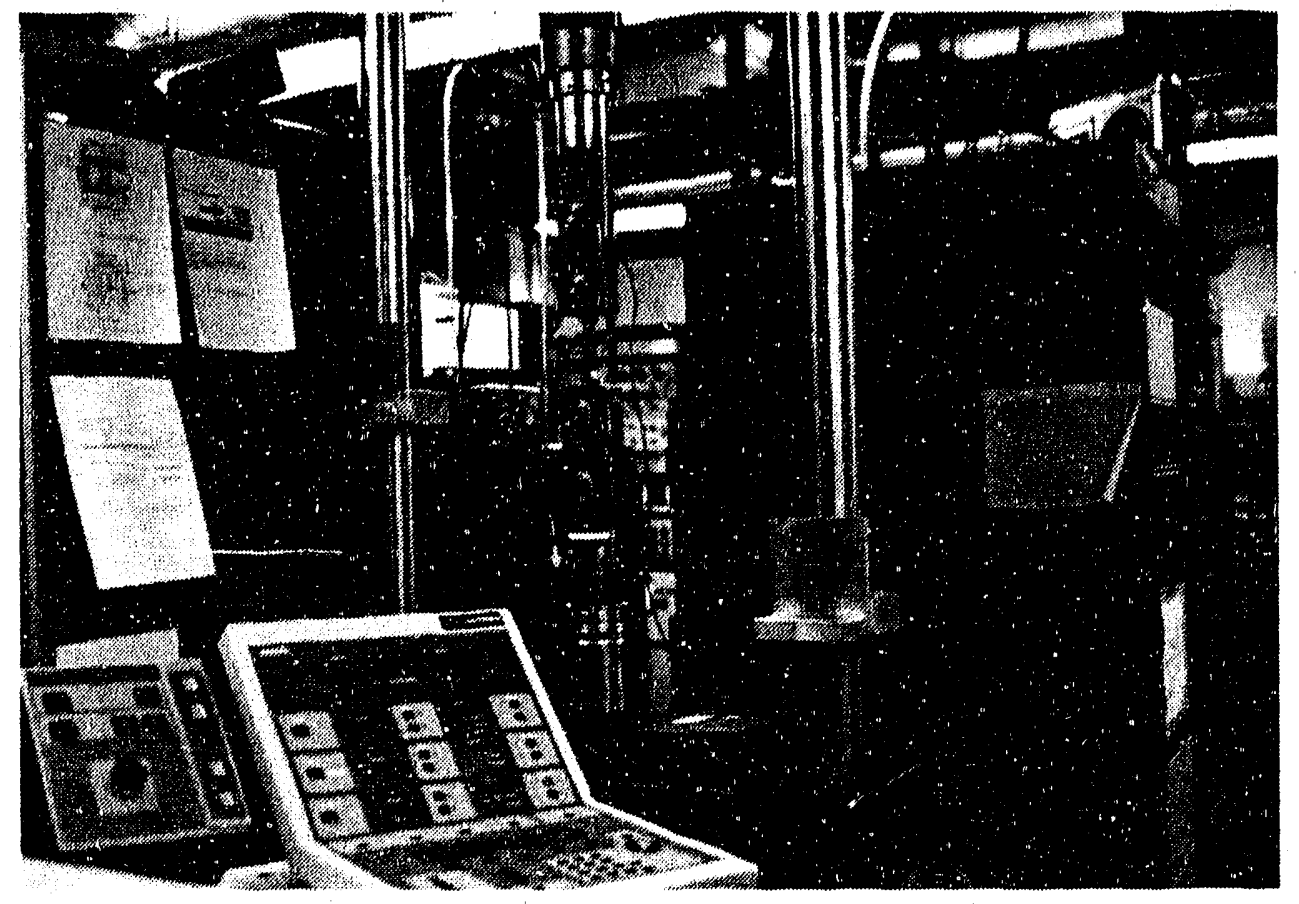

Figure 3.2: The Closed Loop Servohydraulic Fatigue Testing Machine. The Instron 8500 Series controller is shown in the foreground, while MTS fatigue frame with a tensile specimen in the grip assembly is shown in the background. 
inertia may limit the maximum frequency of a test. Usually, larger actuator inertia results in a lower maximum frequency.

Because the load cell is temperature sensitive, precautions had to be taken to prevent the load cell from freezing. Extreme temperature changes will cause a zero shift in load cell readings. As a result, external heater tape is used in the lower portions of the load cell to limit cooling by conduction and nitrogen vapor. In order to ensure that the heater tape would not short to the load cell Capton insulation is wrapped on the outer surface of the load cell. A layer of fiberglass tape is wound on the Capton, and then the layers of heater tape is wound in place. A rheostat is used to ensure correct load cell temperature, and a ther nocouple with a digital display monitors load cell temperature. Before each test, the load cell is rebalanced at an ambient ternperature (Usually $23^{\circ} \mathrm{C}$ ) with the specimen in place but with the lower pin removed. The dewar is then filled with liquid nitrogen while the load cell heater keeps the load cell at the rebalanced temperature. The load then remains at this temperature throughout the test.

A liquid nitrogen level controller was fabricated consisting of a cryogenicrated solenoid valve, a relay box, and a pair of thermistors. When both thermistors are exposed, the relay opens the solenoid valve and liquid nitrogen flows into the dewar. When both thermistors are submerged in liquid nitrogen, the relay closes the solenoid valve and nitrogen filling is stopped.

A phase-separator box was constructed out of styrofoam and polyethylene and teflon tubing. The phase-separator box separates nitrogen vapor and liquid so that only liquid enters the dewar, and thus, it minimizes liquid nitrogen consumption. In order to expedite liquid nitrogen filling, two drain holes with Teflon tubes feeding into the dewar were bored in the styrofoam phase-separator. Using two feeder tubes into the dewar, liquid nitrogen filling times averaged between 1.5 and 2.5 minutes.

In order to minimize liquid nitrogen boiling losses, styrofoam "pcpcorn" was 
used to fill the space separating the liquid nitrogen surface and the top edge of the dewar. This styrofram popcorn created a "floating" lid for the dewar, which was quite advantageous since there were many cables and tubes feeding into the dewar from the top. A thin sheet of foam was then placed on top of the styrofoam popcorn to further minimize liquid nitrogen boiling. This system worked quite well to insulate the top of the dewar. As a result, the primary heat flux into the dewar came from the flanges and the GORE-TEX, which was expected. 


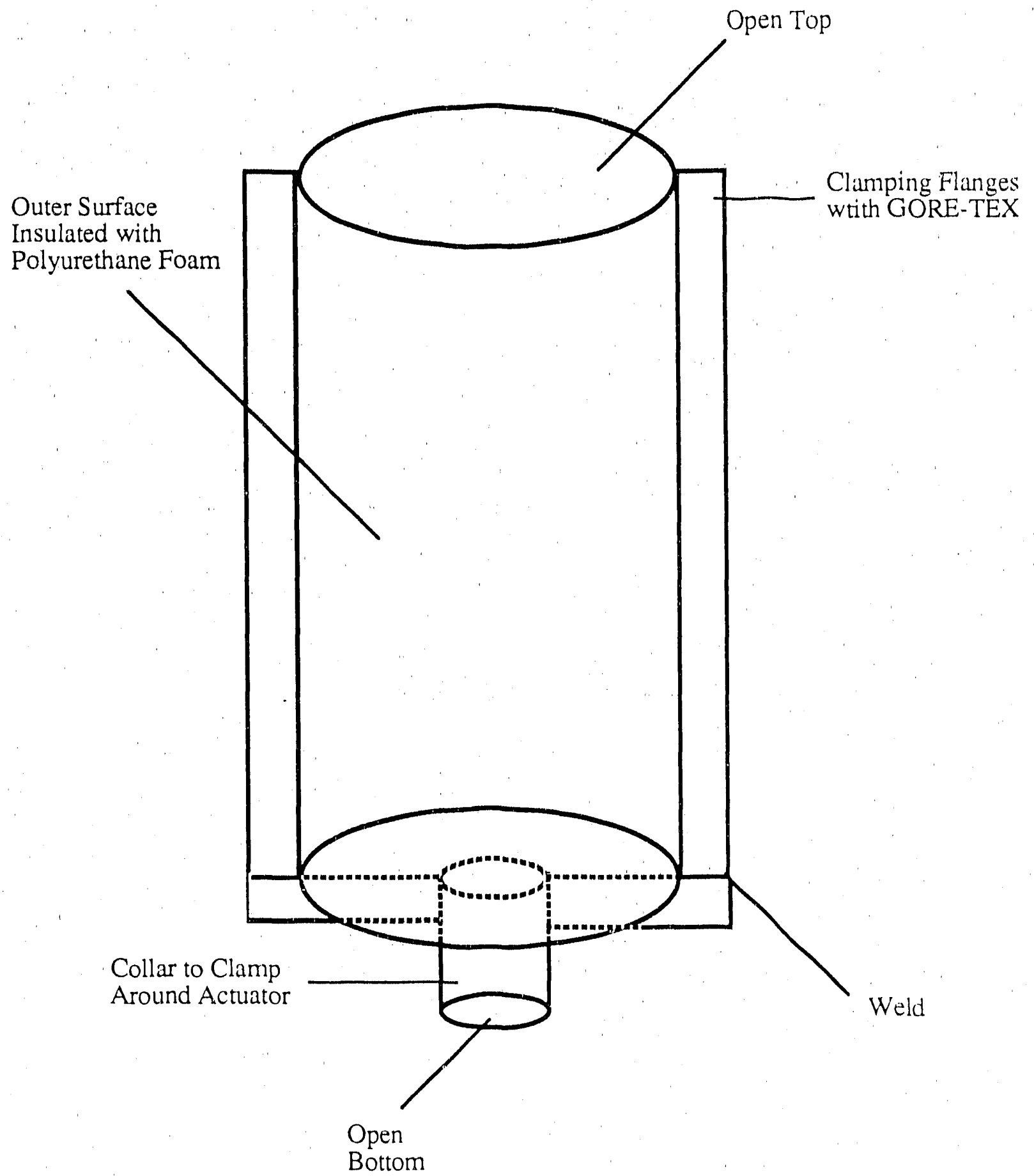

Figure 3.3: Schematic of the Cryogenic Dewar 


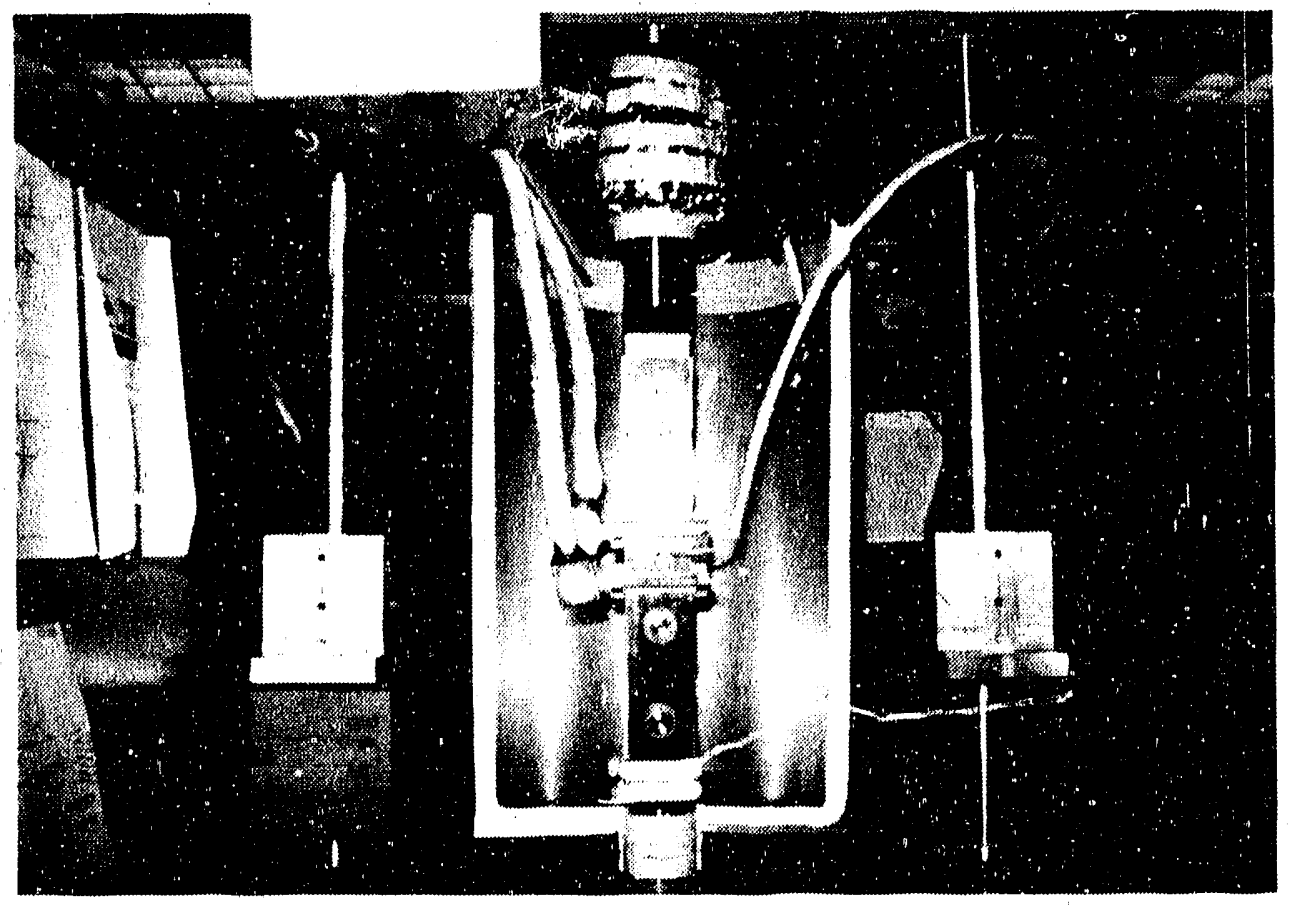

Figure 3.4: Cryogenic Dewar with Specimen and D.C. Potential Drop Crack Measurement Cables in Place. GORE-TEX gasket is shown in white along the outer flange. The thick cables on the left of the grip assembly are the D.C. current cables, the thin cable on the right is the probe cable which measures the voltage across the crack. The phase-separator box is shown in white in the upper portion of the photograph. The load cell is shown enclosed with heater tape and foil. 


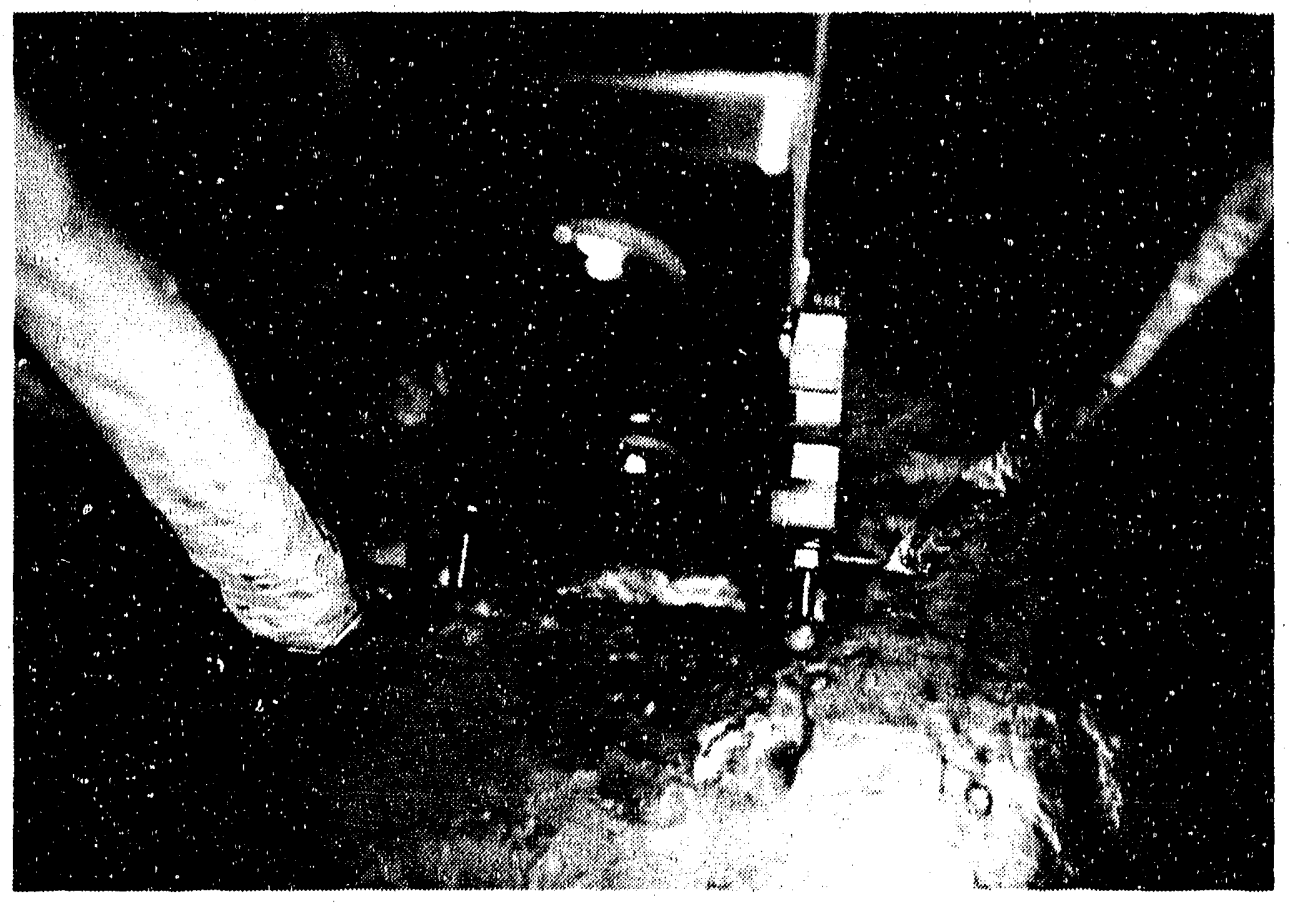

Figure 3.5: Liquid Nitrogen Filling Cryogenic Dewar with Laminate CCT Specimen. The liquid nitrogen level has covered approximately half of the CCT specimen. The D.C. current cables ure shown attached to the specimen via specially-made copper "clamps" which are fixed onto the front and back faces of the specimen. 


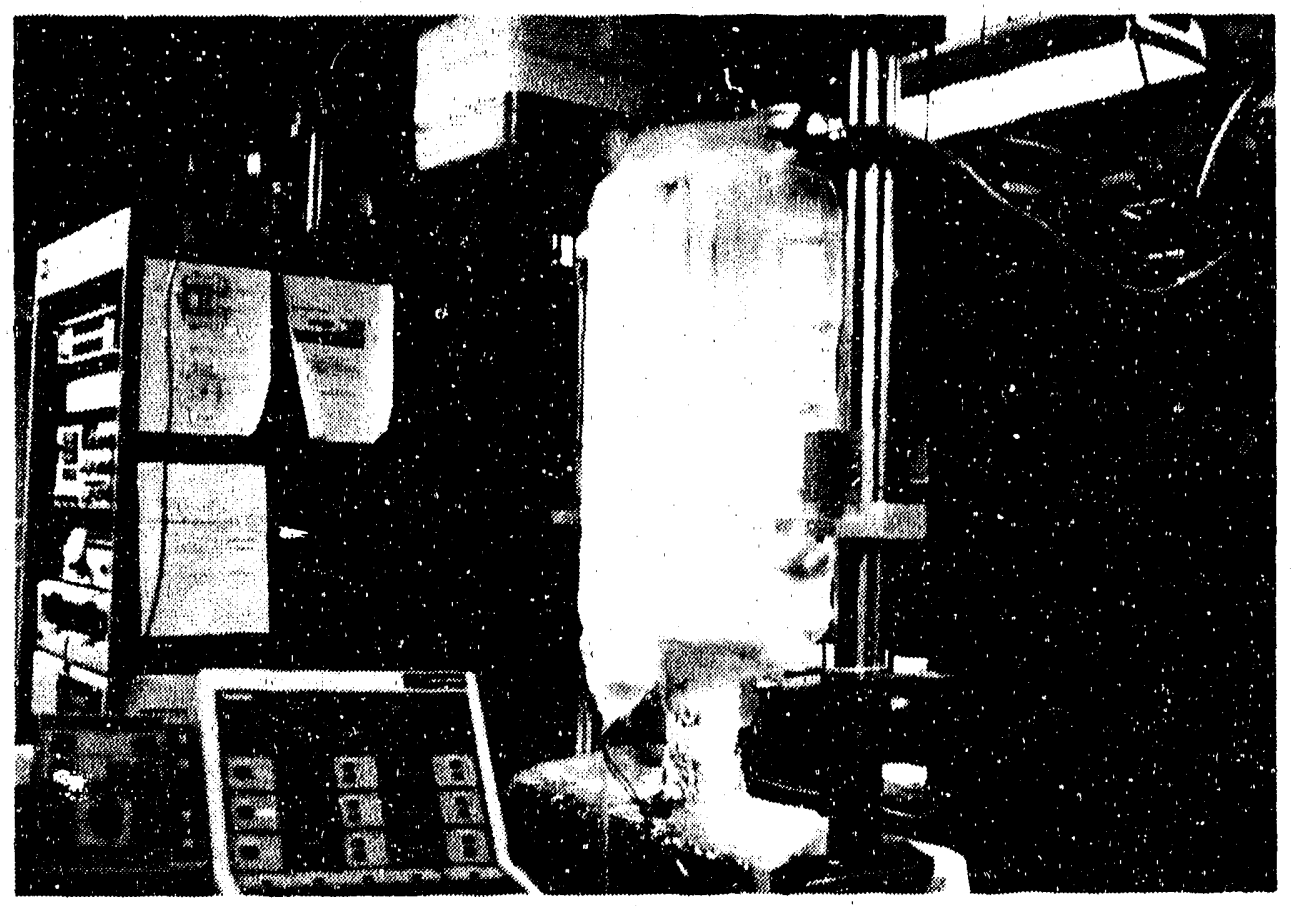

Figure 3.6: Cryogenic Fatigue Testing System After Four Days of Continuous Operation. No evidence of liquid nitrogen leaks were apparent. A substantial amount ice has covered the cryogenic dewar. Ice has also completely covered the outer flanges. The fatigue crack growth test was run at a testing frequency of 8 Hertz. The cryogenic testing system ran continuously for seven days without any major difficulties. 


\subsection{Specimen Design}

Two types of specimens were used in the mechanical tests: a dog-bone shaped tensile test specimen and a center cracked tension panel (CCT). The tensile test specimen design was used in both the tension tests and fatigue tests. Test specimens were made of three materials: Inconel 718, Copper 107, and the explosively bonded laminate. Inconel 718 and Copper 107 specimens were made from extra plates that were not used in the TF core, but had passed the requirements in the materials specifications. The laminate specimens were cut from two explosion bonded plates that had passed the C-MOD QA inspection criteria. These laminate plates represented the "best" explosion bonded plates that were produced (Plate Nos. M15 and M13).

In order to account for directional effects, two directional specimens were made from each material: one longitudinal and one transverse. The longitudinal and transverse directions for the Inconel 718 and Copper 107 were defined as parallel and perpendicular to the rolling direction respectively. In the laminate, the longitudinal and transverse directions were defined in relation to the explosion direction and ripple orientation. The longitudinal and transverse directions are defined in Figure 3.7 .

The laminate plates had an as-bonded thickness of $2.54 \mathrm{~cm}$. Due to space and load capacity limitations in the testing machine, the maximum specimen thickness is $1.27 \mathrm{~cm}$. As a result, the laminate specimens were reduced in thickness by grinding to $1.27 \mathrm{~cm}$. Much care had to be taken during this process to ensure that the Inconel 718 remained located at the specimen midplane. At most $0.254 \mathrm{~mm}$. were ground from each side of the specimen during each pass. This also ensured that the specimen did not warp due to residual stresses present at the interfaces. 


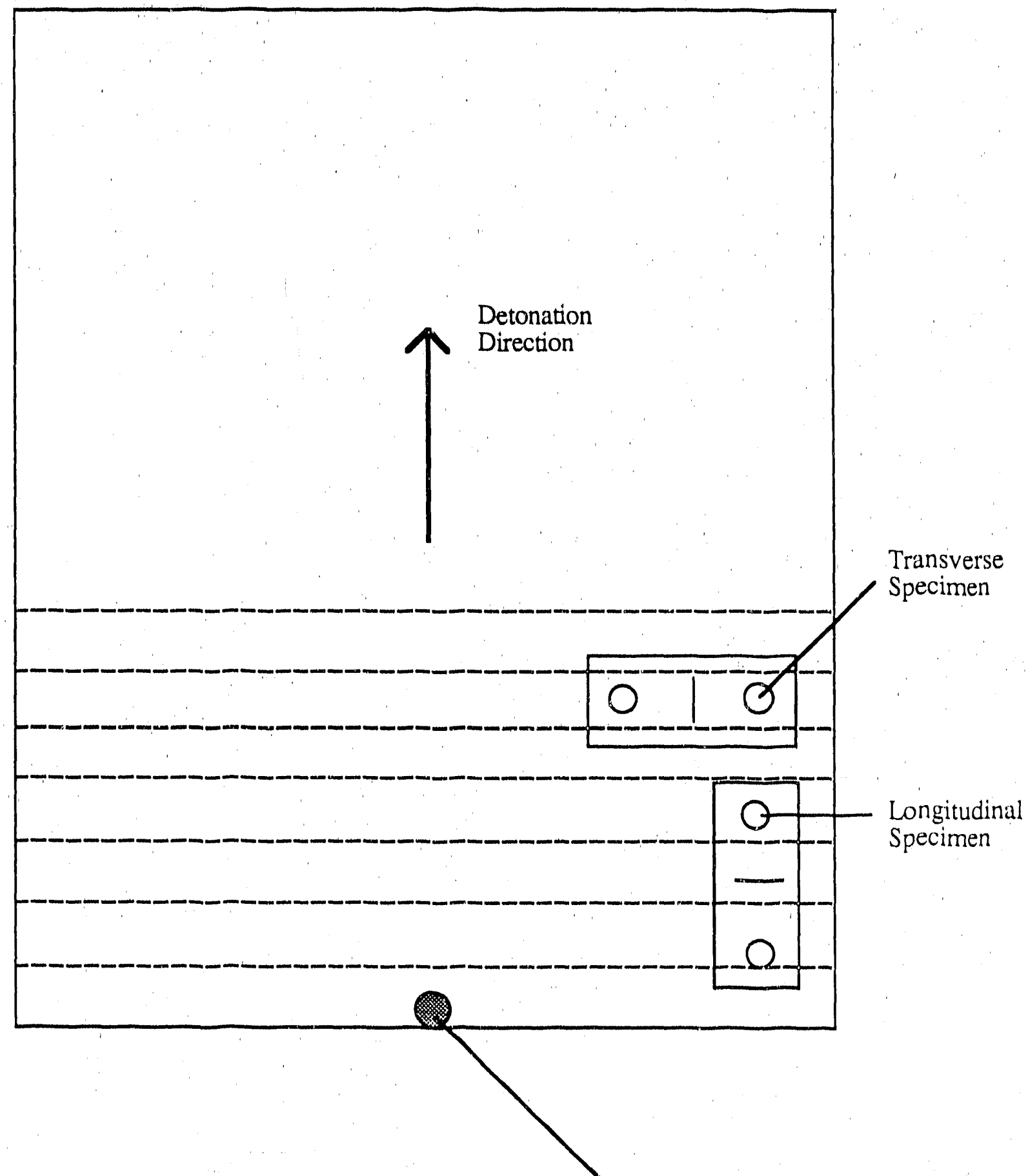

Detonation

Point

Figure 3.7: Longitudinal and Transverse Specimen Orientations in the Explosion Bonded Laminate Plates 


\subsubsection{Tensile Test Specimens}

The tensile test specimen was designed in accordance with the ASTM E-8 standard on tensile testing [68]. The specimen is shown in Figure 3.8 The specimen is 25.4 $\mathrm{x} 7.62 \times 1.27 \mathrm{~cm}$. and has a $5.08 \mathrm{~cm}$. gage length where it is $1.27 \mathrm{~cm}$. wide. It contains $2.54 \mathrm{~cm}$. diameter holes for fixturing in the grips. All specimens were water-jet cut from furnished plates.

\subsubsection{Center Cracked Tension Panel}

The center cracked tension panel was designed in accordance with the ASTM E647 standard for fatigue crack growth [67]. The specimen is shown in Figure 3.9. The specimen dimensions are $23 \times 7.62 \times 1.27 \mathrm{~cm}$. with $2.54 \mathrm{~cm}$. diameter holes for fixturing. A $3.05 \mathrm{~cm}$. starter notch was cut in the center of the specimen by electric discharge machining (EDM) techniques. As with the tensile test specimens, the specimen thickness of at most 1.27 . cm. inches was required by testing machine space and load limitations.

In determining the length of the starter notch in the CCT specimen, ASIMM E 647 requires the following relationship between the specimen's uncracked ligament, $W-2 a$, where $W$ is specimen width and $2 a$ is the notch length, and specimen thickness, $B$ :

$$
(W-2 a) \geq 1.25 \frac{P_{\max }}{B \sigma_{y}}
$$

This relationship essentially ensures that there is a 1.25 factor of safety in the specimen design such that the specimen's uncracked ligament is not yielding or under going plastic deformation at the maximum load during a test. Using the Feddersen equation 2.4 for the stress intensity factor of a CCT specimen, $\mathrm{P}_{\max }$ may be eliminated in favor of $K_{\max }$. A relationship between $K_{\max }$ and specimen 
geometrical parameters results and is shown in Figure 3.10. 


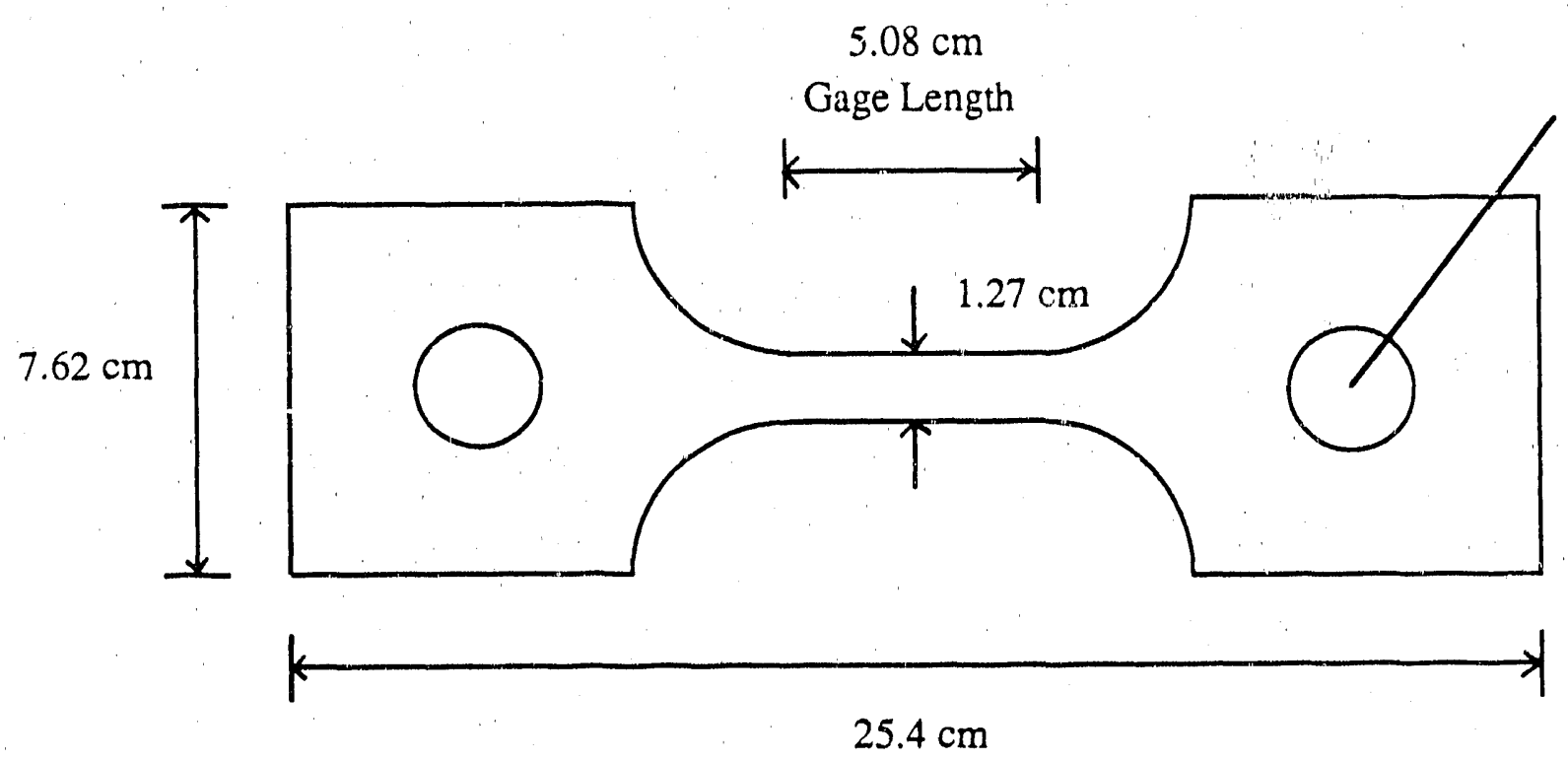

$2.54 \mathrm{~cm}$ Diameter Holes

Figure 3.8: Tensile Test Specimen Design

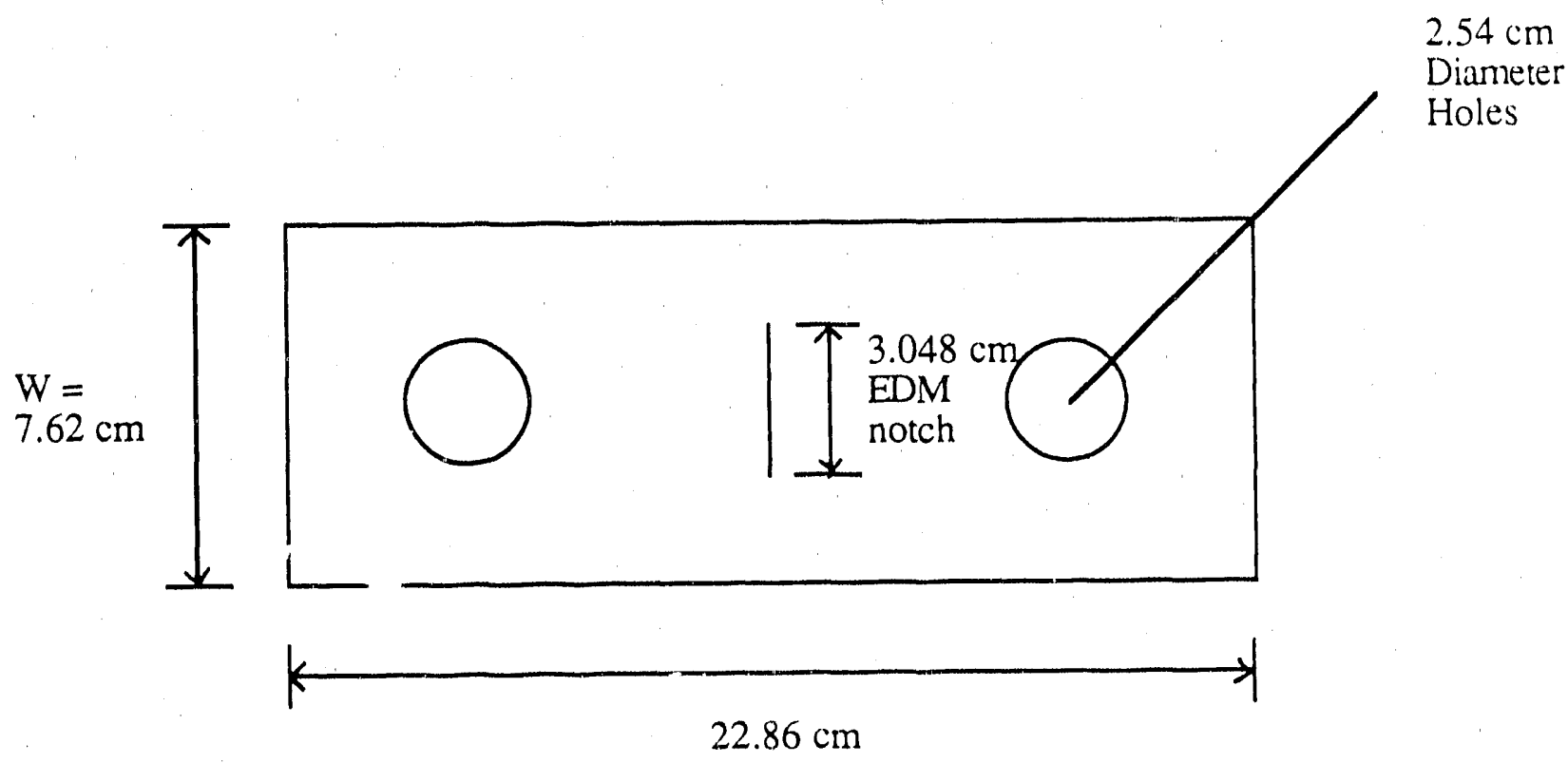

Figure 3.9: Center Cracked Tension (CCT) Specimen Design 


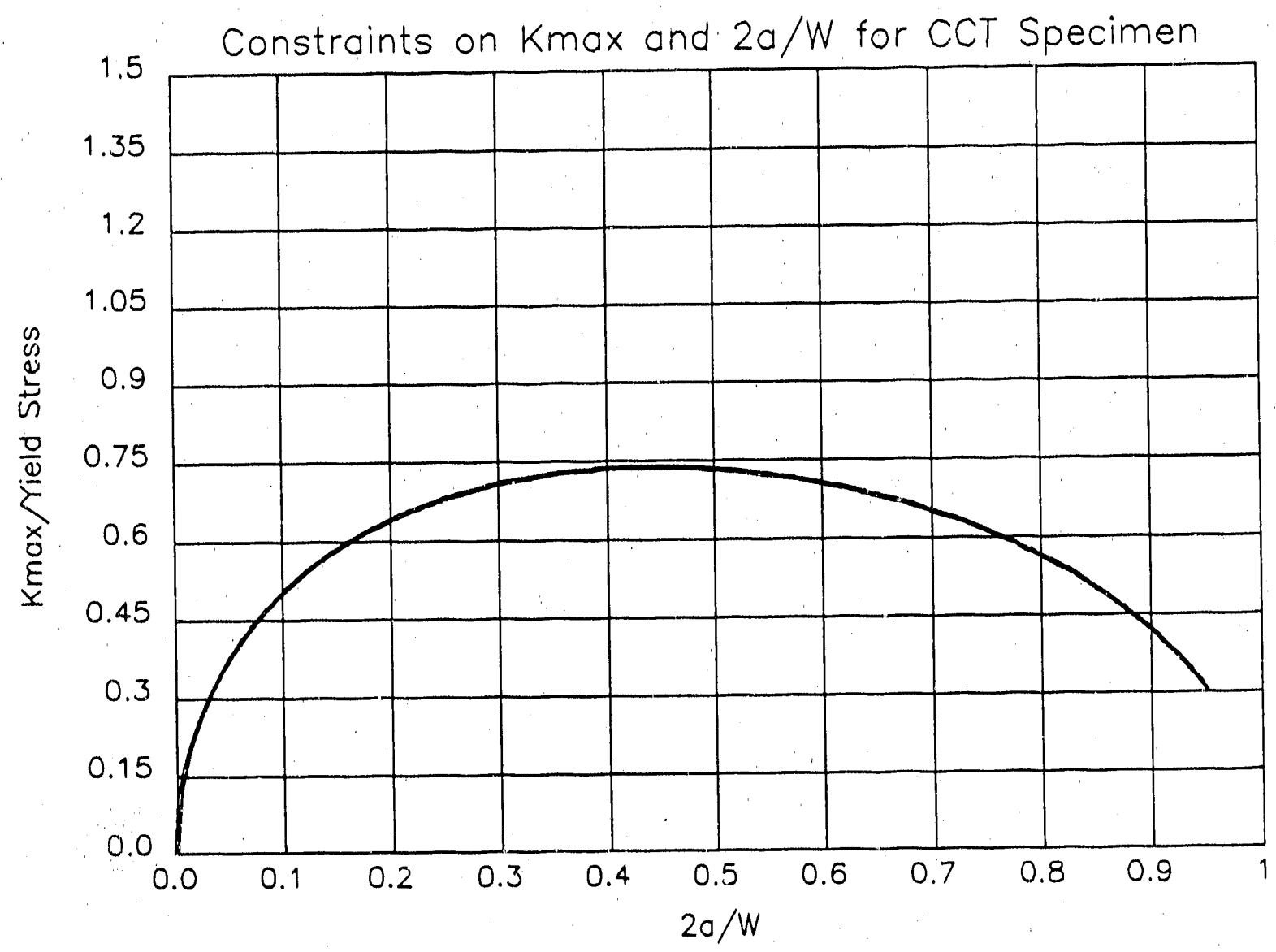

Figure 3.10: Normalized Size Requirements for a 3.0 inch wide CCT Fatigue Crack Growth Specimen 


\subsubsection{Grip Design}

The specimen grips are shown in Figure 3.11. These grips were used in the tensile, $\mathrm{da} / \mathrm{dN}$ crack growth, and fatigue tests at both room temperature and $77^{\circ} \mathrm{K}$. The grips were made of Inconel 718 and age hardened according to AMS 5596E [29]. Inconel 718 was chosen because (1) since grips would operate at room temperature and $77^{\circ} \mathrm{K}$, it was necessary to have the material not exhibit ductile-to-brittle transitional behavior, and (2) since high tensile operating stresses were anticipated, a high strength alloy was desired. A double pair pin arrangement was employed to allow self-alignment of the specimen in the load train. G-10 fiberglass sleeves between each pin and each side plate to ensure that the specimen was electrically isolated from the upper and lower clevis pieces. G-10 spacers were used to center the specimen between the pairs of side plates. Teflon sheet spacers $(0.8 \mathrm{~mm}$. thick) were used as insulation between the side plates and the upper and lower clevis pieces. The upper and lower clevis pieces were lock to the load cell and actuator respectively by steel spiral lock washers. The clevis pieces were turned-on-center when they were machined and thus, no additional alignment devices were requirement when the grips were mounted in the fatigue frame. 


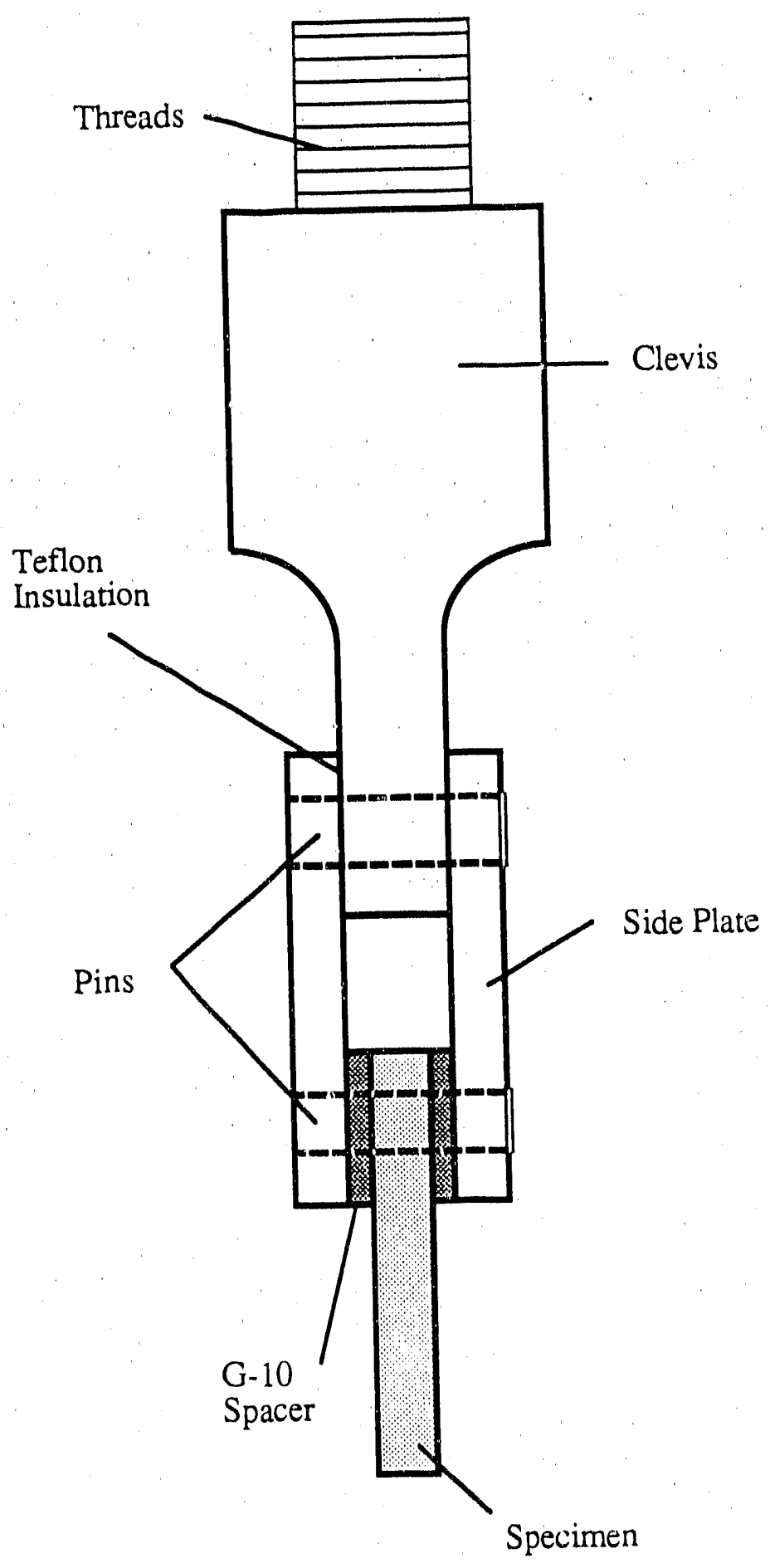

Figure 3.11: Specimen Grip Assembly 


\subsubsection{Specimen Machining Techniques}

Since age-hardened Inconel 718 was present in the specimens, conventional machining techniques would be expensive and time consuming. As a result, two specimen machining techniques in which material hardness is not a factor were employed: water-jet cuing and electric discharge machining (EDM). Water-jet cutting was used to cut the Individual specimens from the large plates, while EDM was used to cut the center notch of the center cracked panel specimen. Water-jet cutting has a resolution of approximately $3.18 \mathrm{~mm}$. and is thus more surited to specimen perimeter cutting. EDM, on the other hand, was able to achieve a root radius in the center notch of less than $0.254 \mathrm{~mm}$, and thus, EDM is more suited to precise cutting applications.

\section{Water-jet Cutting}

The water-jet cutting method is quite straightforward: a high pressure water jet with a particulate is used to cut the material. Typically, the water pressure is approximately $241 \mathrm{MPa}$, and garnet particulate is used. At first, sapphire nozzles were used. However, due to their longer wear times, graphite nozzles are commonly used today. The surface finish of the cut piece is dependent on cutting speed. The typical speed used in cutting my specimens was about $5.08 \mathrm{~cm}$. per minute. However, in the transition regions of the tensile specimens, slower speeds were used to ensure good continuity in transitions between radius and flat regions.

\section{Electric Discharge Machining (EDM)}

The general EDM process is schematically shown in Figure 3.12. The electric discharge machining method is also quite straightforward. The are two types of EDM in use today: conventional and wire. Conventional uses a single electrode, typically graphite, to bore holes, engrave, or create surface flaws. Wire EDM uses a moving 
wire electrode to cut a specified contour from plate or bar stock. The nature of wire EDM requires that through thickness cuts be made in the stock material. The EDM process is only applicable to conducting materials. The basic idea of EDM is that the workpiece is placed in a dielectric, usually oil or de-ionized water, the electrode is then brought into close proximity to the workpiece and electrically pulsed. This pulse is sufficient to exceed the breakdown voltage of the dielectric, and as a result, an arc is created between the electrode and workpiece. This arc causes a small amount of material in the workpiece to be vaporized and flushed away. The process is then repeated until the desired cut is achieved. In the case of wire EDM, the wire is mounted on spools and always moving, which ensures a clean electrode. Typically, the wire is pulsed at 50 or $60 \mathrm{~Hz}$.

The EDM process has many advantages over conventional machining, especially for high Lardness materials. Since there is no tool force on the machine, electrode, or workpiece, the hardness of the material is not really a factor. Anything which conducts electricity may be machined by EDM. Since an EDM machine is usually computer-controlled, intricate and unusual shapes may be created, great precision may be achieved, and repeatability and full-automation are easily implemented [84]. Since the electrode never comes into contact with the workpiece, no residual stresses are induced, and the EDM surface finish is very smooth. There are some disadvantages of the EDM process. The workpiece must be conductive. Electrode wear can produce inaccuracies and may require the use several electrodes for a particular job. An efficient flushing system is necessary to flush vaporized material.

The center starter notches in the CCT specimens were cut using the wire EDM process. Since the ASTM standard specified a root radius in the notch of less than $0.254 \mathrm{~mm}$ [67], $0.152 \mathrm{~mm}$. diameter Copper-Zinc wire was used. Using de-ionized water as the dielectric not only provided a good dielectric, but also aided in cooling the workpiece and flushing the vaporized material. Since the EDM equipment was 
computer-controlled, the repeatability and precision of cutting the same notch in every specimen was very good.

For the laminate CCT specimens, additional surface grinding was necessary to ensure that the specimen lay flat in the EDM machine and that the Inconel was located in the center of the specimen where the starter notch was to be cut. Although the original surface grinding to reduce the specimen thickness from 2.54 to $1.27 \mathrm{~cm}$. kept the Inconel centered to the best practical degree, sometimes the Inconel would be warped or twisted in the CCT specimen. The degree of the warp or twist was different for each laminate specimen. As a result, the EDM shop recommended the additional surface grinding. This surface grinding was performed very meticulously. At most $0.127 \mathrm{~mm}$. was removed from each side. The specimen was then placed in an optical comparator with a resolution of $0.0025 \mathrm{~mm}$. to examine the centering the Inconel layer. If the Inconel was not centered, grinding then resumed to remove at most another $0.127 \mathrm{~mm}$. inches. This process was iterated until the Inconel lay in the center of the specimen where the starter notch would be cut. 


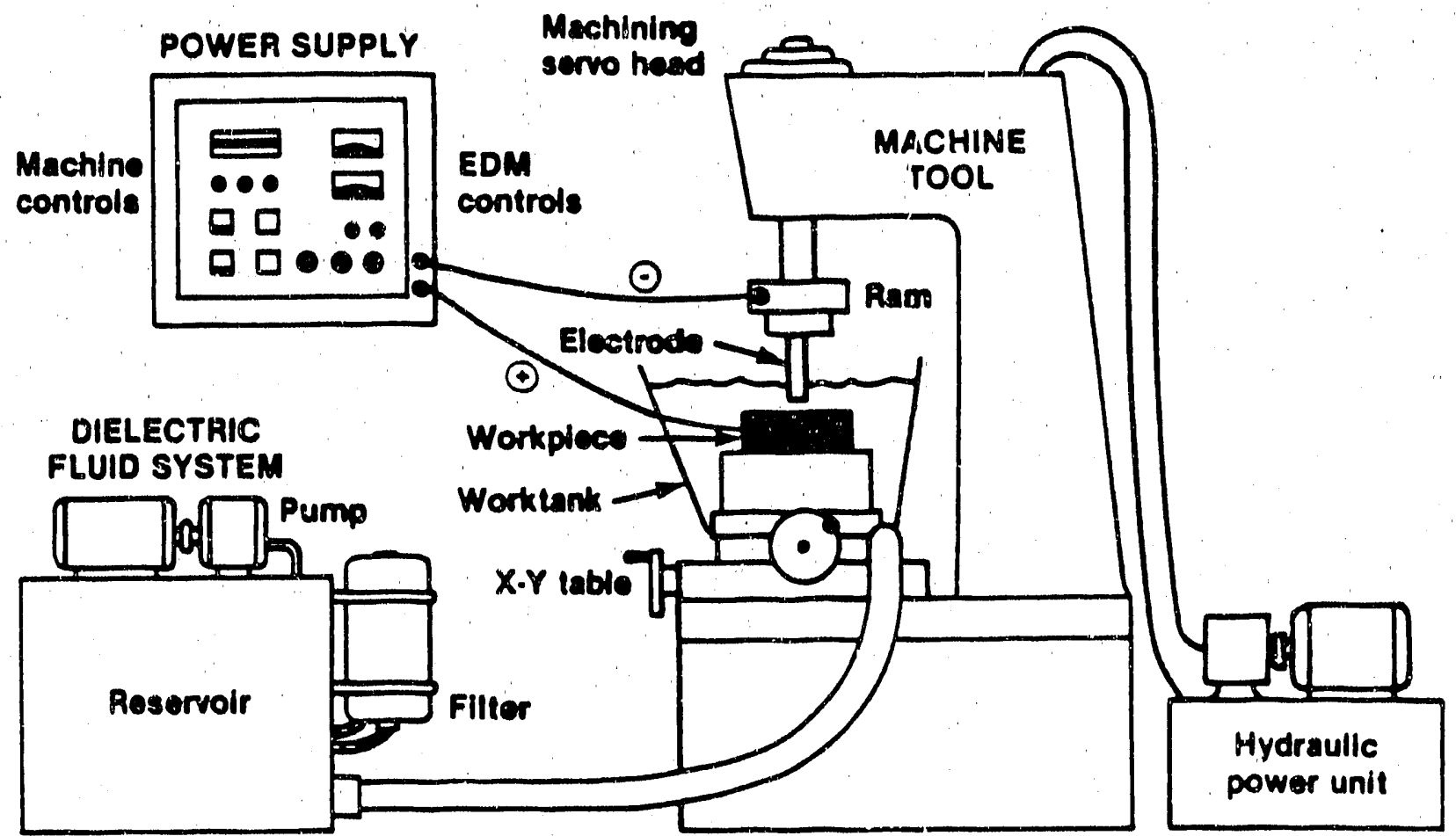

Figure 3.12: Schematic of Electric Discharge Machining (EDM) Process. From [84] 


\subsection{Experimental Procedures}

This section describes the experimental preparations and procedures that were employed in the tensile and fatigue crack growth tests. The test matrix for all specimens is shown in Table 3.3.

\subsubsection{Tensile Tests}

The gage length of each tensile specimen was polished to reduce the presence of surface flaws. The transition from radius to flat in the reduced section of the specimen was especially sanded to ensure a very smooth transition. All of the tensile tests were run in strain and stroke control. In the elastic region, the test was run in strain control. The changeover from strain to stroke control occurred at a strain of approximately $6-8 \%$. The test then operated in stroke control until final failure. The strain rate was within the range of 0.005 to $0.01 \%$ per minute. The final stroke rate was 0.05 inches per minute.

In order to determine elongation of the $5.08 \mathrm{~cm}$. gage length, pairs of lines, $5.08 \mathrm{~cm}$. apart, were scribed in the reduced section of each specimen. The specimen was then reassembled after the test to determine the elongation.

A $1.27 \mathrm{~cm}$. MTS extensometer was use in the tensile tests.

\subsubsection{Fatigue Crack Growth Tests}

In order to lo .e the potential drop probes in the same location for each specimen, two holes were drilled at a distance of $2 \mathrm{~mm}$ above and below the EDM starter notch. This is shown in Figure 3.13. After the probe holes were drilled in the CCT specimen, that face was polished first with 400 and 600 grit silicon carbide paper, and then with 6,3, and 1 micron diamond paste. This procedure led to 
an adequately polished surface in which the fatigue crack can easily been observed and measured with a travelling microscope. After polishing, the $\mathrm{CCT}$ specimen was ultrasonically cleaned in chlorothane.

The voltage probes were then soldered to the CCT specimen with woodsmetal solder. Having applied solder flux to the copper probe tips and the drilled holes, the copper probes were then lightly coated with woodsmetal solder. A heat gun was used to heat the specimen to about $75^{\circ} \mathrm{C}$, and the specimen temperature was monitored with a thermocouple. The woodsmetal-coated probe wires were then located in the probe holes at an orthogonal direction to the face of the CCT specimen. The specimen was air-cooled and then placed in the fatigue machine.

In the case of Inconel, Inconel 718 probe wires were spot-welded at locations of $2 \mathrm{~mm}$ above and below the EDM starter notch. The probe wires were spot-welded at an orthogonal direction to the face of the CCT specirnen. Due to the delicate nature of the spot weld, the probe wires were spot-welded after. the specimen had been mounted in the fatigue machine.

Before each fatigue test, the Inconel 718 pins which hold the specimen in the fatigue machine were polished on a lathe with 400 and 600 grit sandpaper. T] polishing removed any oxides or surface flaws encountered during the previous fatigue tests, and thus, prolonged the life of the pins.

The load cell was re-balanced prior to each test. After the pre-crack length of 0.3 inches was achieved, the lower pin of the load train was removed, and the load cell was again re-balanced. 

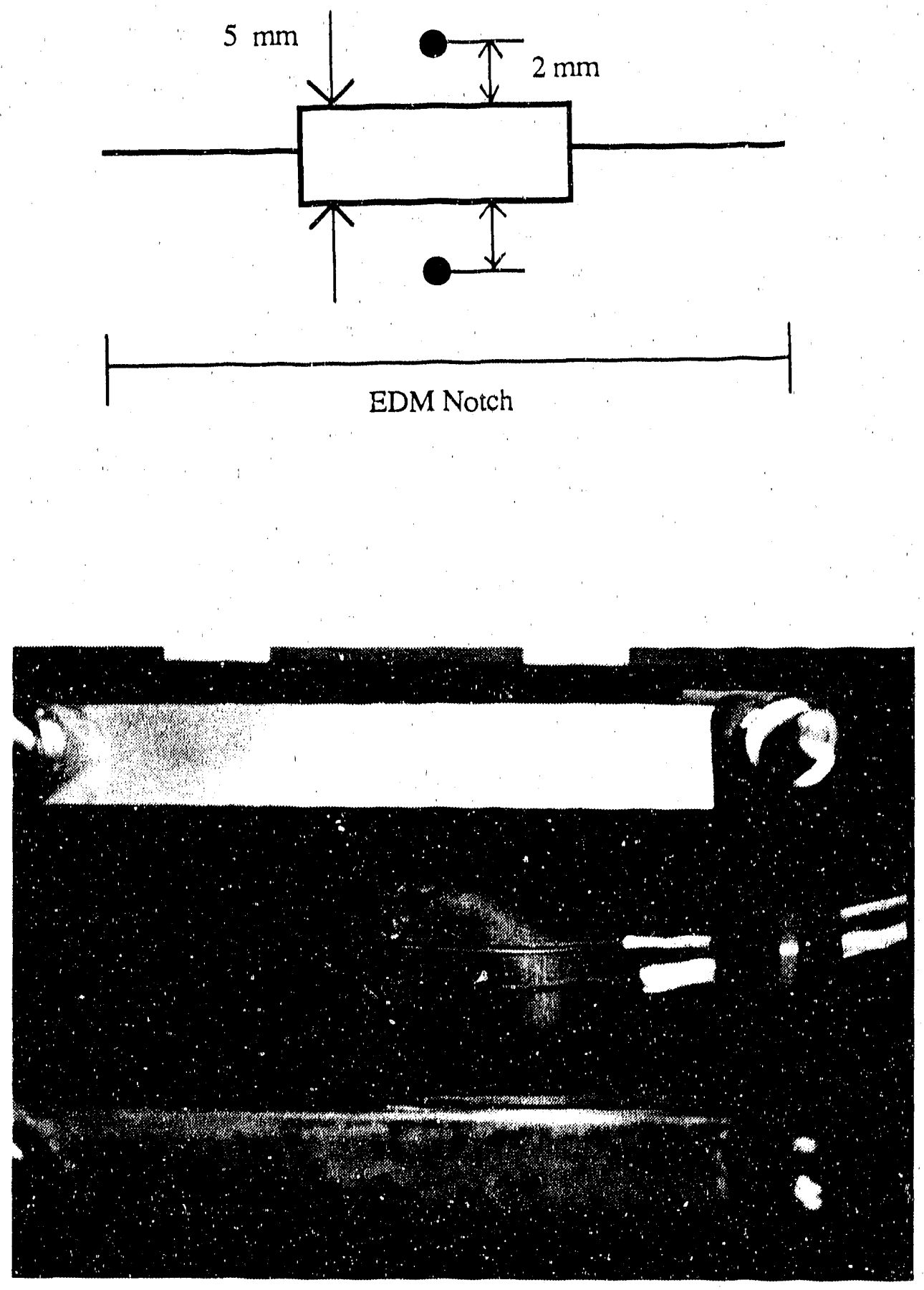

Figure 3.13: Probe Hole Locations for D.C. Potential Drop Crack Measurement in CCT Specimens 


\subsubsection{Simulation of Alcator C-MOD TF Core Loading}

This section describes the choice of experiment parameters to appropriately simulate the loading behavior of the Alcator C-MOD TF core. The loading - time history of the TF core is diagrammed in Figure 3.14, and peak stresses during the "flattop" portion at the nose and centerline of the core are given in Table 3.1. In order to simulate this loading in a uniaxial fatigue machine, the peak stresses are combined into the resulting in-plane tension stresses, which are shown in Table 3.2. The details of this analysis are given in Appendix A. The highest resulting in-plane tension stress is at the centeline where the plate thickness is $10.2 \mathrm{~mm}$ and thus, the laboratory specimen which has a thickness of $12.7 \mathrm{~mm}$ is a reasonably approximation of the actual laminate plate. This loading - time history is approximated in the fatigue crack growths experiments as a sinusiodal waveform. Since the out-ofplane loads on the copper are not accurately simulated in the experiments, these experiments can only approximate the in-plane tension behavior of the Inconel 718 .

In order to determine the range of $\Delta K$ for the fatigue crack growth tests, the largest value of in-plane tension stress in the Inconel (241 MPa) was used to compute $K_{\text {max }}$. Since the fatigue crack growth tests used through-thickness cracks, a through-thickness crack whose length was the thickness of the Inconel 718 (2.3 $\mathrm{mm}$ ) was assumed. The calculated value of $K_{\max }$ is $23 \mathrm{MPa} \sqrt{\mathrm{m}}$ in the Inconel 718 or $16 \mathrm{MPa} \sqrt{\mathrm{m}}$ on the centerline of in a laminate plate. As a result, the range of $\Delta K$ for the fatigue crack growth tests are chosen to include this calculated value of $K_{\text {max }}$. The ranges of $\Delta K$ for the laminate specimens are tabulated in Table 3.4.

The applied loads in the TF core arise from the Lorentz body forces in the magnet. To simulate this loading behavior in a fatigue machine, the crack growth experiments were conducted in load control. 


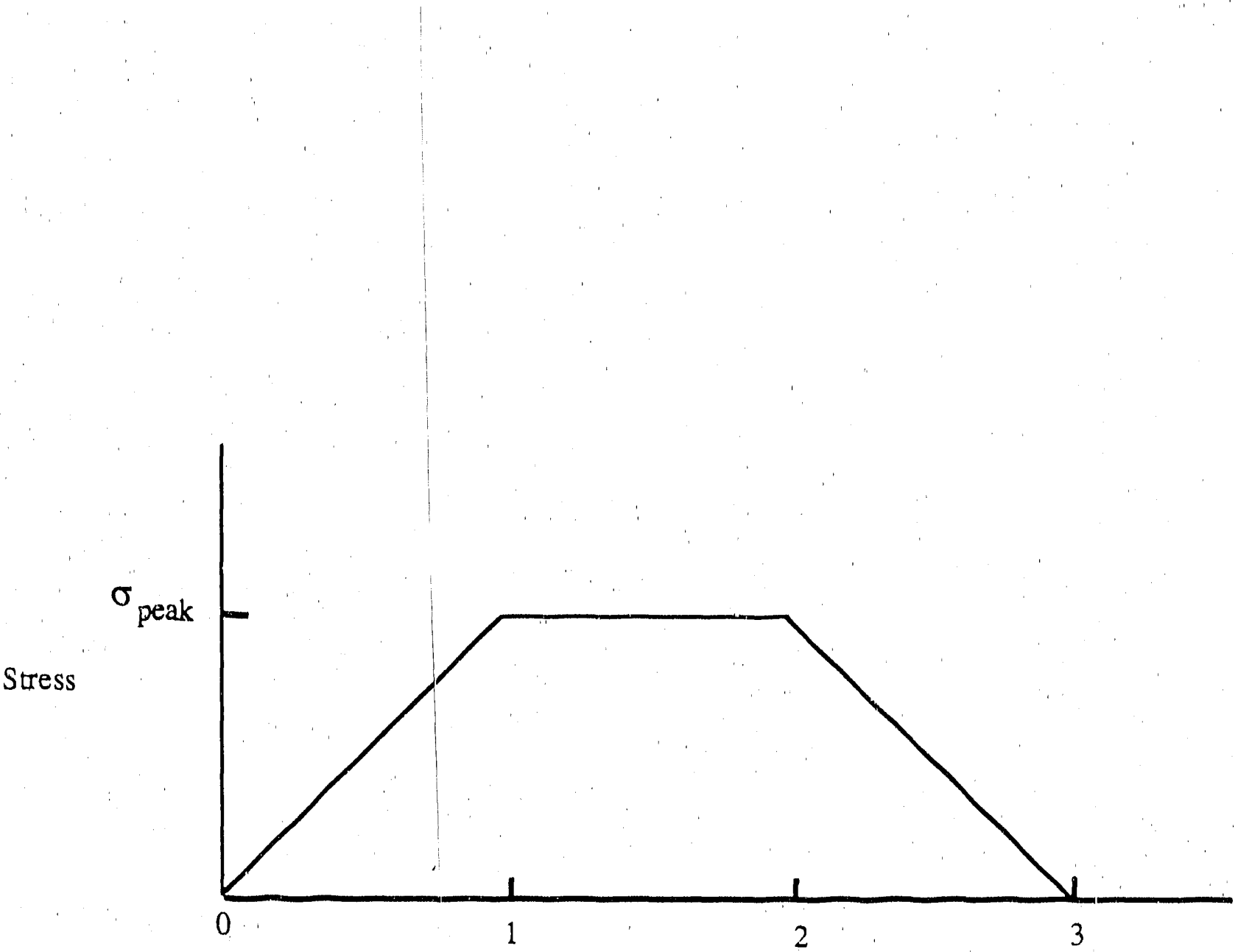

Time $(s)$

Figure 3.14: Alcator C-MOD Loading - Time History For The TF Core. From [26]. The values of $\sigma_{\text {peak }}$ are given in Table 3.1 . 


\begin{tabular}{|l|r|r|}
\hline & N nose & Centerline \\
$\mathrm{MPa}$ & $\mathrm{MPa}$ \\
\hline$\sigma_{f c}$ & -296 & -200 \\
$\sigma_{v t}$ & 82 & 140 \\
$\sigma_{r}$ & 0 & -100 \\
\hline
\end{tabular}

Table 3.1: Alcator C-MOD Peak Stress Summary for Central Column During Flattop Portion of a Full Field Pulse

\begin{tabular}{|l|r|r|}
\hline & $\begin{array}{r}\text { At Nose } \\
(\mathrm{MPa})\end{array}$ & $\begin{array}{r}\text { At Centerline } \\
(\mathrm{MPa})\end{array}$ \\
\hline Total Inconel In-plane Tension & 162 & 241 \\
$\sigma_{r, i, t}$ & 110 & 163 \\
\hline $\begin{array}{l}\text { Total Applied Tension Stress } \\
\sigma_{\text {app }}\end{array}$ & 110 \\
\hline
\end{tabular}

Table 3.2: In-Plane Stress Summary Due to Face Compression and Vertical Tension on Laminate Plates of the TF Core. 


\subsubsection{Experiment Operating Parameters}

The fatigue crack growth test parameters are summarized in Tables 3.4 and 3.5 . All fatigue crack growth da/dN tests were run in constant load. An $R$ ratio of 0.1 was used in all fatigue crack growth tests since 0.1 is commonly used for developing data for comparative purposes [76]. The tests were conducted at frequencies which ranged between $14-16 \mathrm{~Hz}$, at room temperature and $8-10 \mathrm{~Hz}$. at $77^{\circ} \mathrm{K}$. The reason for the difference in test operating frequency between room temperature and $77^{\circ} \mathrm{K}$ is that at $77^{\circ} \mathrm{K}$, the actuator takes on additional inertia from the dewar and liquid nitrogen. As a result, crisp load waveforms could not be achieved at high frequencies. After checking the load waveforms with an oscilloscope, the highest frequency for testing in liquid nitrogen was determined. Table 3.4 summarizes the initial and final $\Delta \mathrm{K}, R$ ratio, and testing frequency for each material.

By specifying $\Delta \mathrm{K}$ and $R$, the maximum and minimum loads in each test were determined by the following procedure. The stress intensity solution for a center cracked tension panel in uniaxial tension is given by the Feddersen equation:

$$
\begin{gathered}
K=\sigma \sqrt{\pi a} \sqrt{\sec \left(\frac{\pi a}{W}\right)} \\
\Delta K=K_{m a x}-K_{m i n}
\end{gathered}
$$

and the $R$ ratio is defined as:

$$
R=\frac{P_{\min }}{P_{\max }}
$$

Since $\sigma$ is the applied stress, it is equal to $\mathrm{P} / \mathrm{A}$. Thus, eliminating $\sigma$ in equation 3.2 and solving equations 3.3 and 3.4 determines $P_{\max }$ and $P_{\min }$.

Pre-cracking and the $\mathrm{da} / \mathrm{dN}$ crack growth tests start at the same initial $\Delta \mathrm{K}$. 
After the pre-crack length was achieved, the specimen loads were re-calculated using the above procedure to set the $\Delta K$ at the initial value. Since the crack has grown during pre-cracking, the loads were always decreased to reset the test to the initial $\Delta \mathrm{K}$.

The D.C. potential drop crack measurement system operating parameters are suminarized in Table 3.5. Since the resistivity of copper decreases by approximately a factor of seven between room temperature and $77^{\circ} \mathrm{K}$, extremely large currents for the D.C. potential drop metisod were required. As it turned out, to obtain a reliably measured $50 \mu \mathrm{V}$ probe output voltage, currents in the $350-450$ amps were necessary. Table 3.5 also summarizes the initial crack length $2 a_{o}$, final crack length $2 a_{f}$, and current used.

\subsubsection{Analysis Procedures}

Fatigue crack growth tests $(\mathrm{da} / \mathrm{dN})$ were performed on both longitudinal and transverse orientations as well as its Inconel 718 and copper 107 components. Data reduction to obtain da/dN values was performed in accordance with ASTM E-647 standard using the incremental polynomial method [67]. This method for computing da/dN involved fitting a second-order polynomial to sets of seven successive data points.

In order to correlate the data to the Paris crack growth equation (Equation 2.1, the correlation coefficients $C$ and $m$ are determined by performing a ieast squares fit on the crack growth data to obtain a linear relationship between $\log (\mathrm{da} / \dot{\mathrm{d} N})$ and $\log (\Delta K)$. 


\begin{tabular}{|c|c|c|c|c|c|c|}
\hline Test & $\begin{array}{c}\text { Inconel } 718 \\
\text { Lng. }\end{array}$ & $\begin{array}{c}\text { Inconel } 718 \\
\text { Trns. }\end{array}$ & $\begin{array}{c}\text { Copper } 10^{\prime} \\
\text { Lng. }\end{array}$ & $\begin{array}{c}\text { Copper } 107 \\
\text { Trns }\end{array}$ & $\begin{array}{c}\text { Laminate } \\
\text { Lng. }\end{array}$ & $\begin{array}{c}\text { Laminate } \\
\text { Trns. }\end{array}$ \\
\hline $\begin{array}{l}\text { TENSILE } \\
295 \mathrm{~K} \\
77 \mathrm{~K} \\
\text { CRACK } \\
\text { GROWTH } \\
295 \mathrm{~K} \\
77 \mathrm{~K}\end{array}$ & $\begin{array}{l}X \\
X\end{array}$ & $\begin{array}{l}X \\
X\end{array}$ & $\begin{array}{l}X \\
X \\
X \\
X\end{array}$ & $\begin{array}{l}X \\
X \\
X \\
X\end{array}$ & $\begin{array}{l}X \\
X \\
X \\
X\end{array}$ & $\begin{array}{l}X \\
X \\
X \\
X\end{array}$ \\
\hline
\end{tabular}

Table 3.3: Testing Matrix Showing All Specimens Tested. Lng.- denotes Longitudinal Specimen Orientation and Trns - denotes Transverse Specimen Orientation.

\begin{tabular}{|l|r|r|r|r|}
\hline Specimen & $\begin{array}{r}\text { Initial } \Delta K \\
(\mathrm{MPa} \sqrt{\mathrm{m}})\end{array}$ & $\begin{array}{r}\text { Final } \Delta K \\
(\mathrm{MPa} \sqrt{\mathrm{m}})\end{array}$ & $\begin{array}{r}R \\
\text { Ratio }\end{array}$ & $\begin{array}{r}\text { Frequency }(\mathrm{Hz}) \\
295^{\circ} \mathrm{K}\left(77^{\circ} \mathrm{K}\right)\end{array}$ \\
\hline Inconel 718 & 15 & & 0.1 & $14(-)$ \\
LAMINATE 295 $\mathrm{K}$ & & & & \\
Copper 107 & 8 & 23 & 0.1 & $1.6(1.0)$ \\
Longitudinal & 11 & 36 & 0.1 & 16 \\
Transverse & 11 & 32 & 0.1 & 16 \\
LAMiNATE 77 $\mathrm{K}$ & & & & 8 \\
Longitudinal & 11 & 41 & 0.1 & 8 \\
Transverse & 11 & 42 & 0.1 & \\
\hline
\end{tabular}

Table 3.4: Fatigue Crack Growth Test Operating Parameters

\begin{tabular}{|l|r|c|c|r|}
\hline Specimen & $\begin{array}{c}\text { Temper- } \\
\text { ature }^{\circ} \mathrm{K}\end{array}$ & $\begin{array}{c}\text { Initial Crack Length } \\
2 a_{0}(\mathrm{~cm})\end{array}$ & $\begin{array}{c}\text { Final Crack Length } \\
2 a_{f}(\mathrm{~cm})\end{array}$ & $\begin{array}{c}\text { Current } \\
\text { (Amps) }\end{array}$ \\
\hline Inconel 718 & 295 & 3.043 & & 20 \\
Lam. Lng & 295 & 3.048 & 6.721 & 50 \\
& 77 & 3.048 & 7.071 & 350 \\
Lam. Trn & 295 & 3.030 & 6.883 & 50 \\
& 77 & 3.028 & 7.137 & 350 \\
Copper 107 & 295 & 3.043 & 6.787 & 100 \\
& 77 & 3.045 & 6.711 & 450 \\
\hline
\end{tabular}

Table 3.5: Fatigue Crack Growth Tests: Crack Length and Current Values 


\section{Chapter 4}

\section{Materials Characterization}

\subsection{Metallography}

Laminate samples were cut from the $\mathrm{da} / \mathrm{dN}$ specimens for metallographic evaluation. The samples were mounted and polished and then etched to reveal metallur-

gical features. Two types of etchants were used. Potassiurn dichromate was used to etch t'se copper, Kalling's etchant (100 ml HCl $+100 \mathrm{ml}$ Ethanol $\left.+5 \mathrm{gm} \mathrm{CuCl}_{2}\right)$ was use to etch the Inconel 718. The copper was etched first and then protected with microstop, and then the Inconel was etched. If the copper is left exposed, the Inconel does not etch.

Prior to etching, the samples were examined microscopically. In some samples, shear cracks were clearly visible near the wavy interface. Figure 4.1 shows a shear crack. These cracks are approximately $100 \mu \mathrm{m}$ in length. Such cracks appear not to be present along the flat interface.

After etching, the severe plastic deformation in the copper at the wavy interface was evident and is shown in Figure 4.2. However, no shear bands appeared to exist in the copper. The degree of plastic deformation in the copper was much more severe at the wavy interface than at the flat interface. 
After etching the Inconel, many metallurgical features were revealed. The most obvious feature were the presence of shear bands spaced at regular intervals throughout the wavy interface which was shown in Figure 2.9. Shear band characteristics are summarized in Tables 4.1 and 4.2. The shear band length ranged from about 0.51 to $0.84 \mathrm{~mm}$. in both longitudinal and transverse orientations. Since the Inconel 718 thickness is $2.3 \mathrm{~mm}$., the shear bands transversed almost one-third of the Inconel. As expected the shear band density is higher for the longitudinal orientation than the transverse, because of the dispersion of the explosion wavefront as it travels longitudinally down the plate. In addition, for the same reason, the shear band angle in the transverse orientation is slightly higher than that of the longitudinal.

The ripple thickness of the wavy interface was measured and found to be approximately $0.14 \mathrm{~mm}$. 


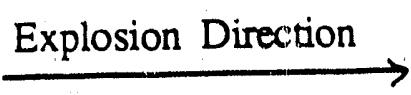

$15 \mu \mathrm{m}$

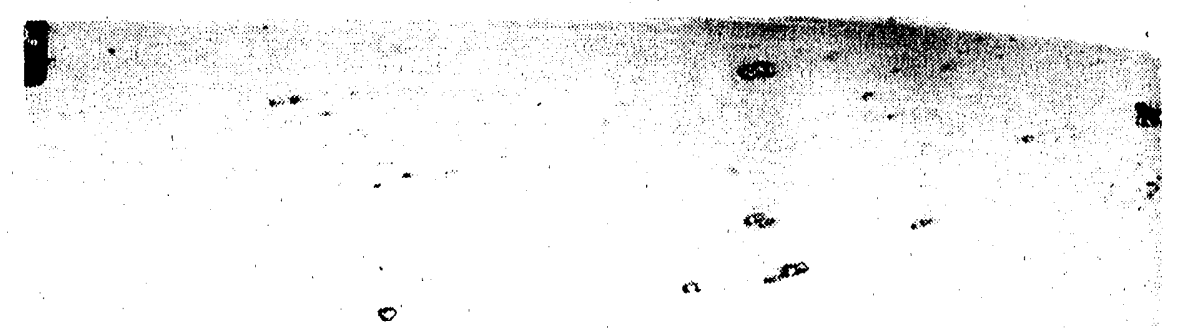

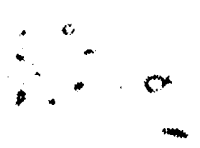

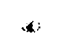

$n$

䑩,

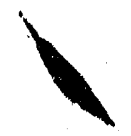

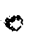

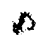
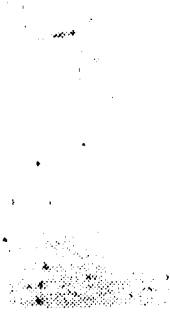

Figure 4.1: Shear Crack in Inconel 718 at Wavy Interface Prior to Etching 


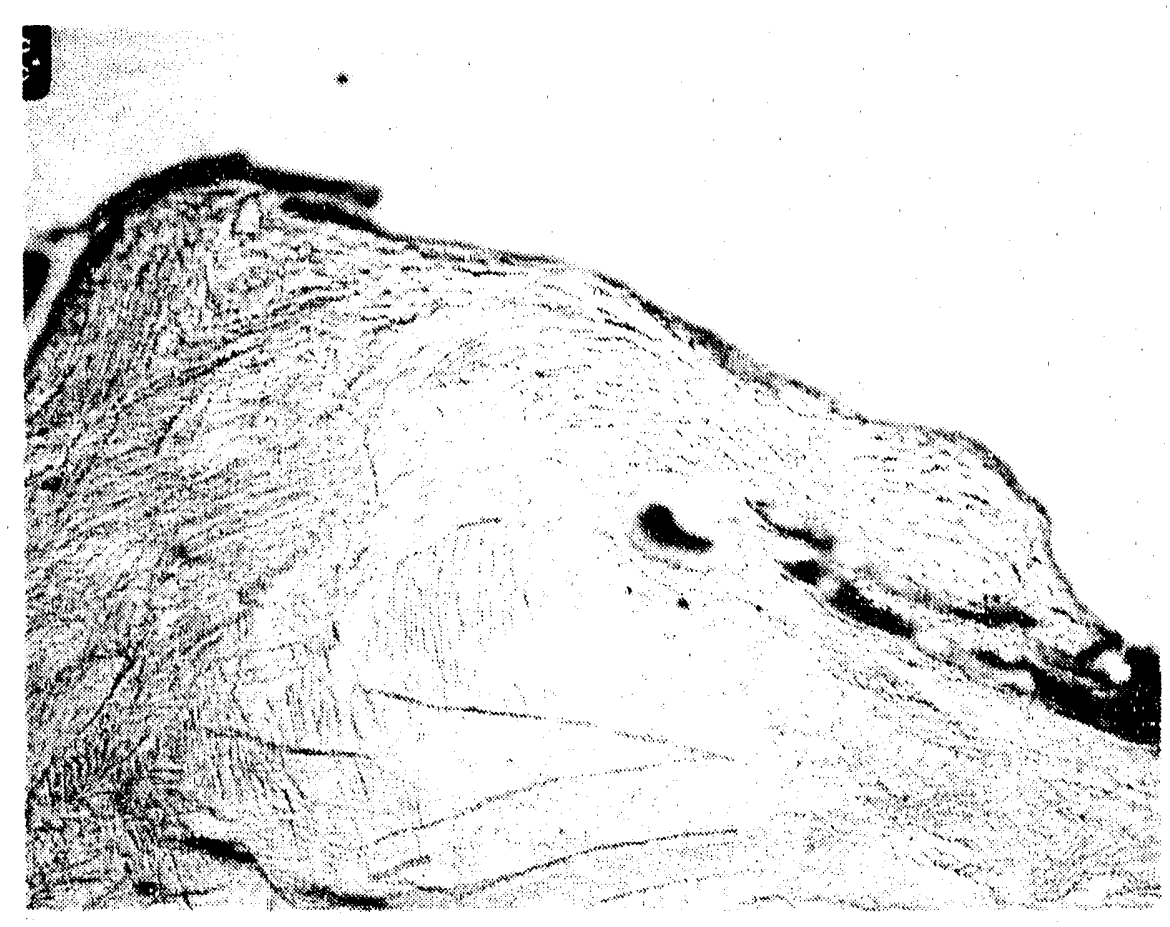

Figure 4.2: Severe Plastic Deformation in Copper 107 at Wavy Interface. Distortion of the copper grains is very evident at the crests of the wave. Copper was etched with potassium dichromate. 


\begin{tabular}{|l|c|c|}
\hline Orientaiion & $\begin{array}{c}\text { Ripple Thickness } \\
\text { Range } \mathrm{mm} .\end{array}$ & $\begin{array}{c}\text { Shear Band } \\
\text { Length Range mm. }\end{array}$ \\
\hline Longitudinal & $0.12-0.13$ & $0.51-0.57$ \\
Transverse & $0.12-0.14$ & $0.61-0.84$ \\
\hline
\end{tabular}

Table 4.1: Metallographically Determined Explosion Bonding Interface Parameters

\begin{tabular}{|l|c|c|}
\hline Orientation & $\begin{array}{c}\text { Shear Band Angle } \\
\text { (Degrees) }\end{array}$ & $\begin{array}{c}\text { Shear Band Density } \\
\text { per cm. }\end{array}$ \\
\hline $\begin{array}{l}\text { Longitudinal } \\
\text { Transverse }\end{array}$ & 40 & 23 \\
$16(40)$
\end{tabular}

Table 4.2: Shear Band Angle and Density 


\section{Microhardness}

Microhardness evaluation was performed across the interfaces of the explosively bonded laminate. The microhardness data is shown graphically in Figure 4.3. As with most explosion bonded laminates, there was no gradual transition in hardness through the interface from one material to another. The hardness changed quite abruptly at the interface. Since one interface is flat and the other wavy, a difference in microhardness was expected. The hardness at the wavy interface should be slightly higher due to the greater degree of work hardening. This hardness behavior is evident in Figure 4.3. Due to the extreme amount of work hardening at the interfaces of the Inconel 718 , it is expected that the hardness of at the interfaces will be slightly higher than in the bulk Inconel. The microhardness inspection verified the high degree of work hardening in the laminate that results from explosion bonding. 


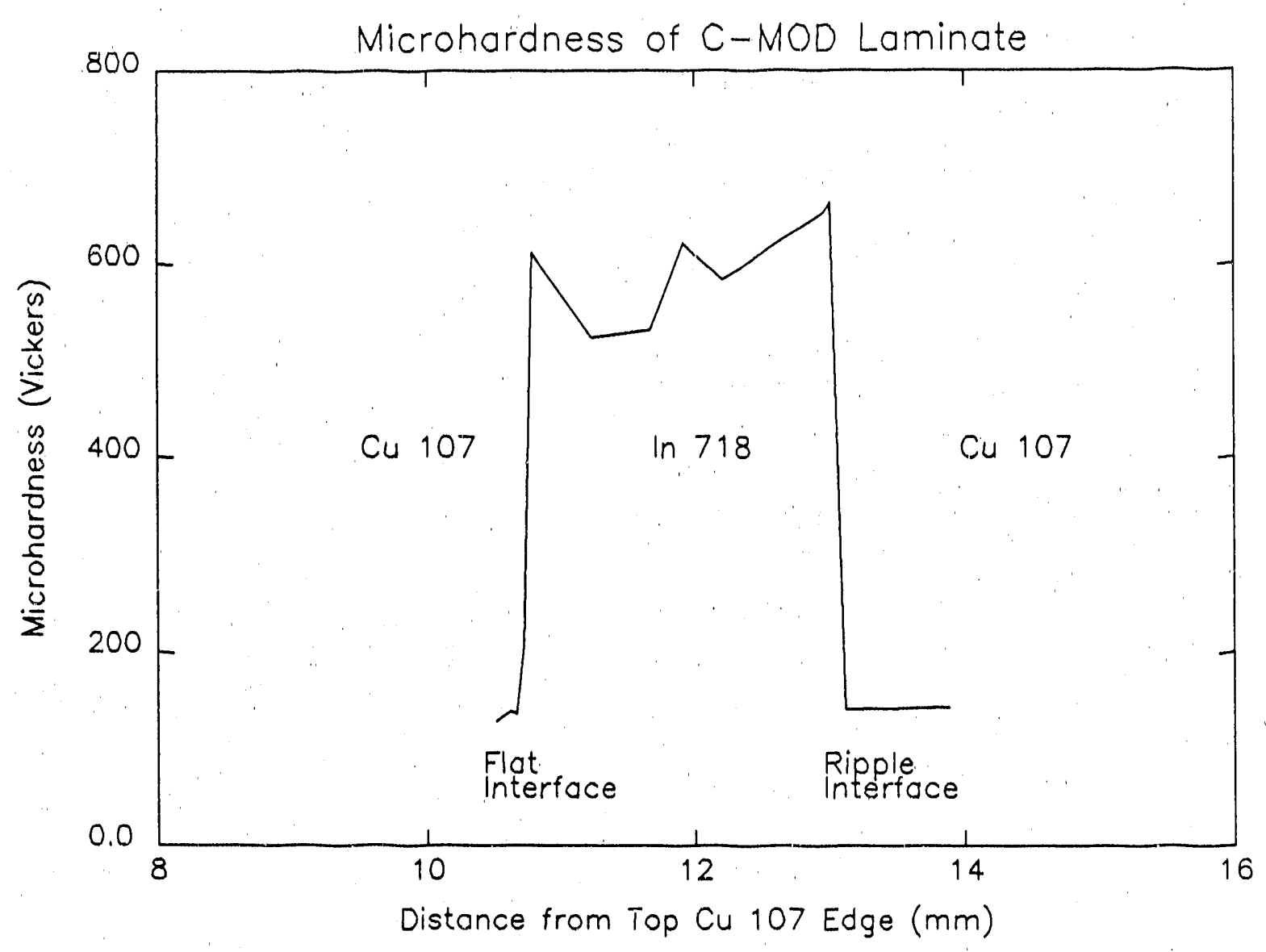

Figure 4.3: Variation of Microhardness Across Laminate Cross Section 


\subsection{Tensile Results}

The tensile test behavior for both temperatures are presented in Tables 4.3 and 4.4 .

In examining the obtain tensile properties of the separate components, Inconel 718 and copper 107, there is good agreement with existing tensile data at room temperature that was obtained as part of the Alcator C-MOD materials specification, Tables 2.1 and 2.4. As expected the variation between specimen orientations of longitudinal and transverse to the rolling direction was negligible. The values of the modulns of elasticity, although calculated by least squares fitting, were quite acceptable. For most materials, the modulus of elasticity is usually determined by ultrasonic means. The values of the modulus of elasticity for Inconel 718 were slightly lower than the published value of $201 \mathrm{GPa}$. [28] (3.7\% error) and is possibly due to the fact the tensile test was performed with an extensometer mounted only one side of the specimen and small discrepancies heat treatment batches. The obtained value of the copper 107 modulus compared quite well with the published value of $117 \mathrm{GPa}$. [39].

The elongation values obtained agree reasonably well with the data from the materials specifications, although some discrepancies may be accounted for by small variations in heat treatments.

As expected at $77^{\circ} \mathrm{K}$, the tensile properties of Inconel 718 and copper 107 exhibited a slight increase. Inconel 718 showed an increass of $14 \%$ in yield strength, while copper 107 exhibited about an 11\% increase. In addition, the Inconel 718 displayed a $14 \%$ increase in modulus, while the copper 107 showed an increase of $5.6 \%$. In elongation values, Inconel 718 showed no change from room temperature values, while copper 107 increased about $50 \%$.

In examining the laminate specimens, the tensile data obtained was as expected for for a composite of Inconel 718 and copper 107. Applying the mixture rule to 
the laminate tensile data was met with moderate success. It oppears that the components of the laminate are significantly work hardened as a result of explosion bonding. This is evident from the significant decrease in laminate elongation values when compared to that of Inconel 718 and copper 107.

Perhaps, the most convincing evidence of extreme work hardening is in the elongation of Inconel 718 before and after bonding. These values are given in Table 4.5. The ductility of the Inconel decreases approximately $60 \%$. This drop in ductility can be attributed to the formation of defects, particularly shear bands, in the Incorel during explosion bonding. 


\begin{tabular}{|l|r|r|r|r|r|}
\hline Test & $\begin{array}{r}\text { Yield } \\
\text { Stress } \\
\text { Specimen }\end{array}$ & $\begin{array}{r}\text { Ultimate } \\
\text { Stress } \\
\sigma_{y}(\mathrm{MPa})\end{array}$ & $\begin{array}{r}\text { Modulus of } \\
\text { Elasticity } \\
(\mathrm{GPa})\end{array}$ & $\begin{array}{r}\text { Elongation of } \\
\text { 2" Gage } \\
\text { Length (\%) }\end{array}$ & $\begin{array}{r}\text { Reduction } \\
\text { in Area } \\
(\%)\end{array}$ \\
\hline LONGITUDINAL: & & & & & \\
Inconel 718 & 1269 & 1455 & 194 & 23 & 28 \\
Laminate & 519 & 574 & 113 & 12 & 51 \\
Copper 107 & 301 & 310 & 117 & 24 & 92 \\
\hline TraNSVERSE: & & & & & \\
Inconel 718 & 1269 & 1448 & 193 & 25 & 29 \\
Laminate & 543 & 587 & 123 & 11 & 48 \\
Copper 107 & 327 & 330 & 122 & & 83 \\
\hline Mixture Rule & & & & & \\
for Laminate & & & 131 & & \\
\hline
\end{tabular}

Table 4.3: Room Temperature Tensile Test Summary

\begin{tabular}{|l|r|r|r|r|r|}
\hline Test & $\begin{array}{r}\text { Yield } \\
\text { Stress } \\
\text { Specimen }\end{array}$ & $\begin{array}{r}\text { Ultimate } \\
\text { Stress }\end{array}$ & $\begin{array}{r}\text { Modulus of } \\
\text { Elasticity } \\
(\mathrm{GPa})\end{array}$ & $\begin{array}{r}\text { Elongation of } \\
\text { 2" Gage } \\
\text { Length (\%) }\end{array}$ & $\begin{array}{r}\text { Reduction } \\
\text { in Area } \\
(\%)\end{array}$ \\
\hline LoNGITUDINAL: & & & & \\
Inconel 718 & 1455 & 1751 & 228 & 25 & 40 \\
Laminate & 630 & 696 & 136 & 20 & 46 \\
Copper 107 & 336 & 420 & 125 & 41 & 63 \\
\hline TrANSVERSE: & & & & & \\
Inconel 718 & 1441 & 1820 & 218 & 16 & 39 \\
Laminate & 574 & 696 & 125 & 39 & 83 \\
Copper 107 & 355 & 410 & 128 & & \\
\hline Mixture Rule & & & & & \\
for Laminate & & & 144 & & \\
\hline
\end{tabular}

Table 4.4: $77^{\circ} \mathrm{K}$ Tensile Test Summary 


\begin{tabular}{|c|c|c|}
\hline $\begin{array}{l}\text { Specimen } \\
\text { Orientation }\end{array}$ & $\begin{array}{r}\text { Elongation } \\
\text { Before } \\
\text { Bonding }(\%) \\
\end{array}$ & 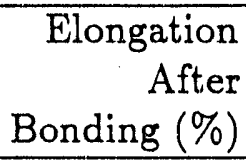 \\
\hline $\begin{array}{l}\text { ROOM TEMPERATURE: } \\
\text { Longitudinal } \\
\text { Transverse }\end{array}$ & $\begin{array}{l}23 \\
25\end{array}$ & $\begin{array}{l}9.6 \\
8.5\end{array}$ \\
\hline $\begin{array}{l}\text { LIQUID NITROGEN: } \\
\text { Longitudinal } \\
\text { Transverse }\end{array}$ & $\begin{array}{l}25 \\
26\end{array}$ & $\begin{array}{r}10.1 \\
9.2\end{array}$ \\
\hline
\end{tabular}

Table 4.5: Inconel 718 Elongation Comparison: Before and After Bonding 


\section{Chapter 5}

\section{Results}

\subsection{Fatigue Crack Growth Results}

The fatigue crack growth data at room temperature are shown in Figures 5.2 - 5.5. The fatigue crack growth data at $77^{\circ} \mathrm{K}$ are shown in Figures $5.6-5.11$.

In Figure 5.2, fatigue crack growth data for Inconel 718 at room temperature are compared with those of James [30], and agreement is good. In Figure 5.3, fatigue data for copper 10700 at room temperature are compared with Yeske [41]. Since Yeske used a polycrystalline copper, exact agreement with copper 10700 was not expected. However, as expected, polycrystalline copper exhibited higher crack growth rates at a given $\Delta K$ than copper 10700, since it has a lower tensile strength than copper 10700 [41]. The slope of the copper 10700 fatigue crack growth data agreeds well that of with Yeske. Thus, taking in to consideration the difference in types of copper used, agreement with Yeske was good. As expected, the longitudinal (Figure 5.6) and transverse (Figure 5.7) data at $77^{\circ} \mathrm{K}$ are essentially identical. 


\subsubsection{Comparison of Crack Growth Rates}

Table 5.1 summarizes the experimentally determined fatigue crack growth curve correlation coefficients. Two laminate specimens of each orientation were tested at $77^{\circ} \mathrm{K}$. For each orientation, both sets of data agreed well. Of the longitudinal specimens, specimen No. 23 had a slightly higher crack growth rate than specimen No. 24 , and as a result, specimen No. 23 will be used" in the ensuing discussion and analysis. Of the transverse specimens, specimen No. 33 had greater data resolution than specimen No. 32 , and as a result, specimen No. 33 will be used in the ensuing discussion and analysis. Täble 5.2 compares the crack growth rate, da/dN, at $\Delta K$ values of 10,15 , and $20 \mathrm{MPa} \sqrt{\mathrm{m}}$ for all of the tests.

At both temperatures, the crack growth results for the laminate exhibit a dependence on orientation. Generally, the transverse laminate appears to have a slower crack growth rate by about a factor of 2 . This behavior is consistent with the orientations of the shear bands in the Inconel 718 with respect to the crack growth plane and direction. In the longitudinal orientation, the crack front propagates along a shear band, while in the transverse orientation, the crack front propagates across the shear bands. The shear bands appear to have a much lower fracture toughness that the bulk Inconel 718. In comparison to the original Inconel 718 and copper 107, the longitudinal laminate generally exhibits crack growth rates of the order of the copper alone, while the transverse laminate generally exhibits crack growth rates similar to the Inconel 718. Such behavior implies that in the longitudinal orientation, the Inconel 718 is not influencing crack growth. However, in the transverse orientation, the crack growth rate approaches that of Inconel 718 , the Inconel is now controlling crack advancement. Again, this difference in behavior may be attributed to the difference in shear band orientation.

As expected, the crack growth rates of copper and the laminate specimens decrease at $77^{\circ} \mathrm{K}$, which is attributed to the increase in yield strength and modulus 
of elasticity. However, the same dependence of crack growth rates on laminate orientation is observed: the transverse orientation exhibits a slower crack growth rate than the longitudinal orientation. As noted earlier, the crack growth rate in liquid nitrogen of the longitudinal laminate is closer to the that of copper alone than the transverse laminate. At $77^{\circ} \mathrm{K}$, the crack growth rate of the longitudinal laminate is not as similar to copper as it is at room temperature. When compared to copper, the transverse laminate specimens display a much lower crack growth rate by about a factor of 5 to 10 , while the longitudinal laminate suows a slower growth rate by about a factor of 2 to 4 .

In comparing the laminate fatigue crack growth at room temperature and $77^{\circ} \mathrm{K}$, there is a noticeable "plateal1" near a $\Delta \mathrm{K}$ value of $17 \mathrm{MPa} \sqrt{\mathrm{m}}$ that is not present at room temperature. In this region, the crack front appears to be slowing down and then begins growing again at a slower rate. These "plateau" regions of the da/dN $-\Delta \mathrm{K}$ curves correspond to a crack length of about $5.08 \mathrm{~cm}$. On examination of the fracture surface, this crack length correspds to a ridge and change in altitude of the crack front in the copper, which is shown in Figure 5.1. This behavior is believed to be due to a transition from plane strain to plane stress in the copper. Examination of the Inconel shows no ridges or change in height of the crack front. Further examination and comparison with the room temperature laminate specinnens reveals that at room temperature the crack front was propagating along a ridge and changing altitude from the beginning of the crack growth test. This phenomena will be discussed further later. 


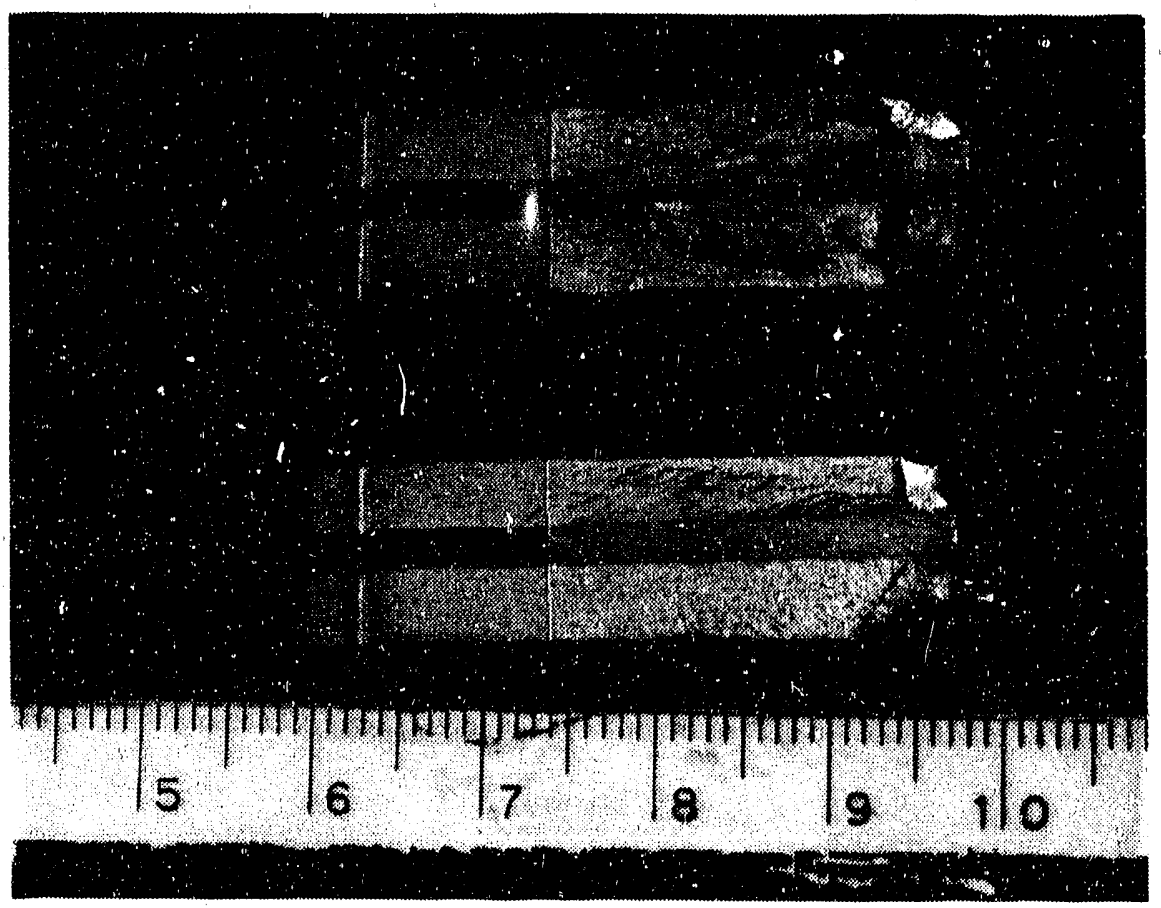

Figure 5.1: Comparison of Fracture Surfaces at Room Temperature and $77^{\circ} \mathrm{K}$. Room temperature specimen (top) appears to be in plane stress. $77^{\circ} \mathrm{K}$ specimen (bottom) appears to be in plane strain until crack front approaches the edge. 


\begin{tabular}{|l|c|c|}
\hline Specimen & $\mathrm{C}$ & $\mathrm{m}$ \\
\hline ROOM TEMPERATURE: & & \\
Inconel 718 & $4.6110 \times 10^{-9}$ & 3.0246 \\
Copper 107 & $2.3668 \times 10^{-10}$ & 4.7419 \\
Lam. Lng. & $7.5383 \times 10^{-13}$ & 6.3320 \\
Lam. Trn. & $1.9005 \times 10^{-10}$ & 3.9862 \\
LIQUID NITROGEN: & & \\
Copper 107 L & $6.9122 \times 10^{-14}$ & 7.4978 \\
Copper 107 T & $7.4767 \times 10^{-14}$ & 7.4805 \\
Lam. Lng. No. 23 & $1.1866 \times 10^{-12}$ & 6.1795 \\
Lam. Lng. No. 24 & $2.1603 \times 10^{-09}$ & 3.2628 \\
Lam. Trn. No. 32 & $1.9964 \times 10^{-11}$ & 4.8298 \\
Lam. Trn. No. 33 & $5.7320 \times 10^{-10}$ & 3.4659 \\
\hline
\end{tabular}

Table 5.1: Experimentally Derived Crack Growth Equations Constants. Lng. - denotes Longitudinal Specimen Orientation and Trn. - denotes Transverse Specimen Orientation.

\begin{tabular}{|l|c|c|c|}
\hline \multirow{2}{*}{$\begin{array}{l}\Delta \mathrm{K}(\mathrm{MPa} \sqrt{\mathrm{m}}) \\
\text { Specimen }\end{array}$} & \multicolumn{3}{|c|}{$\mathrm{da} / \mathrm{dN}(\mathrm{mm} . / \mathrm{cyc})$} \\
\cline { 2 - 4 } & & 15 & 20 \\
\hline ROOM TEMPERATURE : & & & \\
Inconel 718 & $4.880 \times 10^{-6}$ & $1.663 \times 10^{-5}$ & $3.971 \times 10^{-5}$ \\
Copper 107 & $1.306 \times 10^{-5}$ & $8.934 \times 10^{-5}$ & $3.496 \times 10^{-4}$ \\
Lam. Lng. & $1.619 \times 10^{-6}$ & $2.110 \times 10^{-5}$ & $1.304 \times 10^{-4}$ \\
Lam. Trn. & $1.841 \times 10^{-6}$ & $9.268 \times 10^{-6}$ & $2.918 \times 10^{-5}$ \\
LIQUID NITROGEN : & & & \\
Copper 107 & $2.175 \times 10^{-6}$ & $4.547 \times 10^{-5}$ & $3.931 \times 10^{-4}$ \\
Lam. Lng. & $1.794 \times 10^{-6}$ & $2.198 \times 10^{-5}$ & $1.300 \times 10^{-4}$ \\
Lam. Trn. & $1.676 \times 10^{-6}$ & $6.832 \times 10^{-6}$ & $1.852 \times 10^{-5}$ \\
\hline
\end{tabular}

Table 5.2: Comparison of $\mathrm{da} / \mathrm{dN}$ for All Materials at Specified Values of $\Delta \mathrm{K}$ 


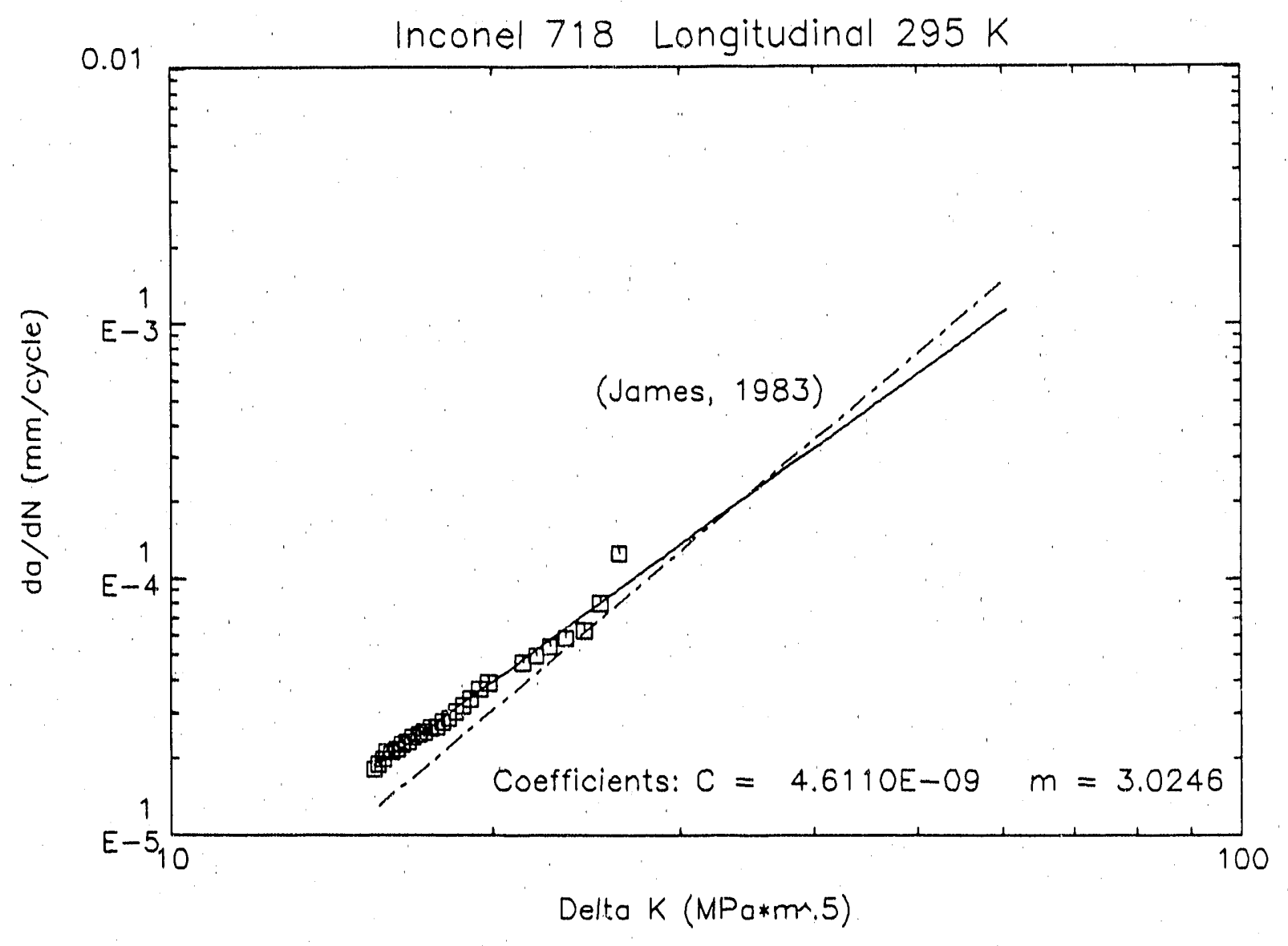

Figure 5.2: Inconel $718 \mathrm{da} / \mathrm{dN}$ vs. $\Delta \mathrm{K}$ at Room Temperature 


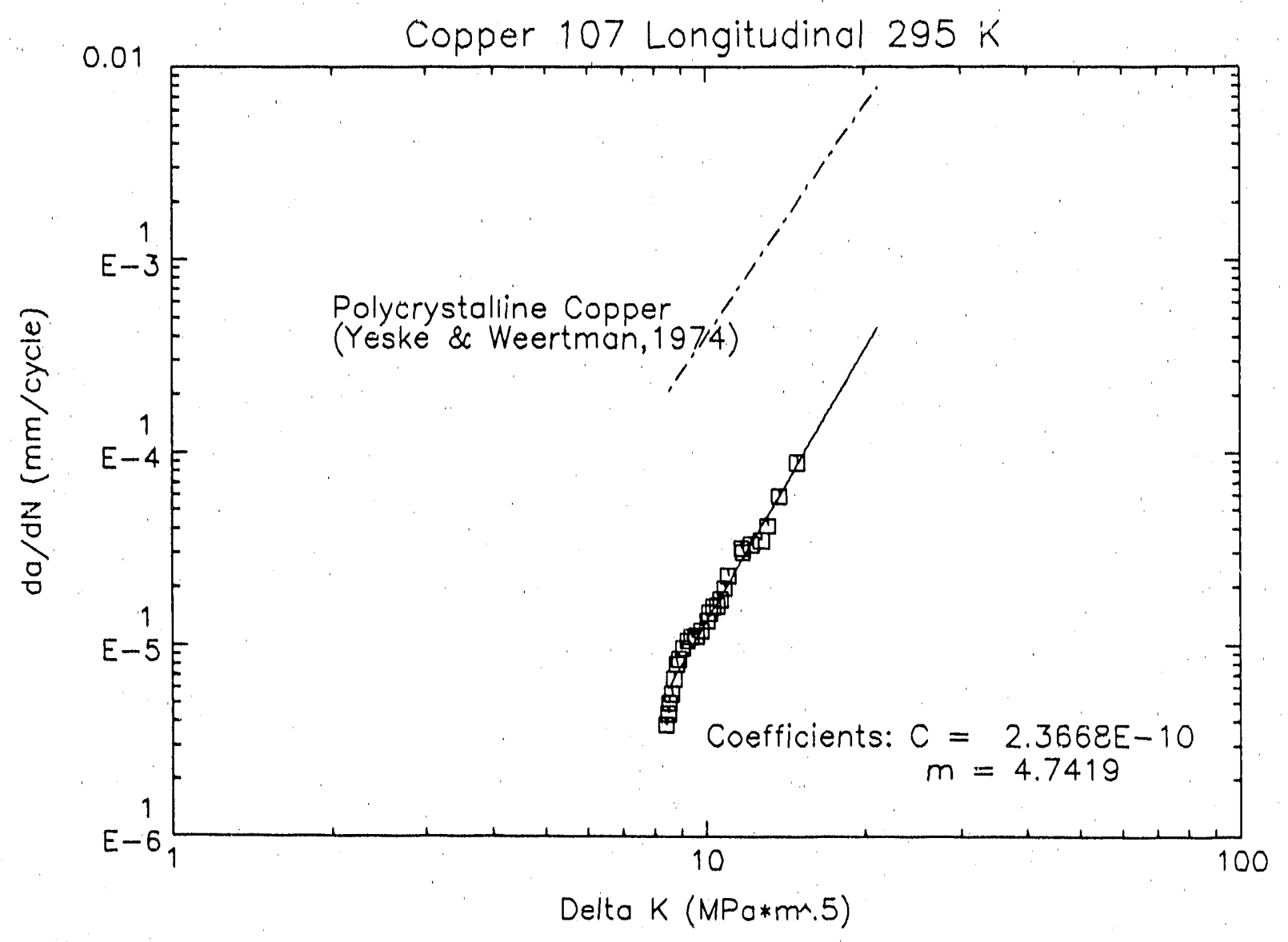

Figure 5.3: Copper $107 \mathrm{da} / \mathrm{dN}$ vs. $\Delta \mathrm{K}$ at Room Temperature 


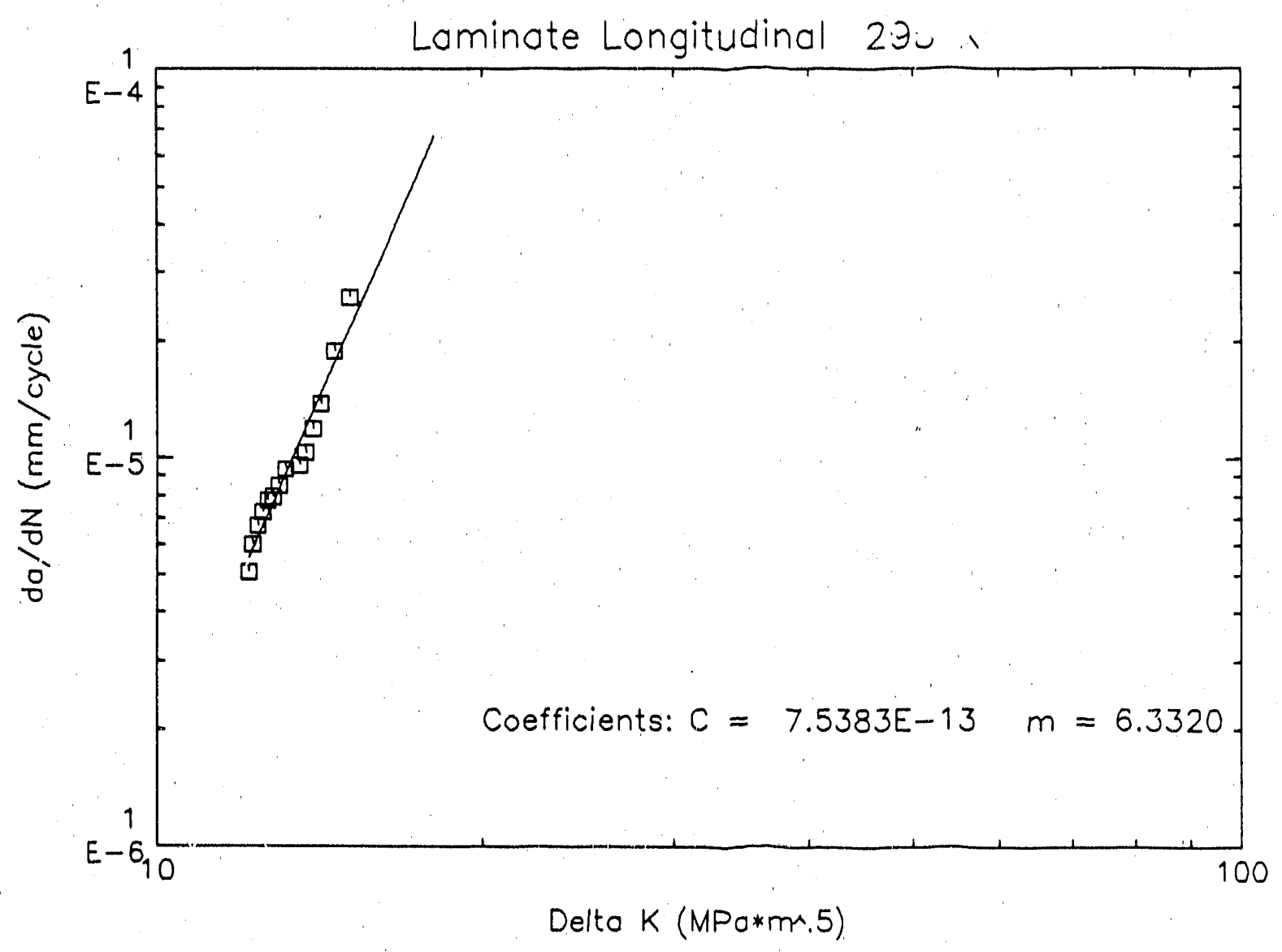

Figure 5.4: Laminate Longitudinal da/dN vs. $\Delta \mathrm{K}$ at Room Temperature 


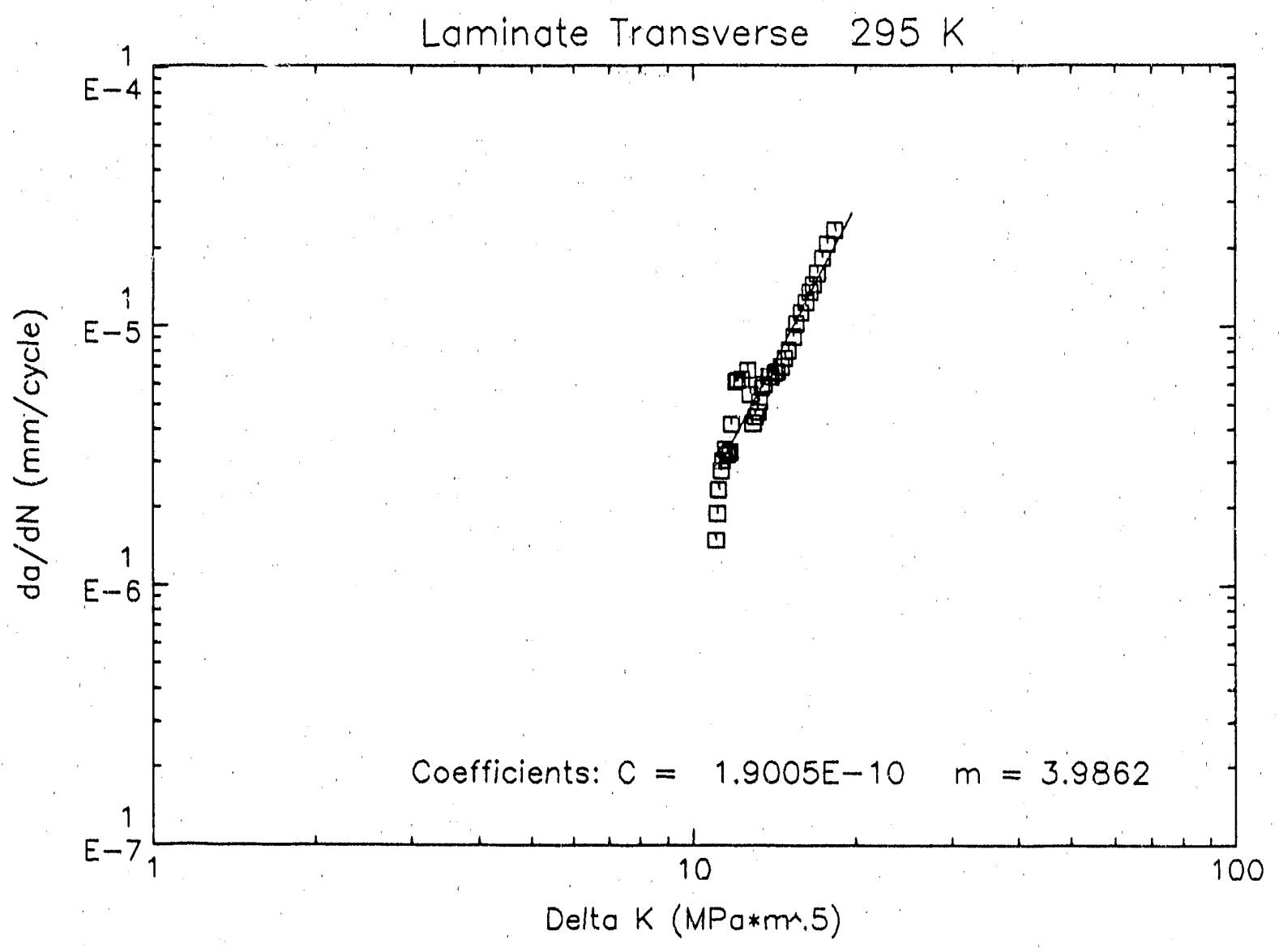

Figure 5.5: Laminate Transverse da/dN vs. $\Delta \mathrm{K}$ at Room Temperature 


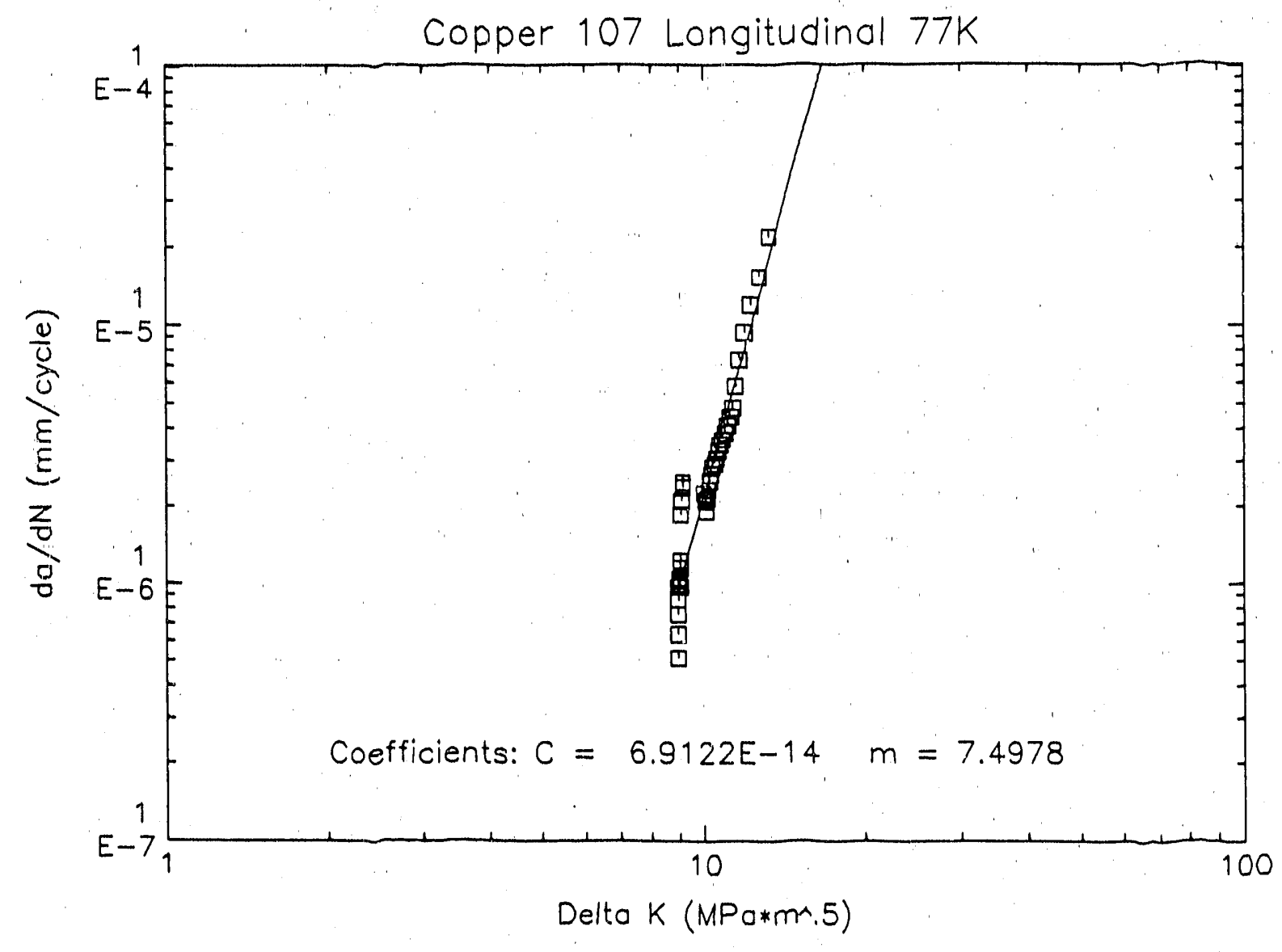

Figure 5.6: Copper 107 Longitudinal da/dN vs. $\Delta \mathrm{K} 77^{\circ} \mathrm{K}$ 


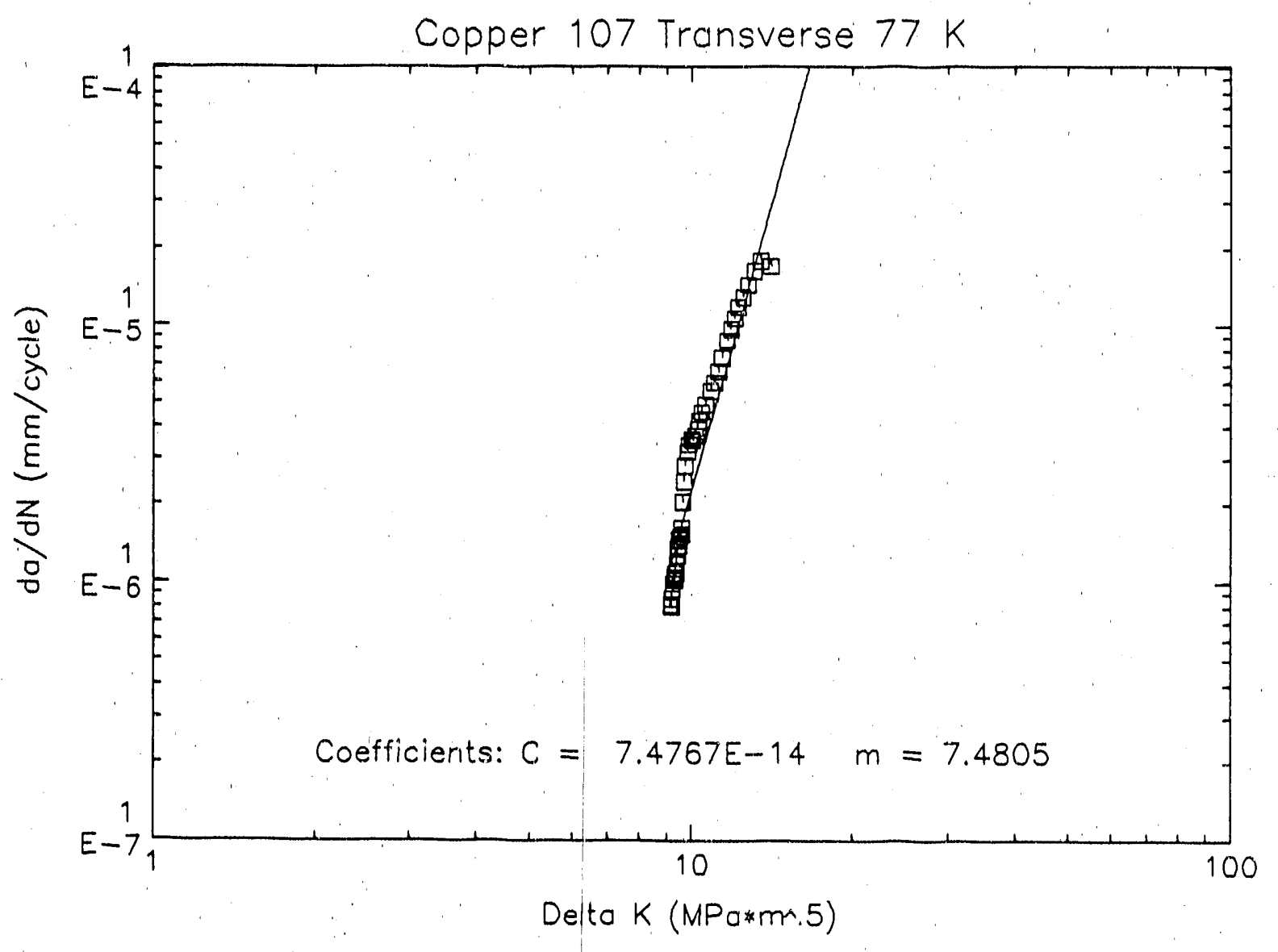

Figure 5.7: Copper 107 Transverse da/dN vs. $\Delta \mathrm{K} 77^{\circ} \mathrm{K}$ 


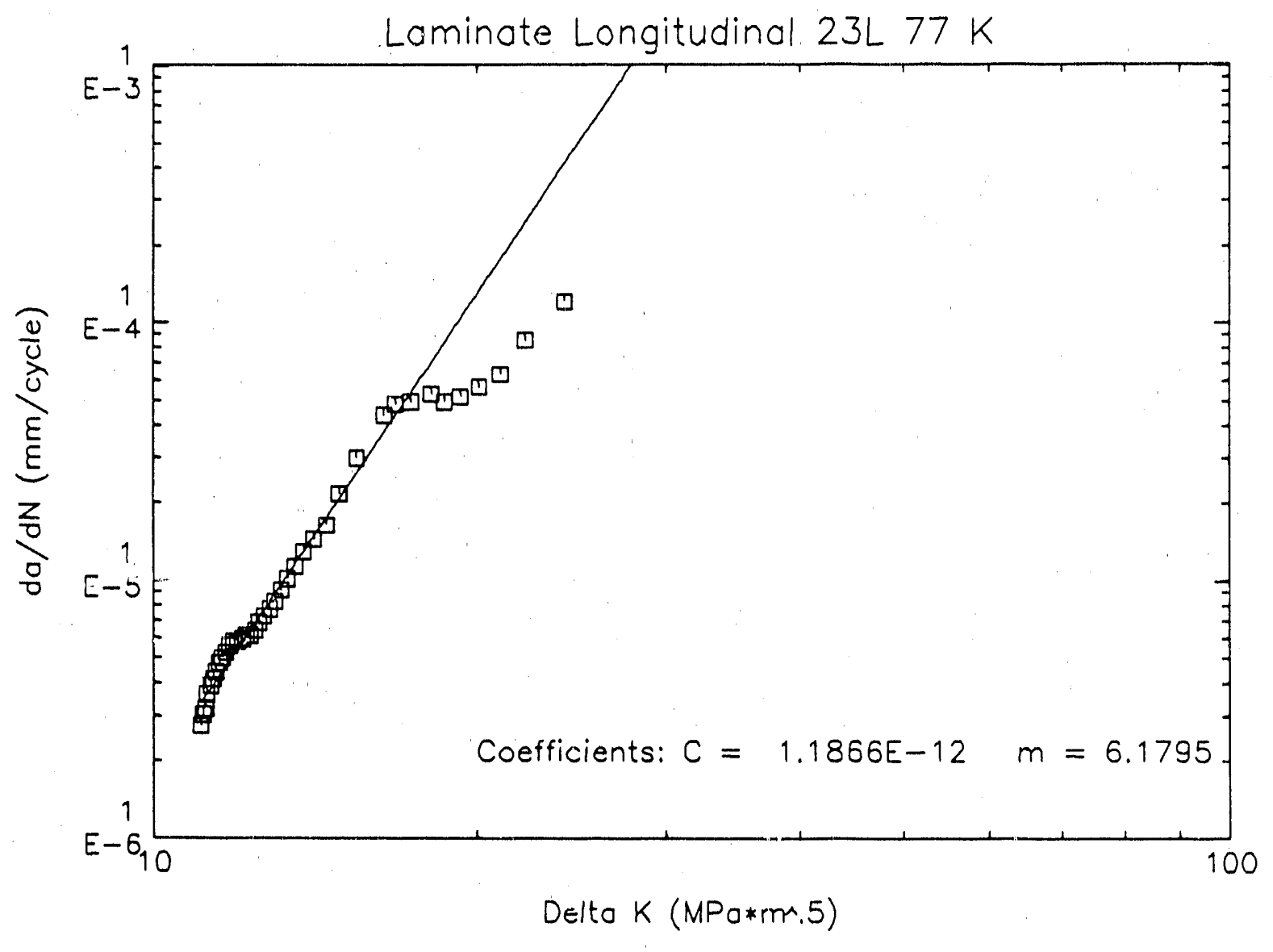

Figure 5.8: Laminate Longitudinal Specimen No. $23 \mathrm{da} / \mathrm{dN}$ vs. $\Delta \mathrm{K}$ at $77^{\circ} \mathrm{K}$ 


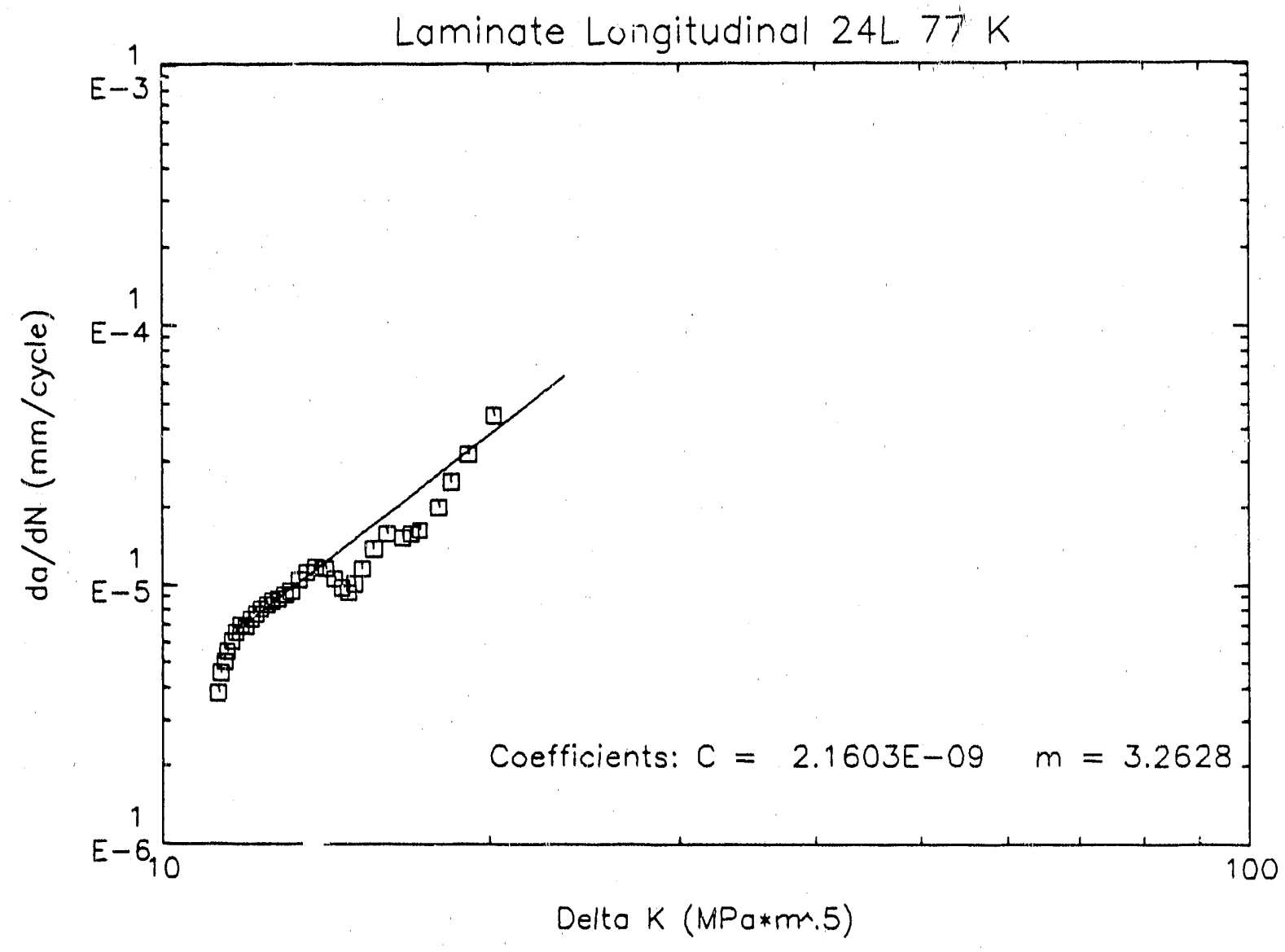

Figure 5.9: Laminate Longitudinal Specimen No. $24 \mathrm{da} / \mathrm{dN}$ vs. $\Delta \mathrm{K}$ at $77^{\circ} \mathrm{K}$ 


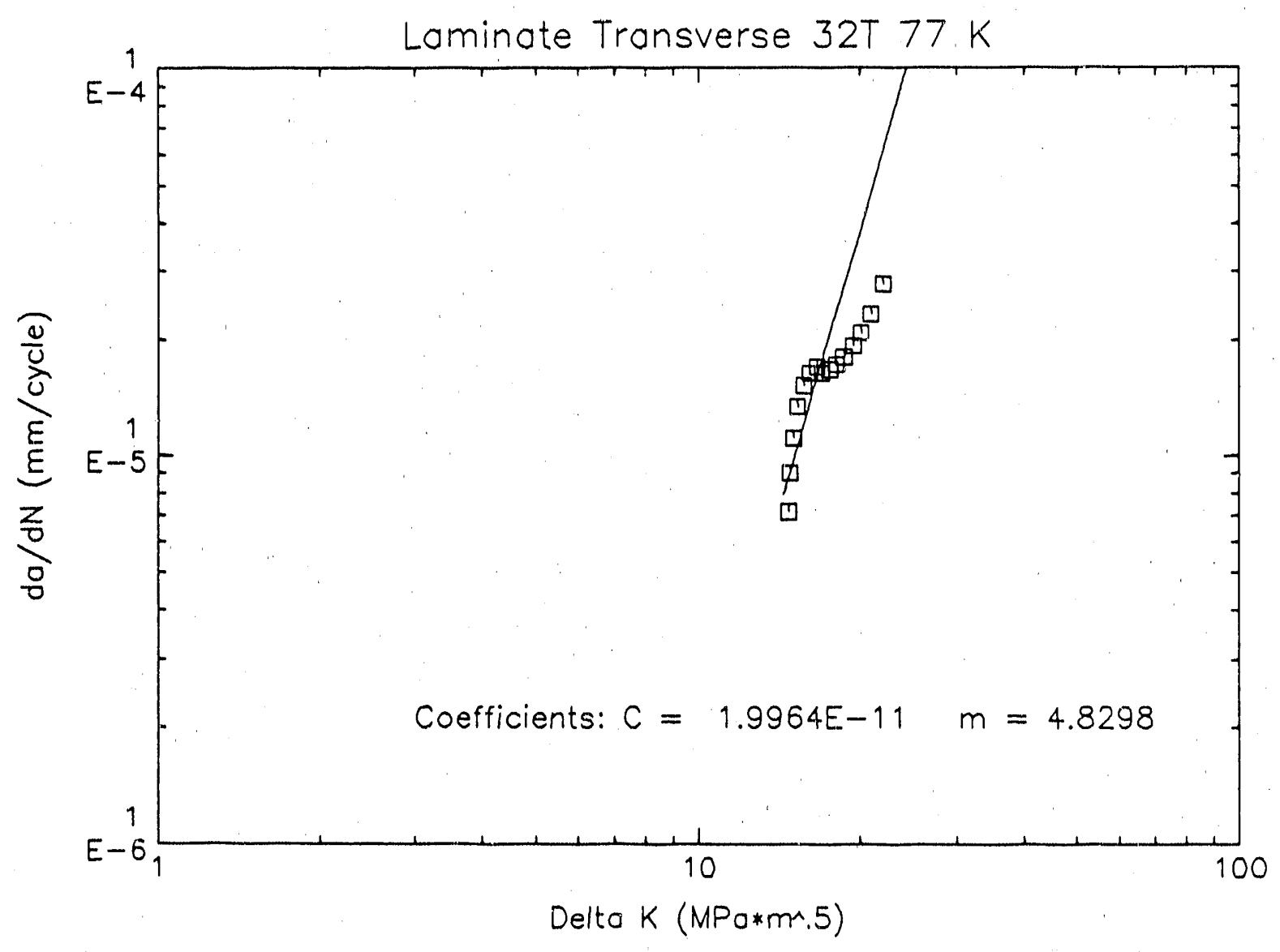

Figure 5.10: Laminate Transverse Specimen No. $32 \mathrm{da} / \mathrm{dN}$ vs. $\Delta \mathrm{K}$ at $77^{\circ} \mathrm{K}$ 


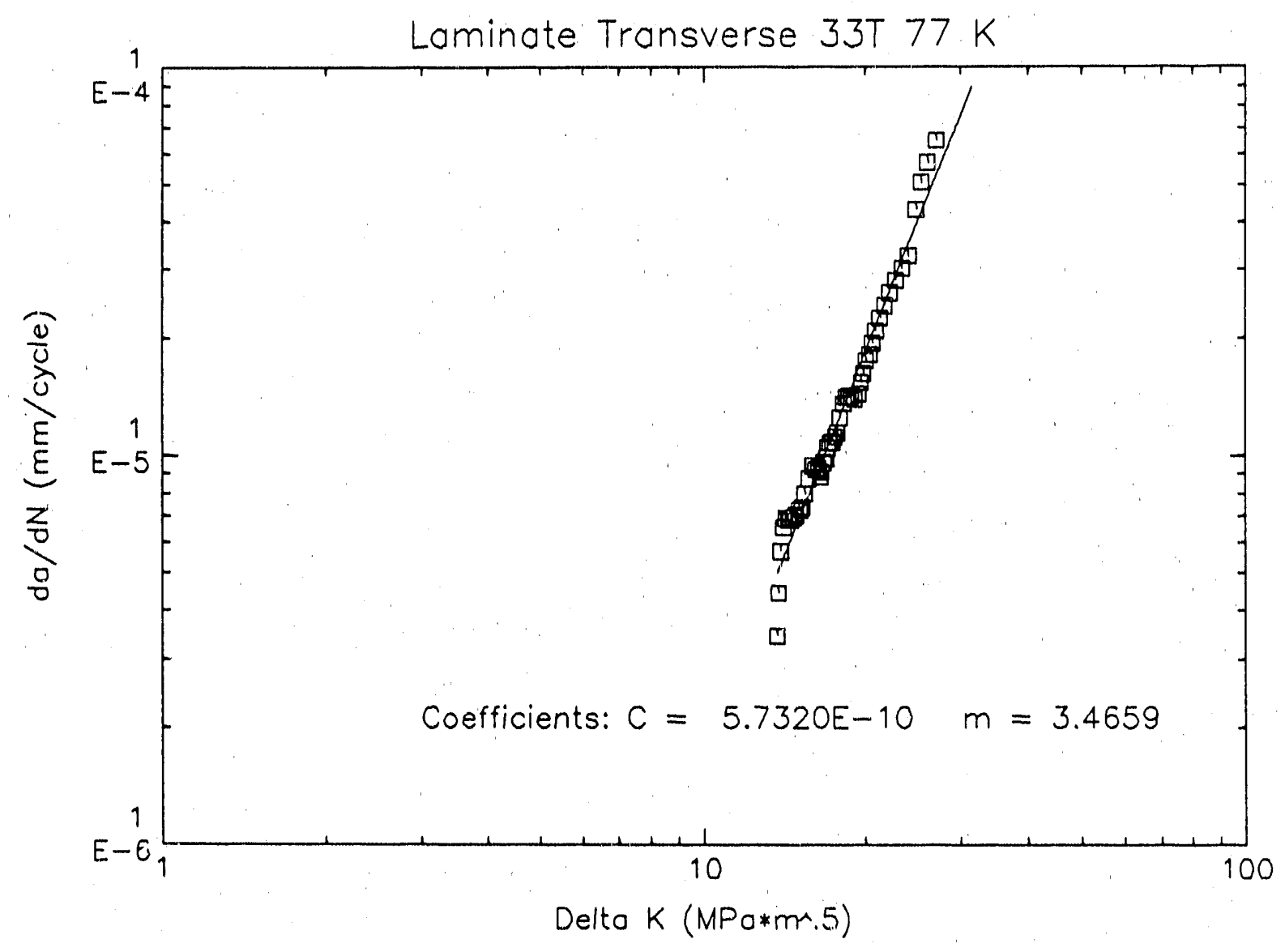

Figure 5.11: Laminate Transverse Specimen No. $33 \mathrm{da} / \mathrm{dN}$ vs. $\Delta \mathrm{K}$ at $77^{\circ} \mathrm{K}$ 


\subsection{Fractography}

Fractogrphic results are shown in Figures 5.12 - 5.16. Fractographic examination of the copper 107 / Inconel 718 / copper 107 interface revealed shear cracks at the interface. The ripple interface is heavily damaged with shear cracks and interfacial cracks as shown in Figure 5.12. The shear cracks appear as shiny pancake-like regions. At higher magnification, the area within the shear crack appears smooth without any striations as shown in Figure 5.13. Shear cracks are typically characterized by ductile fracture in the regions adjacent to the shear crack as shown in Figure 5.14. The typical size of shear cracks at the ripple interface is about $100 \mu \mathrm{m}$.

Shear cracks are also found at the flat Inconel 718 / copper interface, although these cracks are much smaller in size (Figure 5.15) They possess the same characteristic features of the shear cracks at the ripple interface. Similar to the ripple interface, regions of the flat interface appear to contain interfacial cracks. No evidence of non-bonded regions were found.

Examination of a laminate tensile test fracture surfaces show distinct wave action at th ripple interface as shown in Figure 5.16. This figure clearly shows the high degree of plastic deformation in the copper as a result of explosion bonding. The "dimpled" fracture pattern in the Inconel 718 indicates ductile behavior. The dark regions scattered throughout the wavy pattern appear to be surface debris that escape with the jet before bonding was completed. 


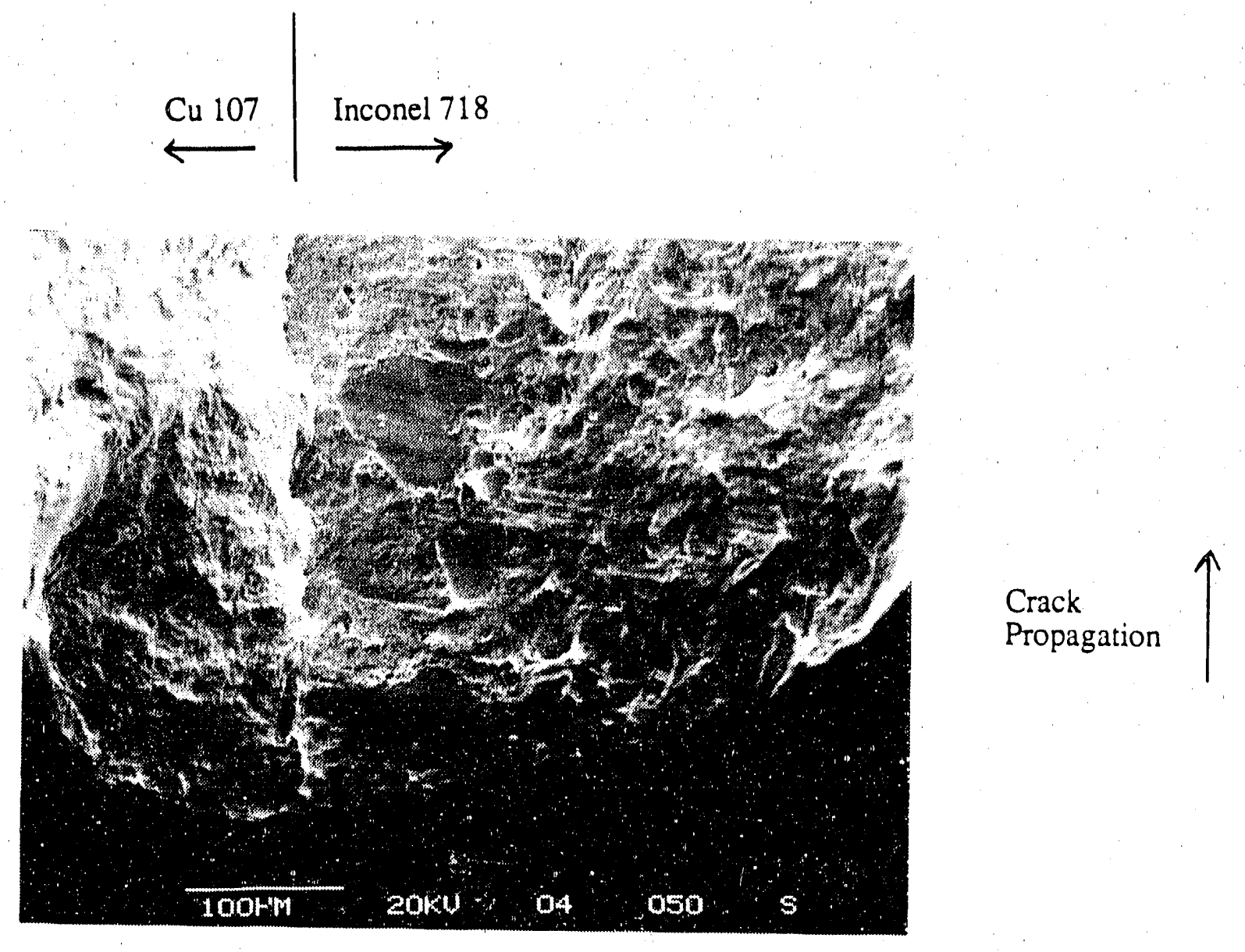

Figure 5.12: Shear Cracks at the Ripple Interface. Shear cracks are visible as smooth pancake-like cavities. 


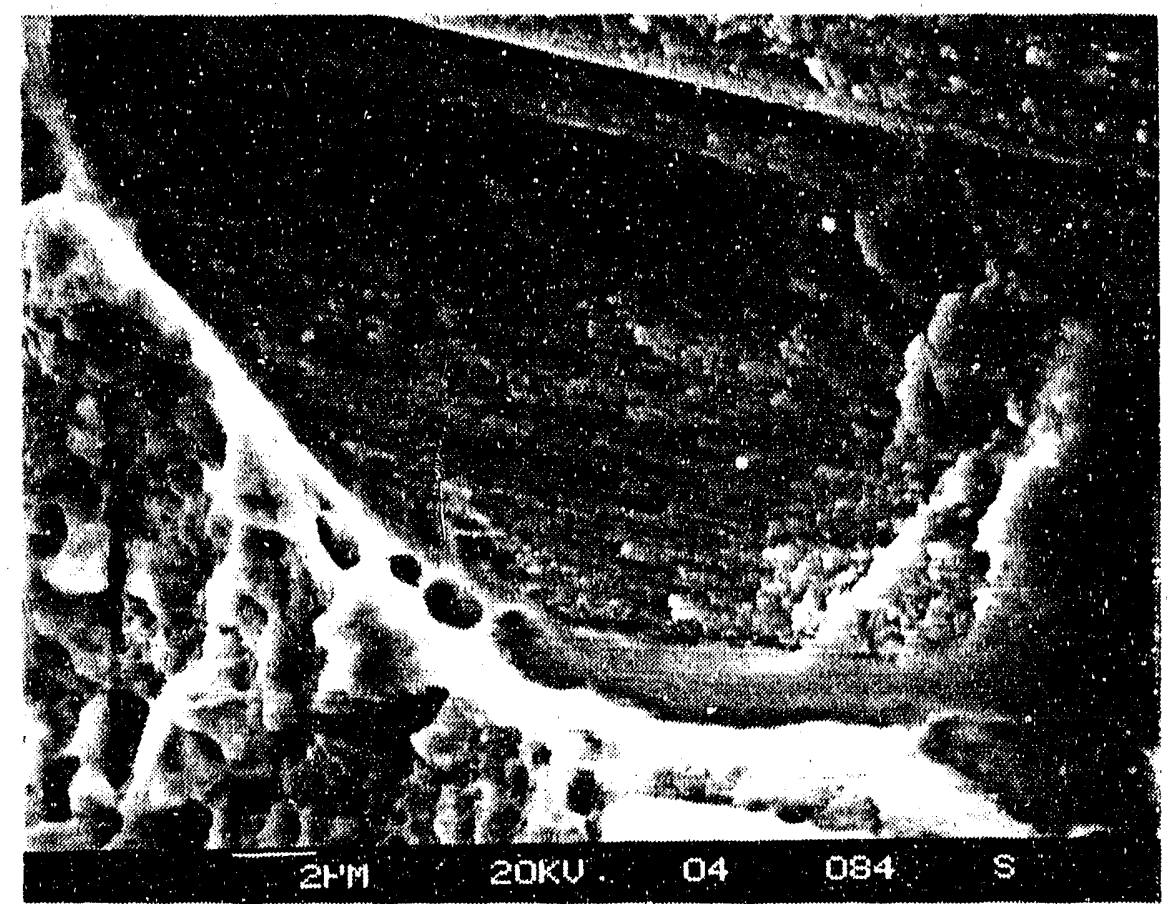

Figure 5.13: Inner Region of a Shear Crack at Higher Magnification. Under high magnification, the inner region of a shear crack is smooth, while there appears to be evidence of ductile fracture at the perimeter. 
$\stackrel{\mathrm{Cu} 107}{\longleftarrow} \mid \stackrel{\text { Inconel } 718}{\longrightarrow}$

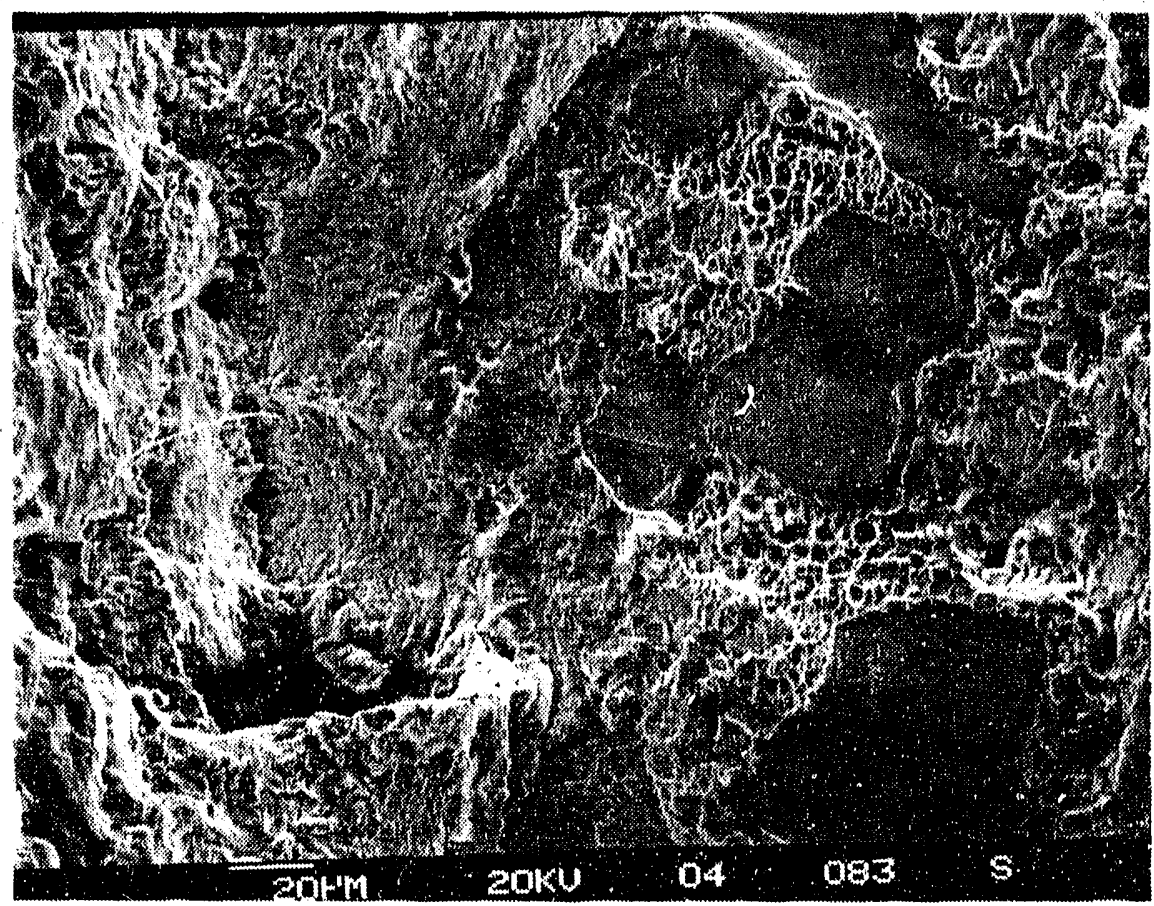

Crack

Propagation

Figure 5.14: Shear Cracks with Ductile Failure in Adjacent Regions. Near the ripple interface in the Inconel 718 , shear cracks are present and exhibit dimple rupture at their perimeters. Thus indicating ductile tearing. 

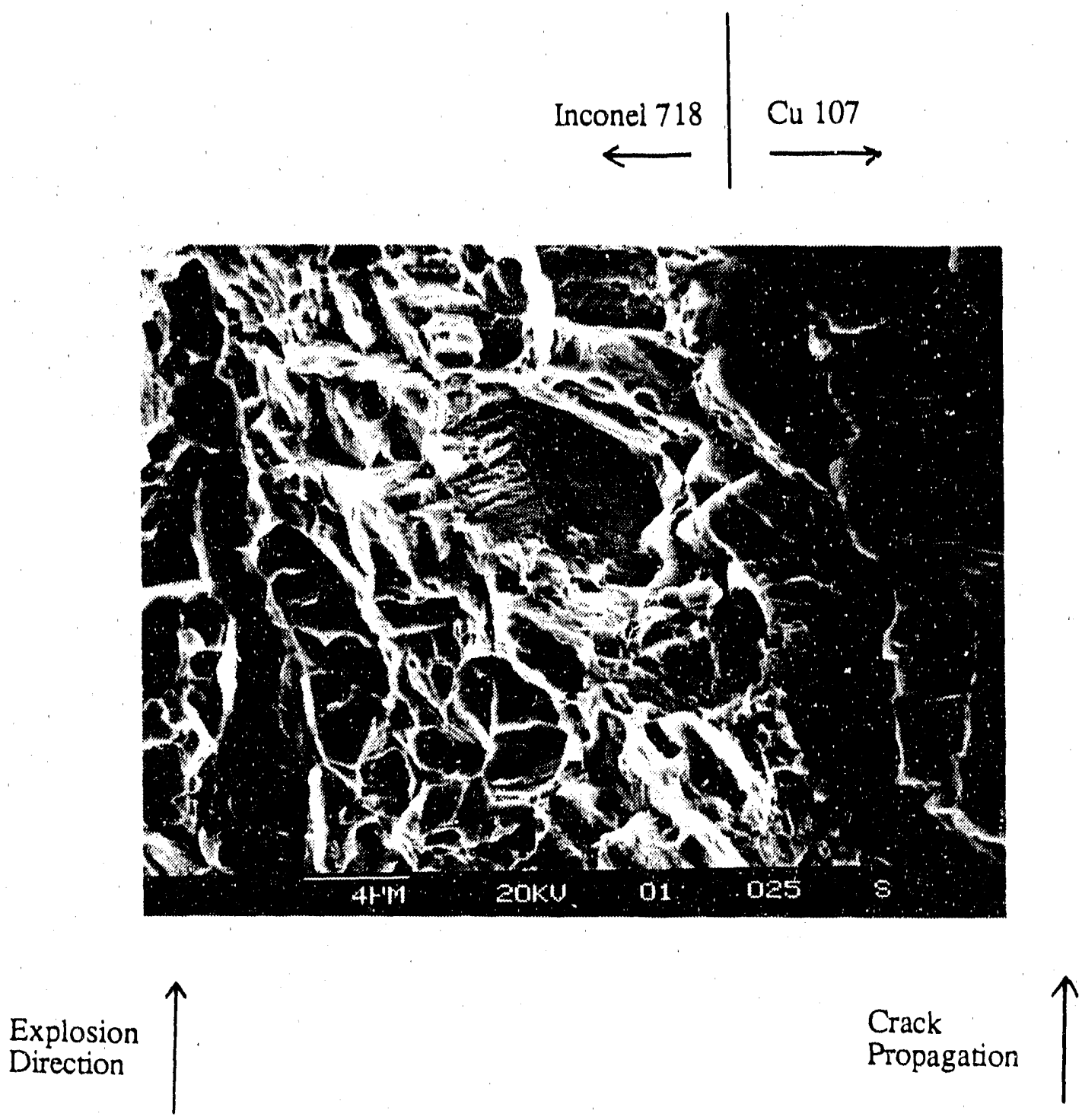

Figure 5.15: Shear Cracks Present Along the Flat Interface. Although much smaller in size, shear cracks were also found along the flat Inconel 718 / copper interface. The crack shown is approximately $8 \mu \mathrm{m}$ at the widest diameter. 


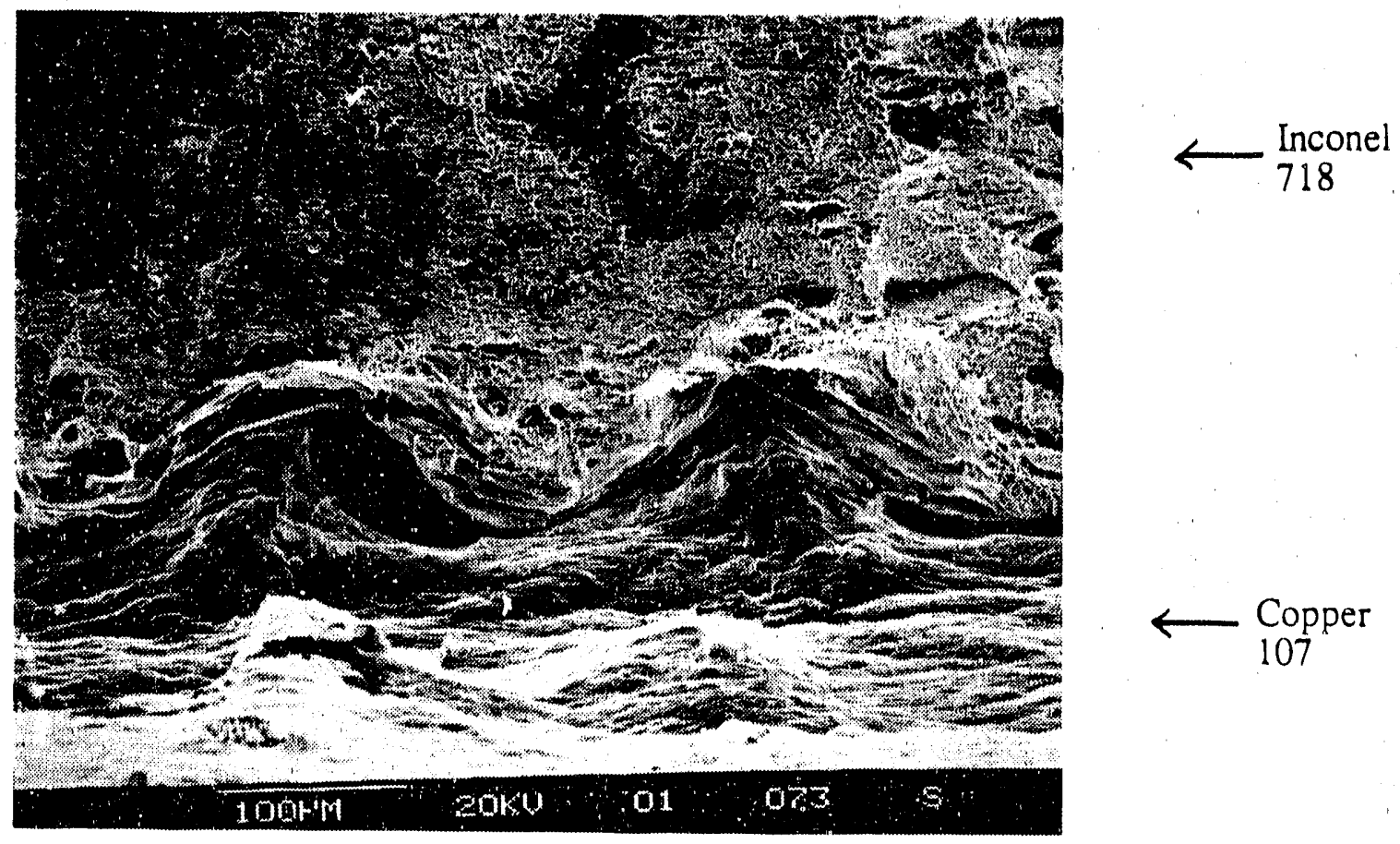

Explosion Direction

Figure 5.16: Transverse Laminate Tensile Test Specimen Interface. At this ripple interface, a high degree of plastic deformation in the copper 107 is evident. Ductile tearing is shown in the Inconel 718. A "pocket" in the wave on the copper side is noticeable. 


\section{Chapter 6}

\section{Discussion}

\subsection{Crack Advancement}

\subsubsection{Observations}

The differences in crack growth rates as a function of orientation can be explained by exarnination of the corresponding fracture surfaces. A schematic drawing of the specimen orientation with respect to explosion direction is shown in Figure 6.1. Fatigue crack growth data in the transverse orientation is slower than in the longitudinal orientation (Table 5.2)

Fracture surfaces exhibit a crack front that is asymmetrical across the laminate thickness in both orientations. The crack fronts are illustrated in Figure 6.2. The crack front is usually more advanced in the Inconel 718 than in the copper and is relatively flat through the thickness of the Inconel. The crack front in the copper usually lags behind the advancing front in the Inconel. However, in the copper/Inconel 718 interface which contains the ripple, the crack front does not lag as far behind the Inconel as in the flat copper/ Inconel 718 interface. The crack front shape in the copper on the side of the flat interface is different depending on 
specimen orientation.

Fatigue crack rates at $77^{\circ} \mathrm{K}$ exhibit a "plateau" region near a $\Delta K$ of approximately $17 \mathrm{MPa} \sqrt{\mathrm{m}}$, which was not evident at room temperature. This phenomenon will be shown to correlate with mechanical behavior.

\subsubsection{Mechanisms}

Work hardening can account for the difference in crack front shape in the copper sections. The copper side that contains the ripple is work hardened more in the bonding process. Consequently, it is less ductile than the copper on the flat interface. Thus, the crack front in the copper on the ripple side can travel at a faster rate which keeps up with the advancing crack front in the Inconel, while the crack front in copper on the flat interface side is more ductile and gets dragged along. This difference in work hardening between the two interfaces is supported by the observed differences in microhardness, which was shown in Figure 4.3. The presence of shear cracks at the interface on the ripple side can also cause crack propagation to occur more easily than on the flat interface side.

\subsubsection{Morphology}

Fractography of the interfaces shows ductile tearing (dimple rupture pattern) in the copper and fatigue cracking in the Inconel 718 Figure 6.3. This supports the notion that the copper at the interfaces is experiencing ductile tearing as the crack front in the Inconel advances. Tearing is more extensive in the copper on the ripple side than in the copper on the flat side 6.4.

Further away from the ripple interface, fatigue striations in the copper are observed (Figure 6.5). It appears that the copper is tearing at the ripple interface, while further away the copper is advancing by fatigue. Such behavior near to and 
far from the interface is possible because lnctalel controls the crack opening and advancement since it carries most of the load. Since the copper is bonded to the Inconel, at the interface the copper crack opening and advancement must match that of Inconel. Since crack advancement in Inconel is rapid, unstable crack growth in the copper causes tearing. However, farther away from the Inconel, crack growth in the copper is no longer unstable, and the cracle front in the copper moves forward by fatigue cracking, instead of ductile tearing.

Shear bands have a profound effect on fatigue crack growth rates in the laminate. More specifically, the orientation of the shear bands account for the difference in crack growth rate. In the longitudinal orientation, crack propagation is along a shear band, and as a result, the crack advances quickly. In the transverse orientation, the crack propagation is across the shear bands. Shear cracks are usually found within a shear band. As the crack front moves forward across these shear bands, it encounters a "line" of cracks at every shear band. This is shown in Figure 6.6. At this point, the crack front has crossed on a free surface and must pass through this line of cracks to continue propagating, which retards crack growth. Since there are many shear bands in the path of the crack front in the transverse orientation, this behavior leads to a decrease in crack growth rate. Figure 6.6 shows the fatigue striations leading up to the line of cracks; and the fatigue striations created after initiating on the opposite side of cracks in order to continue advancing. Crack retardation as a result of interaction with the shear bands can account for slower crack growth rate in the transverse orientation,

Shear band orientation can explain the difference in crack front shape in the two orientations. In the longitudinal orientation, crack propagation is along a shear band and thus, is very rapid. As a result, the cracks in the copper unstably propagate as the crack front in the Inconel 718 advances and the copper just tears at the interface. Being more ductile than the copper on the ripple side, the copper on the flat interface side tears and is dragged as the crack front advances. Thus, a large 
amount of lag behind the crack front in the Inconel is exhibited in the copper on the flat interface side.

In the transverse direction, crack growth is across the shear bands and consequently much slower. Fatigue cracks can now initiate, and the front in copper can advance at a pace which is closer to that of the Inconel 718. As a result, tearing in the copper is minimized, and the crack front in the copper on the flat interface side does not lag as far behind as it does in the longitudinal orientation. 


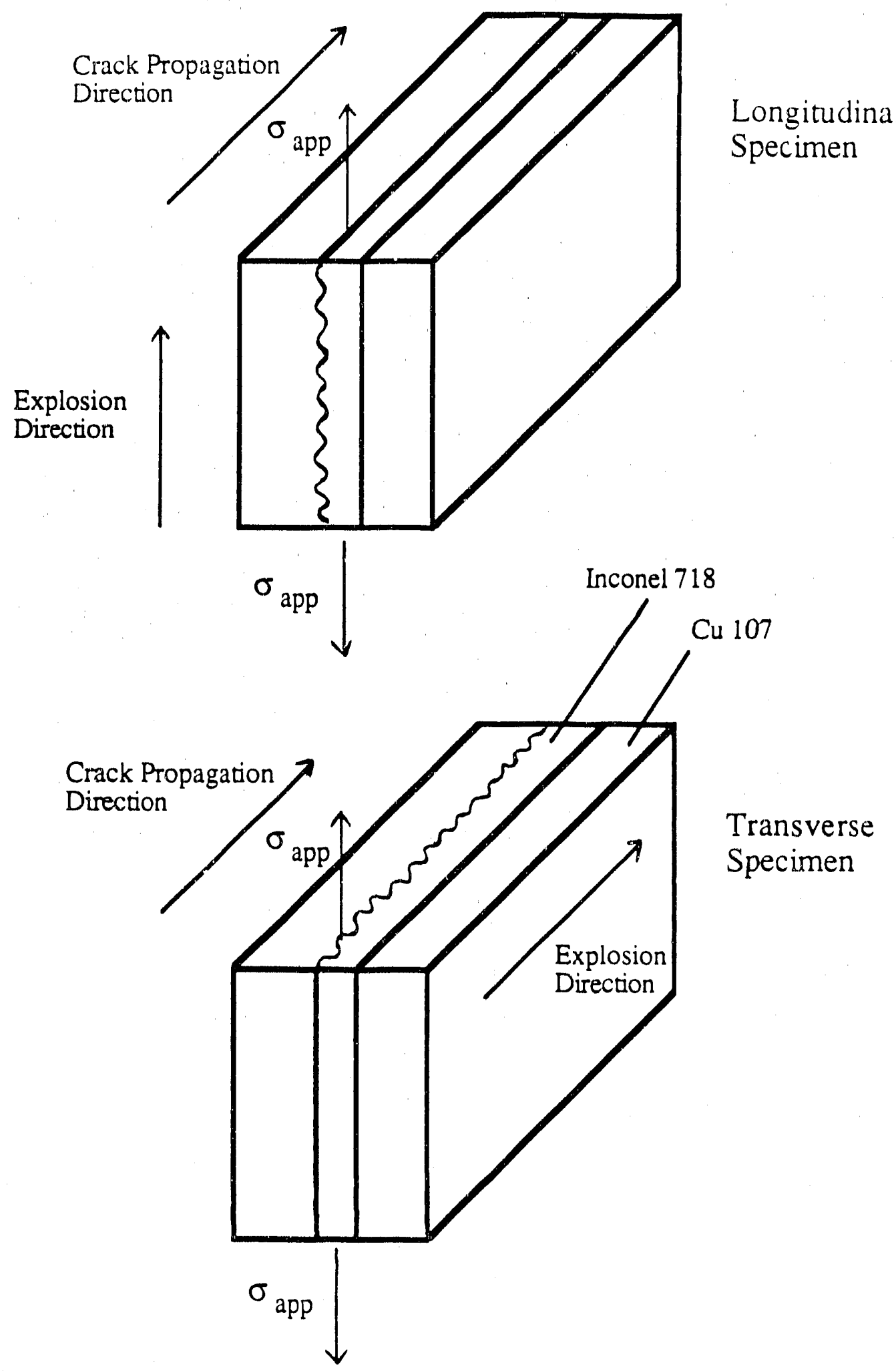

Figure 6.1: Schematic Showing Specimen Orientation, Explosion Direction, and Direction of Crack Propagation. In the longitudinal specimen, the direction of crack propagation is perpendicular to the explosion direction. In the transverse specimen, the direction of crack propagation parallels the explosion direction. 


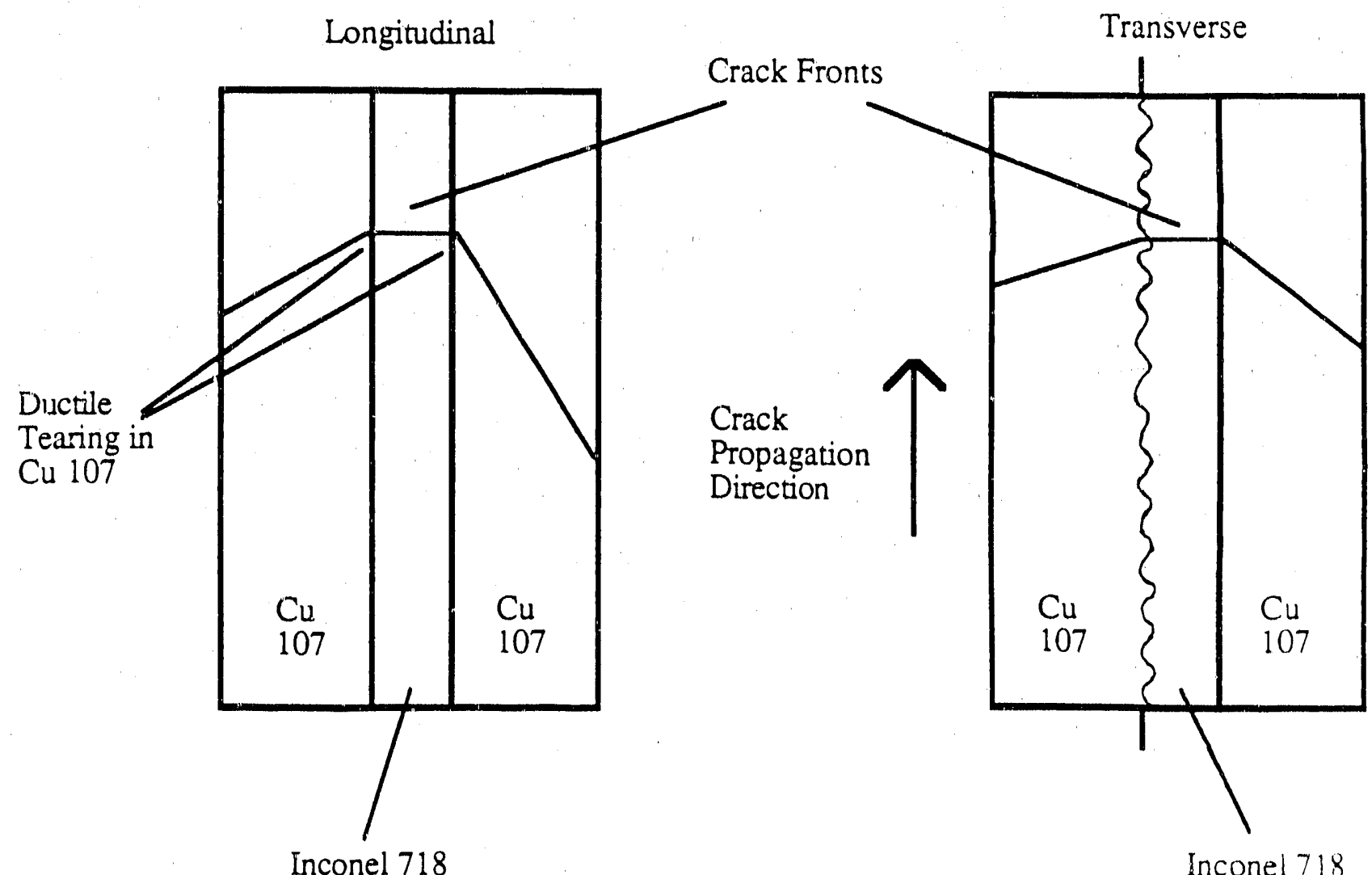

Figure 6.2: Crack Front Shapes in Longitudinal and Transverse Orientations. In the longitudinal specimen, the crack front in the copper on the flat interface side lags quite far behind the advancing crack front in the Inconel 718 . However, in the transverse specimen, this crack front lags much less due to the slower advancement of the crack front in the Inconel 718. In both specimens, ductile tearing in the copper is evident at both interfaces. The crack front in the Inconel 718 is always the most advanced. 

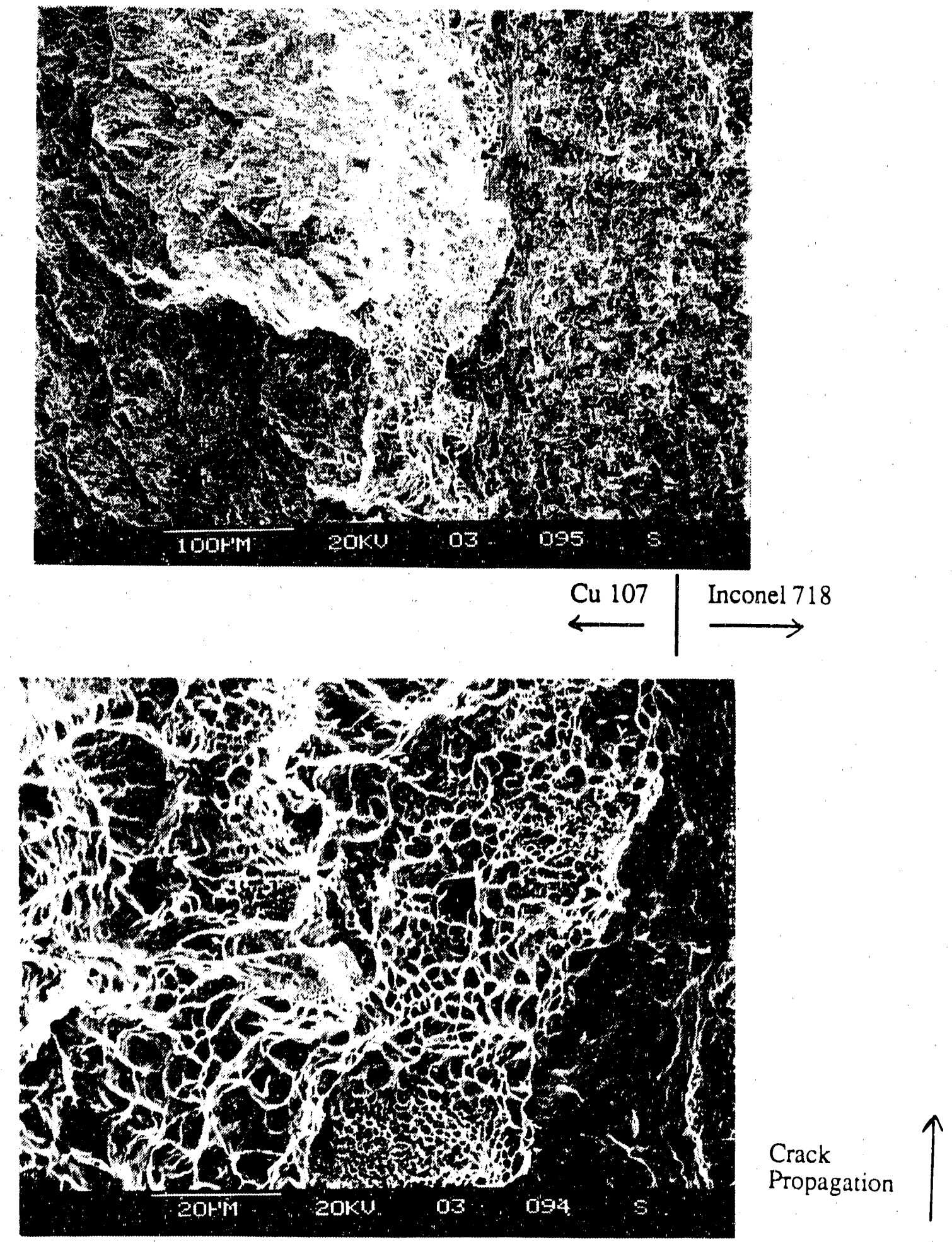

Figure 6.3: Ductile Tearing of Copper 107 at the Ripple Interface. At the ripple interface, extensive dimple rupture is exhibited in the copper 107. The top micrograph shows the interface at a lower magnification. The white regions are regions of ductile tearing. In the lower micrograph, the dimple rupture pattern in the copper becomes very pronounced. 

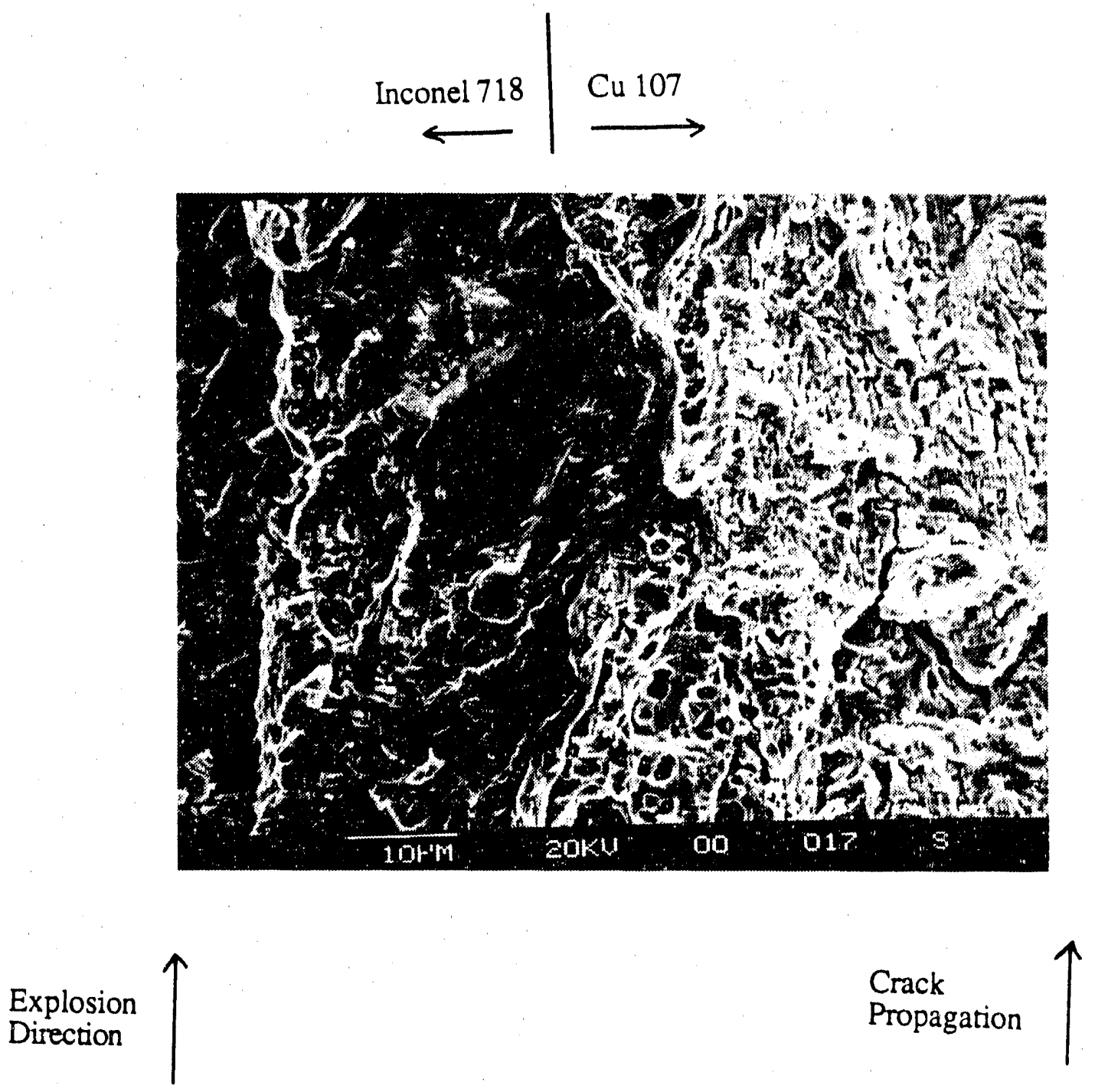

Figure 6.4: Ductile Tearing of Copper at the Flat Interface. The ductile tearing is not as pronounced at that of the copper at the ripple interface. 

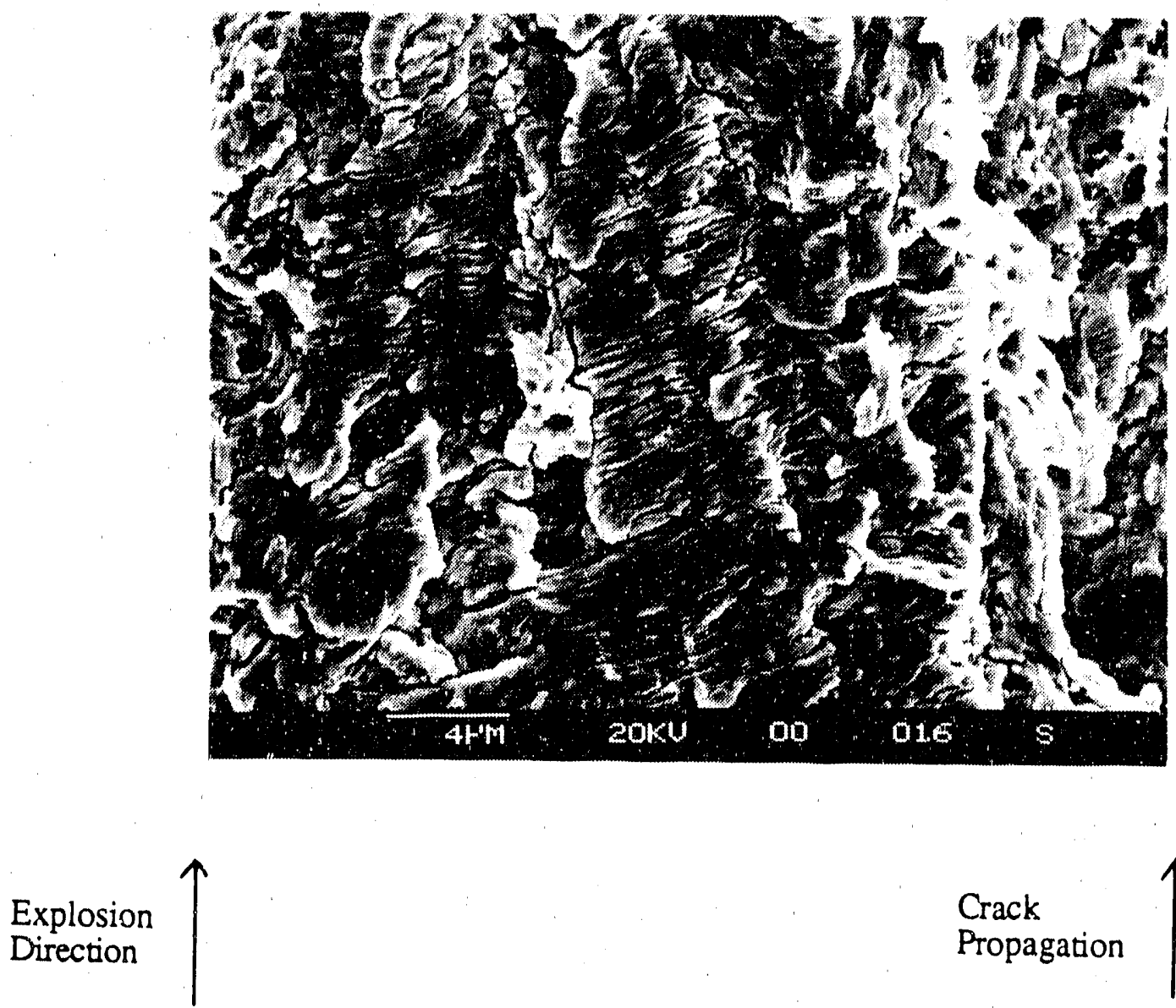

Crack
Propagation

Figure 6.5: Fatigue Striations in Copper 107 Far From the Ripple Interface. Fatigue striations are shown approximately half way across the copper on the ripple interface side. The presence of such striations indicates that the crack in this region is advancing by fatigue cracking. 


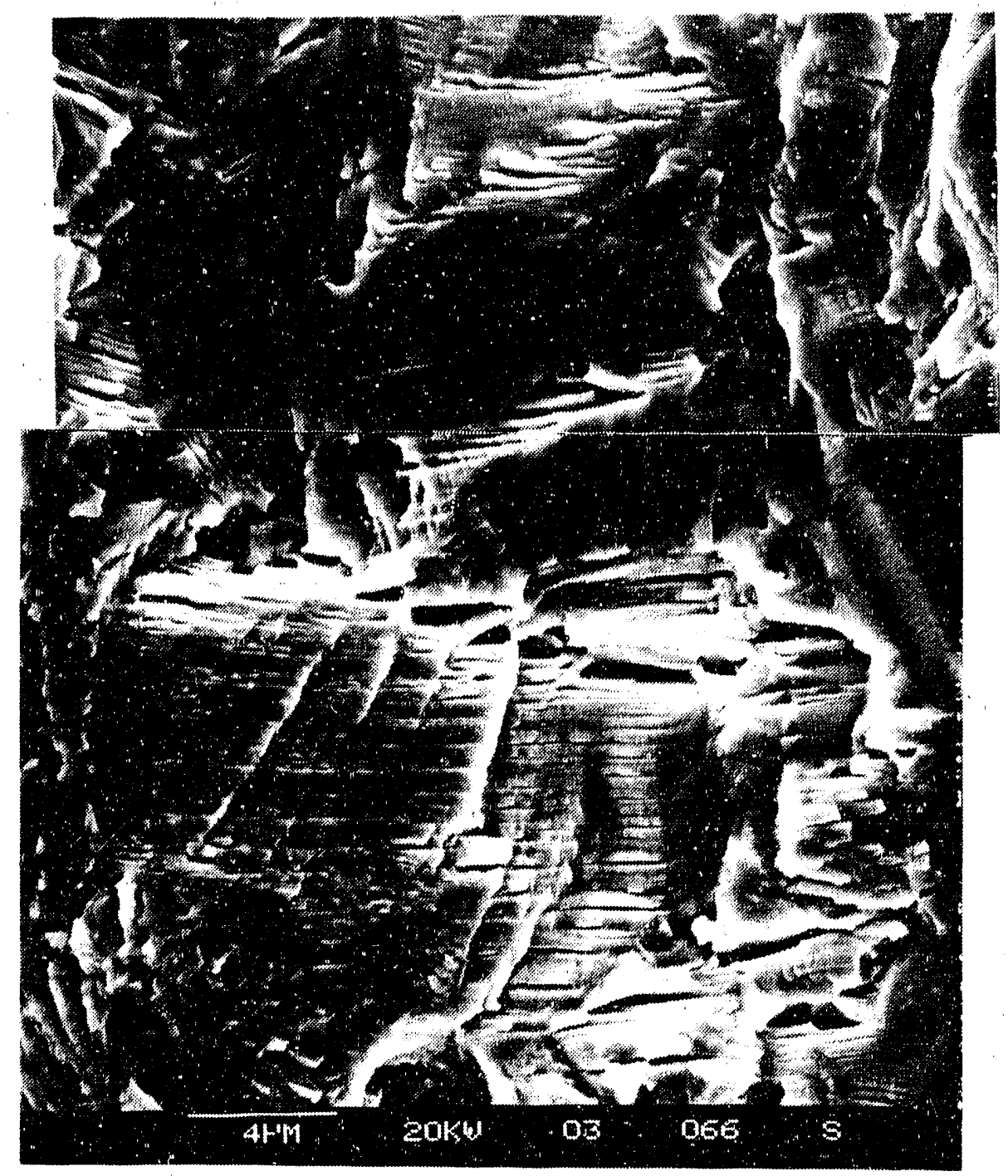

Explosion

Direction

Crack

Propagation

Figure 6.6: Line of Cracks Within a Shear Band in a Transverse Specimen. Fatigue striations are shown to be propagating toward the line of shear cracks with a shear band. Fatigue striations are also evident after the crack front has crossed the shear cracks indicating that crack re-initiation has occurred. Such behavior of the crack front could account for the slower crack growth rate in the transverse laminate specimens. 
A trarsition from plane strain to plane stress can explain the "plateau" regions of the fatigue crack growth data at $77^{\circ} \mathrm{K}$ near a $\Delta K$ of $17 \mathrm{MPa} \sqrt{\mathrm{m}}$ which is not observed at room temperature. The transition from plane strain to plane stress occurs when the plastic zone size becomes comparable to the thickness of the material; in this case, copper. The plastic zone size for a given $\mathrm{K}$ at $77^{\circ} \mathrm{K}$ will be less than that at room temperature because of the increase in yield strength at $77^{\circ}$ $\mathrm{K}$. A calculation of plastic zone sizes at room temperature and $77^{\circ} \mathrm{K}$ reveals that for a crack length of about $5 \mathrm{~cm}$. in liquid nitrogen, the plastic zone size is 0.41 $\mathrm{mm}$, while near the beginning of the crack growth test at room temperature, the plastic zone size is $0.30 \mathrm{~mm}$. Broek [57] points out that it has been experimentally shown that plane strain will be exhibited throughout the specimen when the ratio of plastic zone size to specimen thickness, $r_{P} / \mathrm{B} \approx 0.025$. For the liquid nitrogen specimen, $r_{P} / \mathrm{B}=0.093$, and for the room temperature specimen, $r_{P} / \mathrm{B}=0.070$. Clearly now, the specimen is in the realm of plane stress. Broek also points out that crack growth rates are slower in plane stress than plane strain $[57,56]$. Thus, the transition from plane strain to plane stress accounts for the change in slope after the "plateau" regions of the crack growth data at $77^{\circ} \mathrm{K}$.

Other investigators have looked at explosively bonded Inconel 718 / Copper 1.07 / Inconel 718 to formulate an adequate manufacturing criterion to produce acceptable explosion bonded plates for use in the central solenoid of the proposed Compact Ignited Tokamak (CIT) $[11,16,17,18,19,20,21,22,13,14,12]$.

On examination of the Alcator C-MOD laminate displayed several features at the interface that were similar to those found in [11]:

- The Inconel 718 / copper interfaces consist of ripples produced from the explosion bonding process.

- The thickness or amplitude of the ripples, $a$, which is measured from peak to valley depends on explosion bonding parameters. 
- In the case of one-sided explosions, the interface ripples on one side are larger than on the other side because of the difference in collision energy.

- Shear bands are usually found at the apex of the ripples in the Inconel 718 .

- Shear band cracks inside the shear bands are present if the shear bands are sufficiently severe.

Similarly, metallographic evaluation showed severe plastic deformation at the boundary layers of copper and Inconel. As a result of this heavy deformation, the microhardness (HK) is higher in each of boundary layers than in the respective bulk materials $[17,11]$

In order to formulate a manufacturing criteria for explosion bonded plates, it was found by Feng [11] that shear band and shear crack lengths decrease with interface ripple thickness. If the ripple thickness is less than about $0.1 \mathrm{~mm}$, the shear band cracks appear to disappear at 500X. Data supporting this observation is shown in Figure 6.7. Applying this criteria to the Alcator C-MOD laminate, with a shear band and ripple thickness of approximately $0.45 \mathrm{~mm}$ and $0.13 \mathrm{~mm}$ respectively, the C-MOD laminate falls within the scatter of the right hand side of the distribution. Thus, the C-MOD laminate should have shear band cracks at the ripple interface. Such shear bard cracks are observed in the C-MOD laminate by metallographic and fractographic inspection (See Figure 2.9). On the interface which is essentially flat (ripple thickness $\ll 0.1 \mathrm{~mm}$ ), a shear crack of approximately $8 \mu \mathrm{m}$ (Figure 5.15) is observed. Thus, coinciding with the notion that there exists a definite correlation between ripple thickness and shear band cracks [11]

Fractographic comparisons between the laminate and the work by Feng [11] exhibit the following similarities concerning shear bands and shear cracks at the interface:

- Shear cracks can be observed in the shear band prior to etching. 
- Shear band cracks are pancake-like cavities distributed along the shear bands.

- Some shear bands that had opened up after fracture were examined by scanning electron microscopy. These fracture surfaces displayed a mixture of small shiny facets and srnall ductile regions. The shiny areas seem to be amorphous as if they were produced by rapid solidification after melting.

Thus, the similarities of the comparisons between the Alcator C-MOD laminate and that of [11] shows the explosion bonding consistently forms shear bands and shear cracks at the Inconel 718 and copper interface. 


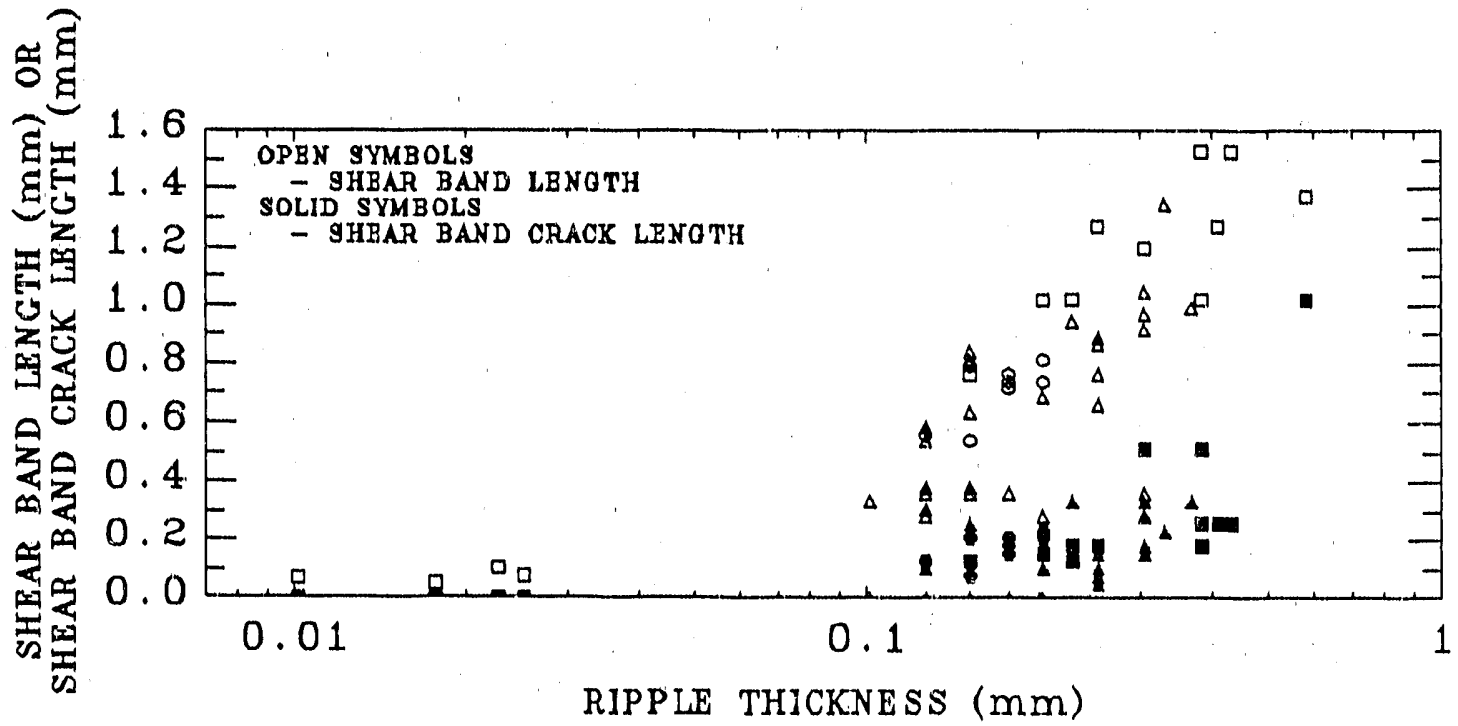

Figure 6.7: Shear Band Length and Shear Band Crack Length as Functions of Ripple Thickness (From [1.1]). 


\subsection{Application to Life Prediction}

In this section, a life prediction is formulated for the laminate using the fatigue crack growth results. The applied stress used in this analysis are the resulting in-plane stress in the copper and Inconel 718 during magnet operation. The derivation of these stresses is given in Appendix A.

\subsubsection{Assumptions}

In the subsequent life prediction analysis of the laminate, the following assumptions are made. Only one defect is present in the material, since the fracture mechanics equations used apply to a material with only one defect. The laminate plate experiences a uniform applied stress distribution and is of constant thickness, which are the conditions under which the fatigue crack growth results were obtained. The interaction between the crack front and the shear bands is not accounted for, since there is no present fracture mechanics theory to model such phenomenon. The initial flaw size is large enough such that the Paris crack growth law is a valid approximation of crack growth behavior. The Paris crack growth is applicable in the linear region (region II) of the $\mathrm{da} / \mathrm{dN}-\Delta K$ graph (See Figure 2.10). Thus, the value of $\Delta K$ must be above the threshold value $\Delta K_{t h}$. For a fixed load, this condition constrains the value of the initial flaw size.

\subsubsection{Definition of Failure: Determination of Critical Crack Size}

The failure process involves the initiation of fatigue cracks which propagate steadily through the material until there is unstable crack propagation and failure of the material occurs. In order to determine failure of the laminate, the critical crack length must be specified. Using the constraint that the crack tip opening displacement 
(CTOD) is equal in both Inconel 718 and copper, expressions for the stress intensity in Inconel $718 K_{718}$ and copper $107 K_{C u}$ are obtained. The details of this analysis are given in Appendix B.

Using the parameters of a fatigue test of a laminate CCT specimen and the final crack length, $K_{718}$ is $82 \mathrm{MPa} \sqrt{\mathrm{m}}$ and $K_{C u}$ is $31 \mathrm{MPa} \sqrt{\mathrm{m}}$. The $K_{I C}$ fracture toughness of Inconel 718 is approximately $100 \mathrm{MPa} \sqrt{\mathrm{m}}[33]$ and copper is estimated to be approximately $25 \mathrm{MPa} \sqrt{\mathrm{m}}[66]$. Since $K_{C u}$ is above the $K_{I C}$ for copper, the copper has fractured and cannot support any more load. As a result, all the load is carried by the Inconel 718. Calculation of $K_{718}$ at this point gives approximately $196 \mathrm{MPa} \sqrt{\mathrm{m}}$, which is much higher than the $K_{I C}$ of the Inconel 718 , and the Inconel 718 fractures. Thus, it is evident that the copper controls the failure of the laminate. The laminate will fail if $K_{C u}$ is greater than $K_{I C}$ of copper.

The critical crack length of the laminate can now be determined from:

$$
a_{\text {crit }}=\frac{1}{\pi}\left(\frac{K_{I C, C u}}{\sigma_{\max } Q}\right)^{2}
$$

where $K_{I C, C u}$ is the fracture toughness of copper, $Q$ is 1.12 , and $\sigma_{\text {max }}$ is the maximum applied stress $\sigma_{\text {app }}$ from Table 3.2. The values of $a_{\text {crit }}$ at the nose and centerline of the TF core are given in Table 6.1. This analysis assumed ideal Inconel 718 and copper. However, in the actual laminate many defects are known to exist. As a result, this analysis gives an optimistic estimate of the critical crack length. The actual critical crack length would probably be lower due to the defects present in the material. 


\begin{tabular}{|l|c|}
\hline Location & $\mathrm{a}_{\text {crit }}(\mathrm{m})$. \\
\hline Nose & 0.0131 \\
Center & 0.0060 \\
\hline
\end{tabular}

Table 6.1: Laminate Critical Crack Size $a_{\text {crit }}$ as a Function of Location 


\subsubsection{Life Prediction Analysis}

Having determined the total required in-plane tension stress to simulate the inservice loading of the Alcator C-IMOD tokamak TF core (see Table 3.2), the life of the TF core may now be estimated from the fatigue crack growth data.

Recalling the integrated form of the Paris equation (Equation 2.7):

$$
N=\frac{1}{(C \Delta \sigma \sqrt{\pi} Q)^{m}} \frac{1}{\left(\frac{m}{2}-1\right)}\left(\frac{1}{a_{o}^{\frac{m}{2}-1}}-\frac{1}{a_{f}^{\frac{m}{2}-1}}\right)
$$

where $\Delta \sigma$ is obtained from Table A.2 and is equal to $0.9 \sigma_{a p p}$ since $R$ is $0.1, Q$ is 1.12, $C$ and $m$ are the crack growth law coefficients from Table 5.1. Thus, only expressions for initial crack size $a_{o}$ and final crack size $a_{f}$ need to be determined. In the worst possible situation, final crack size $a_{f}$ is equal to critical crack size $a_{c r i t}$, which are given in Table 6.1. Since the fatigue crack growth data was obtained with through-thickness specimens, the initial crack size $a_{o}$ will be taken to be $2.3 \mathrm{~mm}$ which is of the order of the Inconel 718 thickness.

Equation 2.7 is now used to compute the life of the laminate at room temperature and $77^{\circ} \mathrm{K}$ for stresses at the nose and centerline of the Alcator C-MOD TF core. These results are summarized in Table 6.2. As expected the longitudinal orientation is the worse case because of its much higher crack growth rate, and consequently, the predicted life is very short. However, in the transverse orientation, the crack growth rate is much slower and thus, the predicted life is longer. As expected, the life predictions at $77^{\circ} \mathrm{K}$ were usually slightly longer than those at room temperature, because of the observed slower crack growth rate at $77^{\circ} \mathrm{K}$. It is very interesting that life did not vary much between room temperature and $77^{\circ} \mathrm{K}$. Such behavior is an indication that the shear bands appear to have a dominating effect on crack growth behavior. In the transverse orientation the crack is propagating across many shear bands, which accounts for the longer life estimation. As a result, shear bands affect crack growth more strongly than temperature. Since Alcator 
C-MOD is designed for 50,000 cycles, the life prediction results of the longitudinal orientation at the centerline gives a factor of safety on life of approximately 1.4, while in the transverse orientation the factors of safety are in the range of 4 to 6 . At the nose region, the factors of safety increase to the range of 17 to 33 . The large difference in safety factors is due to the difference in applied stress at the centerline and nose regions. 


\begin{tabular}{|l|c|c|r|}
\hline Orientation & Temperature & Location & $\begin{array}{r}\text { Number } \\
\text { of Cycles }\end{array}$ \\
\hline Longitudinal & $295 \mathrm{~K}$ & Nose & 932,000 \\
Transverse & $295 \mathrm{~K}$ & Nose & $\begin{array}{r}1,310,000 \\
\text { Longitudinal }\end{array}$ \\
Transverse & $77 \mathrm{~K}$ & Nose & 861,000 \\
& & Nose & $1,660,000$ \\
\hline & & & \\
Longitudinal & $295 \mathrm{~K}$ & Center & 69,000 \\
Transverse & $295 \mathrm{~K}$ & Center & 204,000 \\
Longitudinal & $77 \mathrm{~K}$ & Center & 67,000 \\
Transverse & $77 \mathrm{~K}$ & Center & 297,000 \\
& & & \\
\hline
\end{tabular}

Table 6.2: Laminate Life as a Function of Orientation, Temperature, and Location. Final crack length $=a_{\text {crit }}$ is assumed. Initial crack length $=2.3 \mathrm{~mm}$ 


\subsection{Applicability of Life Prediction Criteria to Alcator C-MOD TF Core}

The life prediction formulation presented in the preceding section differs in its assumptions from the actual Alcator C-MOD toroidal field magnet core in two respects : geometry and applied stress. In reality, the TF core plates are tapered in thickness and are thinner at the nose of the magnet, whereas the life prediction was derived with specimens of constant thickness. The actual applied stress in the TF core varies with position and is highest at the nose region and decreases across the width of the TF core. In the life prediction model, a constant applied stress was used. These differences actually show that the life prediction is conservative.

The life prediction model assumed that a through-thickness edge crack, whose length was that of an average projected shear band, started growing from the nose of the magnet through its width. In the crack growth experiments, the crack propagated under constant stress and in a constant thickness component. However, in the actual TF core, this crack would experience propagation into a decreasing applied stress field and an increasing material thickness. Although the uncracked ligament of the TF core is decreasing as the crack propagates, the decreasing applied stress and increasing thickness would more than likely offset this factor. Thus, it is estimated that the crack growth rate would likely retard as the crack propagated. through the width of the TF core. As a result, the life prediction presented can be viewed as conservative.

The thermal behavior of the actual TF magnet is different than that of the experimental simulation. The TF magnet is pre-cooled to $77^{\circ} \mathrm{K}$ with liquid nitrogen before each pulse and during this pulse the TF magnet is allowed to heat up to about $200^{\circ} \mathrm{K}$, whereas the crack growth experiments tested the laminate at room temperature and $77^{\circ} \mathrm{K}$ respectively. However, the life prediction model formulated 
can be used to estimate the effects of this thermal behavior on the life of the TF core.

In comparing the life prediction results for the laminate at room temperature and $77^{\circ} \mathrm{K}$ the dependence on temperature was very slight. As a result, it could be inferred that the actual thermal behavior of the TF core would not significantly change the life of the laminate, unless the induced thermal stresses were considerably high.

This fact that the longitudinal orientation is much worse than the transverse is quite unfortunate since the longitudinal orientation is the one in which the TF core plates were to be manufactured from explosively bonded plates. If explosion bonded plates were to be used, this analysis shows that the transverse direction would be the favorable direction, because of its slower crack growth and longer estimated life.

In this explosively bonded composite, the shear bands and shear cracks have a dominant effect on crack growth behavior and hence, on life prediction. The life prediction analysis presented here assumes one crack propagating in a relatively homogeneous material. In reality, this composite contains many cracks and is very non-homogeneous. In the case of the longitudinal orientation, this analysis may be unconservative because the crack propagation is along a shear band and may link up with other shear bands to result in a value of life shorter than that predicted. However, in the case of the transverse orientation, the life prediction may be conservative because the crack propagation is across the shear bands and crack growth is retarded as the crack front has to pass through a a line of cracks before propagating further. Such behavior would result in a value of life longer than predicted. Again, the transverse orientation appears to be the most favorable. 


\subsection{Implications for TF Core Service}

The asymmetric shape of the crack front creates ambiguities during service inspections. Since the ohmic transformer is wound around it and denies accessibility, the actual TF core cannot be inspected once it is in service. However, even if this were not the case and it could be inspected, the asymmetric shape of the crack front could lead to errors in crack measurement. If the crack measurement was performed on the face closest to the ripple interface, the measurement error would not be large. However, if the crack measurement was done on the face closest to the flat interface, measurement would grossly underpredict the actual length of the crack. When the laminate is in service, it would be very difficult to determine which interface was wavy or flat without the ability to observe the interfaces under optical magnification, unless the assembly specifications dictated the orientation of the plates with respect to interface type. Thus, caution must be exercised when formulating crack length inspection procedures for this laminate.

Metallographic inspection revealed a flat and wavy interface between the Inconel 718 and copper 10700 and shear cracks in the Inconel 718. The presence of such features would make accurate crack detection through ultrasonic inspection quite difficult. The wavy interface between the Inconel 718 and copper will cause extraneous echoes in ultrasonic readings leading the operator to interpreting these signals as cracks. As a result, it would be impossible to confidently detect smali cracks within the ripple thickness of the wavy interface. However, small shear cracks were shown to exist at the wavy interface of this explosively bonded laminate. Furthermore, the small size of these shear cracks, approximately $100 \mu \mathrm{m}$, is beyond the resolution of the ultrasonic technique.

There is much speculation on what is an accurate resolution of the ultrasonic method in inspecting these laminates. A minimum detectable crack length of approximately $1 \mathrm{~mm}$ was used in the ultrasonic inspection of the actual explosion 
plates for Alcator C-MOD. However, most of the cracks detected were of the order of the Inconel 718 thickness and thus, were much larger than the ripple thickness. Clearly, more work is needed to appropriately determine the reliable resolution of ultrasonic methods in detecting small cracks in this laminate. 


\section{Chapter 7}

\section{Summary, Conclusions, and \\ Recommendations for Future}

\section{Work}

\subsection{Summary and Conclusions}

This thesis investigated the fatigue crack growth behavior of an explosively bonded laminate conductor which consisted of layers of copper 107 / Inconel 718 / copper 107. Shear bands and shear band cracks were created in the Inconel 718 as a result of the explosion bonding process. These shear bands were shown to have a detrimental effect on the crack growth behavior of the laminate, by significantly reducing the load carrying capability of the reinforcement layer and providing for easy crack propagation paths.

Experiments were performed to investigate the fatigue crack growth behavior of the laminate at room temperature and $77^{\circ} \mathrm{K}$ and at two orientations, longitudinal and transverse to the detonation direction. The results of these experiments were then used to formulate a life prediction for the Alcator C-MOD toroidal field 
magnet, The following summarizes observations of fatigue crack growth behavior in this laminate:

- Fatigue crack growth rate is dependent on explosion orientation aind temperature. The transverse orientation had a consistently lower crack growth rate than the longitudinal orientation. Crack growth rates at $77^{\circ} \mathrm{K}$ were lower than those at room temperature.

- Shear bands appear to have a profound effect on fatigue crack growth rates in the laminate. Fatigue cracks grow faster in the longitudinal orientation since crack propagation is along a shear band, whereas in the transverse orientation, fatigue crack grow slower since crack propagation is across the shear bands.

- Fracture surfaces exhibit a crack front that is asymmetrical across the the thickness of the laminate in both orientations.

- An indication that the Inconel 718 has been severely damaged by the explosion bonding process is the observation that the laminate fatigue crack growth rate in the longitudinal orientation is almost that of copper. Whereas, crack growth rate in the transverse orientation is close to that of Inconel 718.

Analysis and application of the fatigue crack growth results led to the following conclusions on life of the laminate:

- Laminate life is strongly dependent on shear band orientation. When crack propagation is along a shear band, the predicted life was significantly lower than when crack propagation is across the shear bands.

- Laminate life did not very much with temperature. It appears that the shear bands have a dominating effect on crack growth behavior. 
- The life prediction model presented may be unconservative in the longitudinal orientation, but conservative in the transverse orientation. Again, the reason for such a discrepancy arises from the differences in the interactive behavior between crack propagation and shear band orientation.

- The asymmetrical shape of the crack front across the thickness of the laminate could lead to errors in crack length inspection of this laminate.

\subsection{Recommendations for Future Work}

A few recommendations may be made to enhance and expand this work on fatigue crack growth behavior and life prediction behavior of this explosively bonded laminate conductor.

Fatigue crack growth experiments on the Inconel 718 after bonding would be a good indication of how much the explosion bonding process has altered the Inconel 718 materials properties. However, removing the copper may make this task quite difficult, since high residual stresses are present at the interface. As a result, severe bowing occurs when the copper layer is removed by conventional machining. In addition, in this laminate, the Inconel 718 layer was severely twisted or warped. Thus, removing the copper by chemical means would also lead to severe bowing of the sample, since the amount of copper on each side of the Inconel is not equal in these samples.

Investigations of the fatigue crack growth behavior of other types of laminates would improve the understanding of crack propagation in laminate materials. For example, studies of roll-bonded copper / Inconel / copper would enable one to distinguish those features of crack growth behavior that is inherent to laminates not just explosion bonded laminates.

Adjustments and refinements to the explosion bonding process could be made 
in an attempt to obtain two "flat" interfaces. Such adjustments would involve altering the setup parameters such that the same collision energy is imparted to both interfaces.

Material other than Inconel 718 could be used for reinforcement. Preferably it should be a material the does not develop shear bands during explosion bonding. Alternatively, a different heat treatment could be applied to the Inconel 718 which would improve ductility and fracture toughness without significantly sacrificing tensile strength, and in the process, reduce or eliminate the formation of shear bands during explosion bonding.

The crack initiation behavior at shear cracks could be investigated to determine retardation in crack growth caused by cracks propagating across shear bands. This may proved to very difficult since extremely sensitive crack measurement procedures are required. 


\section{Appendix A}

\section{Stresses in C-MOD Laminate}

\section{Conductor}

The stresses on a typical element of the Alcator C-MOD TF central core are shown in Figure A.1. The definition of in-plane and out-of-plane stresses is shown in Figure A.2. These stresses arise from three applied loads: (1) the face compression loads caused by the radial inward Lorentz body forces on tapered core laminate plates from the interaction of the vertical current with the toroidal field, (2) the in-plane vertical tension load caused by the interaction of the toroidal magnetic field with the current flowing in the upper and lower "ears" of the central core, and (3) the inter-plate shear from the out-of-plane loads arising from interaction of the vertical current with the poloidal fields. This third load is neglected in the present study because it does not produce an in-plane tension load and there is negligible contribution of the shear to the copper Tresca stress. In order to predict the effects of these loads on laminate behavior in a uniaxial fatigue machine, the resulting in-plane stresses must be determined. The analysis that follows describes the procedure to determine the resulting in-plane stresses in the copper and Inconel during magnet operation in order to determine the loading to be applied to 
the laboratory specimens for crack growth measurements. An ideal elastic-plastic stress-strain curve for copper is assumed.

The in-plane stresses of each component, copper and reinforcement, are related to the applied in-plane stress by:

$$
\sigma_{i}=\alpha \sigma_{c, i}+(1-\alpha) \sigma_{r, i}
$$

where $\sigma_{i}$ is the applied in-plane stress, $\sigma_{c, i}$ is the in-plane stress in the copper, $\sigma_{r, i}$ is the in-plane stress in the Inconel 718 reinforcement, and $\alpha$ is given by:

$$
\alpha=\frac{t_{\mathrm{c}}}{t_{\mathrm{c}}+t_{\mathrm{r}}}
$$

where $t_{c}$ is the copper thickness and $t_{r}$ is the Inconel 718 thickness. Assuming elastic behavior, the in-plane strains are equal at the interface $\epsilon_{c, i}=\epsilon_{r, i}$, which gives a relation between the in-plane stresses $\sigma_{c, i}=E_{c} \sigma_{r, i} / E_{r}$, where $E_{r}$ and $E_{\mathrm{c}}$ are the moduli of the reinforcement. Eliminating $\sigma_{r, i}$ in Equation A.1 yields:

$$
\sigma_{i}=\sigma_{r, i}\left[\alpha \frac{E_{c}}{E_{r}}+(1-\alpha)\right]
$$

A similar relationship was shown in [23] to relate the Young's Modulus of a laminate to the moduli of its components.

$$
E_{i}=\alpha E_{c}+(1-\alpha) E_{r}
$$

The peak stresses in the Alcator C-MOD central column were determined by finite element analysis that was done by Stone \& Webster Engineering Corporation. These peak stresses are summarized in Table A.1. 


\section{A.1 Determination of In-Plane Stresses Due to Face Compression Under Elastic Conditions}

At the interface of the laminate, the strains in the two materials are assumed to be equal and elastic. Also, the in-plane forces must balance. Thus,

$$
\epsilon_{\mathrm{c}, i}=\epsilon_{r, i}
$$

Or,

$$
\frac{\nu \sigma_{f c}}{E_{c}}-(1-\nu) \frac{\sigma_{c, i, f c}}{E_{c}}=\frac{\nu \sigma_{f c}}{E_{r}}+(1-\nu) \frac{\sigma_{r, i, f c}}{E_{r}}
$$

where $\nu$ is Poisson's ratio, $\sigma_{f c}$ is the face compression stress, $\sigma_{c, i, f c}$ and $\sigma_{r, i, f c}$ are the in-plane components in copper and Inconel 718 due to face compression, and

$$
\left(\sigma_{r, i, f c}\right) t_{r}=\left(\sigma_{c, i, f c}\right) t_{c}
$$

Equations A.5 and A.6 can now be solved for $\sigma_{r, i, f_{c}}$ and $\sigma_{c, i, f_{c}}$. For example,

$$
\sigma_{r, i, f c}=\frac{\nu \sigma_{f}\left(E_{r}-E_{c}\right)}{(1-\nu) E_{c}} \frac{1}{\left(1+\frac{E_{r}}{E_{c}} \frac{t_{r}}{t_{c}}\right)}
$$




\section{A.2 Determination of Stress in Inconel 718 When The Applied Tresca Stress Exceeds The Cop- per Yield Strength}

Given a face compression stress $\sigma_{f c}$, the compressive in-plane stress in the copper $\sigma_{c, i, f c}$ can be determined from equations A.6 and A.7. Thus, the Tresca stress ${ }^{1}$ in the copper due to face compression and vertical tension is:

$$
\sigma_{\text {tresca }}=\sigma_{f c}-\left(\sigma_{c, i, v t}+\sigma_{c, i, f c}\right)
$$

If the Tresca yield criterion is assumed $\sigma_{\text {tresca }}=\sigma_{y}$, fraction of stress above the yield is:

$$
f=\frac{\sigma_{\mathrm{c}, y}}{\sigma_{\text {tresca }}}
$$

where $\sigma_{c, y}$ is the copper yield stress. Thus, the values of face compression and vertical tension which produce the Tresca yield criterion in the copper are:

$$
\begin{aligned}
& \sigma_{f c}^{\prime}=f \sigma_{f c} \\
& \sigma_{v t}^{\prime}=f \sigma_{v t}
\end{aligned}
$$

The increment of face compression stress, which is above the Tresca yield of the copper, is:

$$
\Delta \sigma_{f c}=\sigma_{f c}-\sigma_{f c}^{\prime}
$$

\footnotetext{
${ }^{1}$ The Tresca stress is the largest algebraic difference between any two of the three principal stresses at a point [59].
} 
It is for these increments of stress that are above the Tresca yield of the copper that the copper is hydrostatic $\left(\Delta \sigma_{c}=\Delta \sigma_{f c}\right)$, and consequently, the copper cannot support any further increases in in-plane tension. The increases are supported by the Inconel 718. These increments of in-plane stress in the Inconel 718 is given by: compression and vertical tension is given by :

$$
\Delta \sigma_{r}=\Delta \sigma_{c} \frac{t_{c}}{t_{r}}
$$

Thus, the total in-plane tension stress in the Inconel 718 due to face compression, vertical tension, and increments of stress above the yield of the copper is expressed as:

$$
\sigma_{r, i, t}=\sigma_{r, i, f c}+\sigma_{r, i, v t}+\Delta \sigma_{r}
$$

A total applied stress $\sigma_{\text {app }}$ on the laminate, such that the Inconel 718 in-plane stress is equal to $\sigma_{r, i, t}$, can be constructed by substituting $\sigma_{r, i}=\sigma_{r, i, t}$ in Equation A.2. A summary of $\sigma_{r, i, t}$ and $\sigma_{a p p}$ is given in Table A.2 at two locations in the TF core, the nose and centerline, which are defined in Figure 1.2. 

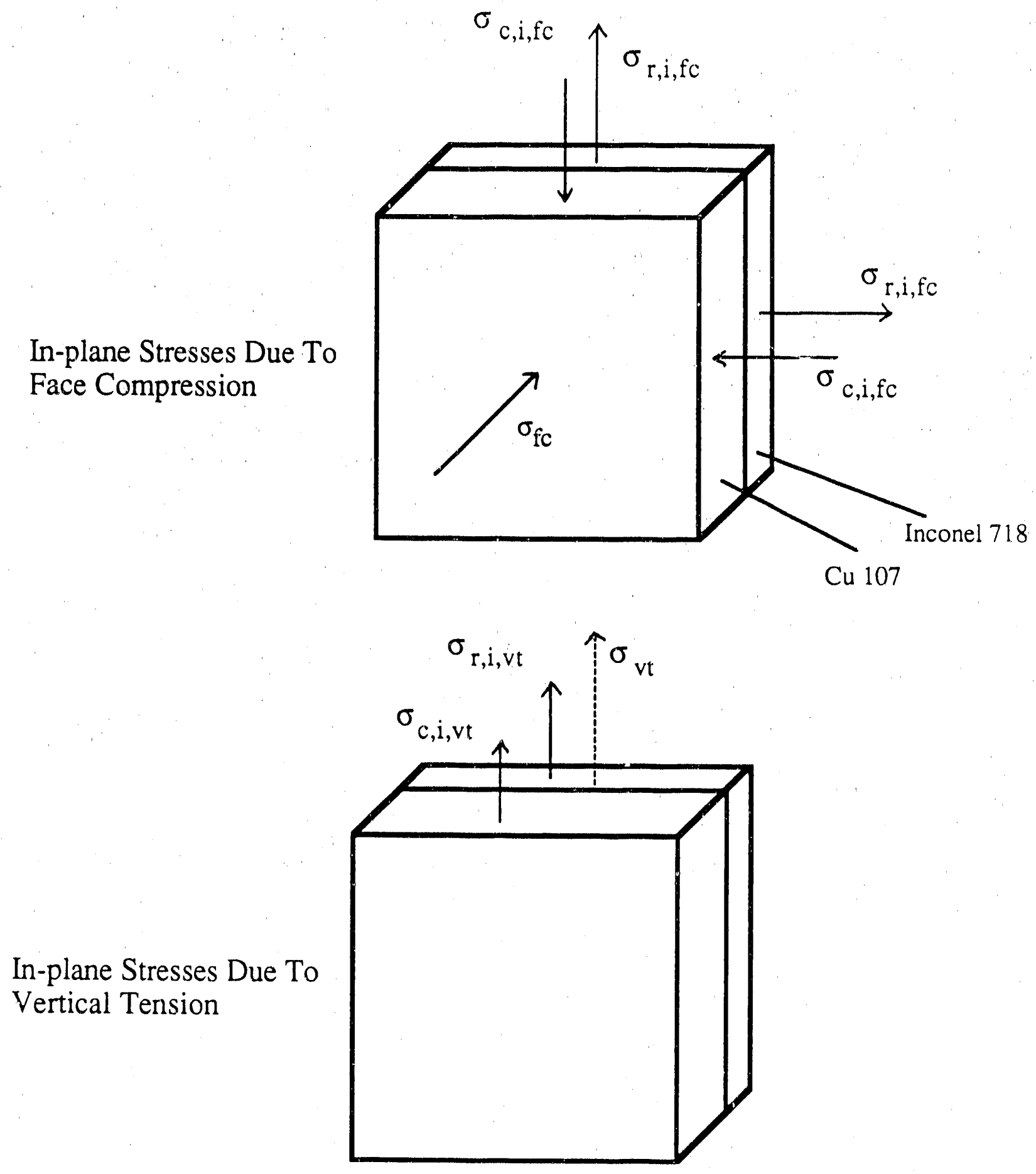

Figure A.1: Stresses On An Element of Laminate Conductor. The resulting inplane tension stresses due to face compression and vertical tension are shown. The face compression stress is denoted by $\sigma_{f c} . \sigma_{c, i, f c}$ and $\sigma_{r, i, f c}$ are the in-plane copper and Inconel 718 stresses due to face compression. The vertical tension stress is denoted by $\sigma_{v t} . \sigma_{r, i, v t}$ and $\sigma_{c, i, v t}$ are the in-plane stresses in the Inconel 718 and copper due to $\sigma_{v t}$. 


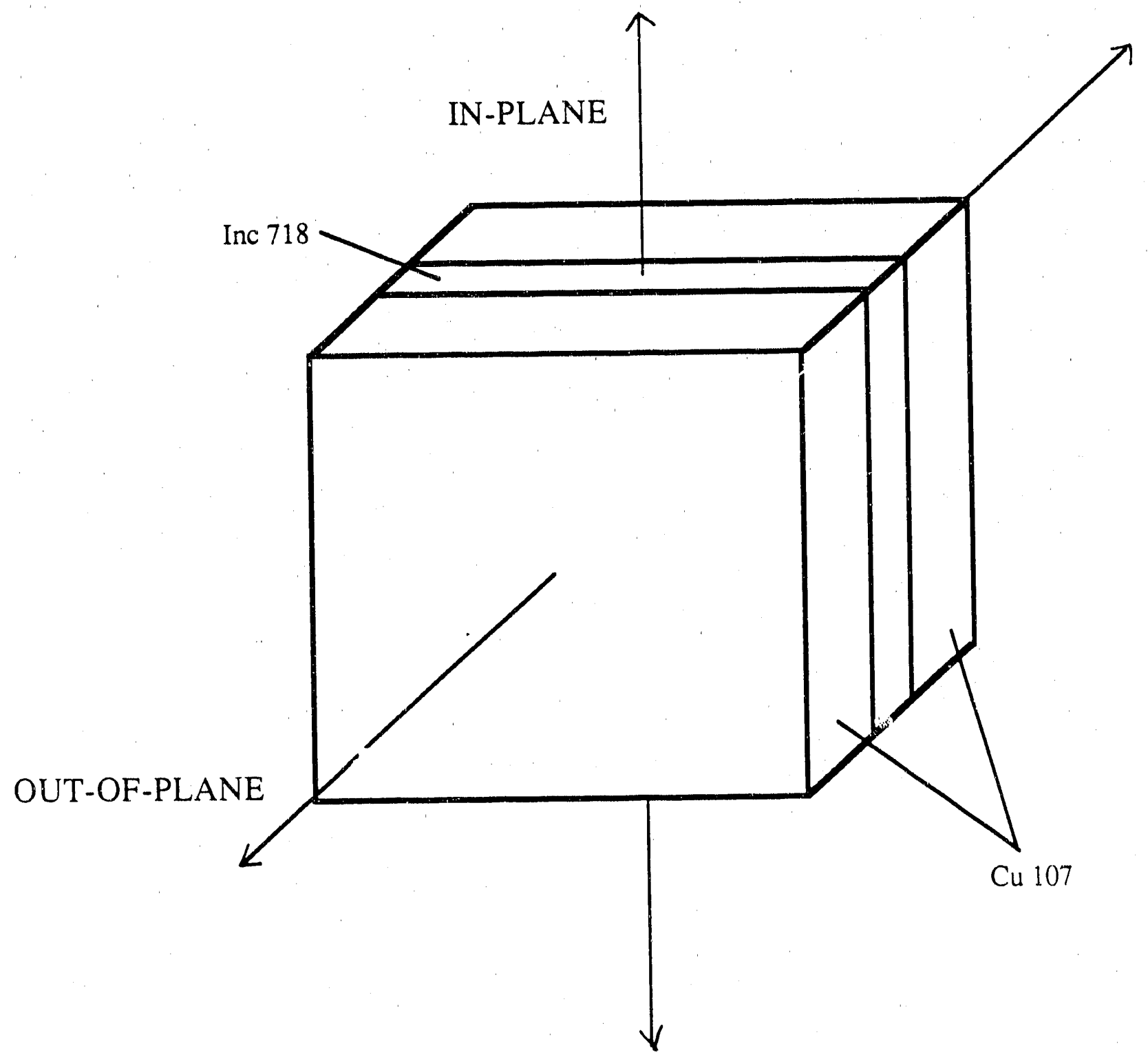

Figure A.2: Definition of In-plane and Out-of-Plane Directions 


\begin{tabular}{|l|r|r|}
\hline & Nose & Centerline \\
& $\mathrm{MPa}$ & $\mathrm{MPa}$ \\
\hline$\sigma_{f c}$ & -296 & -200 \\
$\sigma_{v t}$ & 82 & 140 \\
$\sigma_{r}$ & 0 & -100 \\
\hline
\end{tabular}

Table A.1: Alcator C-MOD Stress Summary for Central Column

\begin{tabular}{|l|r|r|}
\hline & $\begin{array}{r}\text { At Nose } \\
(\mathrm{MPa})\end{array}$ & $\begin{array}{r}\text { At Centerline } \\
(\mathrm{MPa})\end{array}$ \\
\hline Total Inconel In-plane Tension & 162 & 241 \\
$\sigma_{r, i, \mathfrak{t}}$ & & \\
Total Applied Tension Stress & 110 & 163 \\
$\sigma_{\text {app }}$ & & \\
\hline
\end{tabular}

Table A.2: In-Plane Stress Summary Due to Face Compression and Vertical Tension 


\section{Appendix B}

\section{Calculation of Stress Intensity}

Factors in Inconel 718 and

\section{Copper 107 Based on Equal CTOD}

As a crack propagates in the laminate, the crack tip opening displacement (CTOD) is equal in both Inconel 718 and copper 107. An expression for the CTOD is given by:

$$
C T O D=\frac{K_{I}^{2}}{E \sigma y}
$$

where $K_{I}$ is the mode I (tension) stress intensity factor, $E$ is the modulus of elasticity, and $\sigma_{y}$ is the yield stress of the material. Equating the CTODs for the Inconel 718 and copper, gives a relationship for the stresses in Inconel 718 and copper.

$$
\frac{\sigma_{718}}{\sigma_{C u}}=\frac{E_{718}}{E_{C u}} \frac{\sigma_{y, 718}}{\sigma y, C u}
$$


where the subscripts 718 and $C u$ refer to the values of Inconel 718 and copper 107. Using Equation B.2 and Equation A.2, which decomposes an applied stress $\sigma_{a p p}$ into stresses in the Inconel $\sigma_{718}$ and copper $\sigma_{C u}$, expressions for $\sigma_{718}$ and $\sigma_{C u}$ in terms of $\sigma_{a p p}$ are obtained. Thus, given $\sigma_{a p p}$ and crack length $a$, the stress intensity factors in the Inconel $718 K_{718}$ and copper $K_{C u}$ are known.

For a laminate CCT specimen, the final crack length was $6.98 \mathrm{~cm}$ and $\sigma_{a p p}$ is $42 \mathrm{MPa}$. This gives $K_{718}=82 \mathrm{MPa} \sqrt{\mathrm{m}}$ and $K_{C u}=31 \mathrm{MPa} \sqrt{\mathrm{m}}$. At this point, if all the load is carried by the Inconel 718 only, $K_{718}=196 \mathrm{MPa} \sqrt{\mathrm{m}}$. 


\section{Appendix $\mathbf{C}$}

\section{D.C. Potential Drop Crack Measurement Calibration}

Both theoretical and experimental calibrations may be used in the D.C. potential drop technique. Theoretical calibrations are well suited in specimens with simple geometries, whereas experimental calibrations are more applicable in specimens with more complex geometries. An experimental calibration was employed in the fatigue crack growth experiments of this thesis. A travelling microscope was used to optically measure the crack and a resistance measurement was simultaneously obtained. The crack length and resistance data were then normalized to initial values, $a_{o}$ and $R_{o}$ and plotted. A least squares fit polynomial for this data was obtained for each type of specimen: Inconel 718, copper 107, longitudinal laminate, and transverse laminate. The best least squares fit polynomial was chosen based on the minimum variance. The calibration polynomials are given below and the summary of their variance is given in Table C.1.

Inconel 718: 


$$
\begin{aligned}
\left(\frac{\mathrm{a}}{\mathrm{R}_{0}}\right)= & -1.15441+3.49456\left(\frac{\mathrm{R}}{\mathrm{R}_{0}}\right)-1.75871\left(\frac{\mathrm{R}}{\mathrm{R}_{0}}\right)^{2}+0.549662\left(\frac{\mathrm{R}}{\mathrm{R}_{\mathrm{o}}}\right)^{3}-0.104741\left(\frac{\mathrm{R}}{\mathrm{R}_{0}}\right)^{4}+ \\
& 1.16309 \times 10^{-2}\left(\frac{\mathrm{R}}{\mathrm{R}_{0}}\right)^{5}-6.87749 \times 10^{-4}\left(\frac{\mathrm{R}}{\mathrm{R}_{0}}\right)^{6}+1.66995 \times 10^{-5}\left(\frac{\mathrm{R}}{\mathrm{R}_{0}}\right)^{7}
\end{aligned}
$$

Copper 107:

$$
\begin{aligned}
\left(\frac{\mathrm{b}}{\mathrm{a}_{0}}\right)= & 1.87969-4.11566\left(\frac{\mathrm{R}}{\mathrm{R}_{0}}\right)+5.69579\left(\frac{\mathrm{R}}{\mathrm{R}_{0}}\right)^{2}-3.40625\left(\frac{\mathrm{R}}{\mathrm{R}_{0}}\right)^{3}-1.16938\left(\frac{\mathrm{R}}{\mathrm{R}_{0}}\right)^{4}- \\
& 0.248611\left(\frac{\mathrm{R}}{\mathrm{R}_{0} \text { rklk }}+3.31975 \times 10^{-2}\left(\frac{\mathrm{R}}{\mathrm{R}_{0}}\right)^{6}-2.70750 \times 10^{-3}\left(\frac{\mathrm{R}}{\mathrm{R}_{0}}\right)^{7}+\right. \\
& 1.23188 \times 10^{-4}\left(\frac{\mathrm{R}}{\mathrm{R}_{0}}\right)^{8}-2.39559 \times 10^{-6}\left(\frac{\mathrm{R}}{\mathrm{R}_{0}}\right)^{9}
\end{aligned}
$$

Laminate Longitudinal:

$$
\begin{aligned}
\left(\frac{a}{a_{0}}\right)= & 0.693334-0.590598\left(\frac{R}{R_{0}}\right)+1.36403\left(\frac{R}{R_{0}}\right)^{2}-0.599932\left(\frac{R}{R_{0}}\right)^{3}+0.125026\left(\frac{R}{R_{0}}\right)^{4}- \\
& 1.39523 \times 10^{-2}\left(\frac{R}{R_{0}}\right)^{5}+8.05898 \times 10^{-4}\left(\frac{R}{R_{0}}\right)^{6}-1.89676 \times 10^{-5}\left(\frac{R}{R_{0}}\right)^{7}
\end{aligned}
$$

Laminate Transverse:

$$
\begin{aligned}
\left(\frac{a}{a_{0}}\right)= & -1.48338+4.14936\left(\frac{R}{R_{0}}\right)-2.19925\left(\frac{R}{R_{0}}\right)^{2}+0.729157\left(\frac{R}{R_{0}}\right)^{3}-0.150281\left(\frac{R}{R_{0}}\right)^{4}+ \\
& 1.82853 \times 10^{-2}\left(\frac{R}{R_{0}}\right)^{5}-1.19135 \times 10^{-3}\left(\frac{R}{R_{0}}\right)^{6}+3.19078 \times 10^{-5}\left(\frac{R}{R_{0}}\right)^{7}
\end{aligned}
$$

The D.C. potential drop calibration was verified against optical measurements and is summarized in Table C.2. Agreement with optical measurements was good. Verification according to the ASTM E - 399 Standard [67] to account for crack front curvature was performed and summarized in Table tb;dc-astm. Agreement was good, and since the error was less than 5\%, ASTM deems that no correction to the crack length measurements is necessary. 


\begin{tabular}{|l|c|c|}
\hline Material & $\begin{array}{c}\text { Degree of Calibration } \\
\text { Polynomial }\end{array}$ & Variance \\
\hline Inconel 718 & 7 & $1.65 \times 10^{-4}$ \\
Copper 107 & 9 & $5.20 \times 10^{-5}$ \\
Lam. Lng. & 7 & $7.84 \times 10^{-5}$ \\
Lam. Trn. & 7 & $1.05 \times 10^{-3}$ \\
\hline
\end{tabular}

Table C.1: D.C. Potential Drop Calibration Least Squares Polynomial Statistics

\begin{tabular}{|l|c|c|c|}
\hline Specimen & $\begin{array}{c}\text { DC Potential } \\
\text { Drop 2a }\end{array}$ & $\begin{array}{c}\text { Optical } \\
2 \mathrm{a}\end{array}$ & \% Error \\
\hline Cu 107 2L & 1.517 & 1.5161 & 0.06 \\
& 2.003 & 1.9780 & 1.27 \\
Lam Lng 23 & 1.507 & 1.4713 & 2.43 \\
& 2.024 & 2.0083 & 0.78 \\
Lam Trn 32 & 1.513 & 1.3407 & 12.8 \\
& 1.874 & 1.6172 & 15.9 \\
\hline
\end{tabular}

Table C.2: Verification of DC Potential Crack Measurement with Optical Measurement

\begin{tabular}{|l|c|c|c|}
\hline Specimen & $\begin{array}{c}\text { DC Potential Drop } \\
\text { Measurement }\end{array}$ & $\begin{array}{c}\text { ASTM E 647-86a } \\
\text { 3 Point Average }\end{array}$ & \% Error \\
\hline Cu 107 2L & 2.556 & 2.6083 & 2.0 \\
Lam Lng 23 & 2.626 & 2.6597 & 1.3 \\
Lam Trn 32 & 2.614 & 2.6270 & 0.5 \\
\hline Cu 107 2L & & & \\
at 1.5 in. & 1.517 & 1.5347 & 1.2 \\
\hline
\end{tabular}

Table C.3: Verification of DC Potential Crack Measurement with ASTM E647-86a Standard 


\section{Bibliography}

[1] Carlson, R.J., Linse, V.D., and Wittman, R.H., "Explosion Welding Bonds Metals, Large Areas," Materials Engineering, July 1968.

[2] Cowan, G.R., Bergman, O.R., and Holtzman, A.H., "Mechanism of Bond Zone Wave Formation in Explosion-Clad Metals," Metallurgical Transactions, Volume 2, November 1971.

[3] Holtzman, A.H., and Cowan, G.R., "Bonding of Metals with Explosives," Welding Research Council Bulletin No. 104, April 1965.

[4] Linse, V.D., "The Application of Explosive Welding to Turbine Components," A.S.M.E. Paper No. 74-GT-85.

[5] Linse, V.D. and Lalwaney, N.S., "Explosion Welding," Journal of Metals, Volume 36, No. 5, May 1984.

[6] Rhinehart, J.S. and Pearson, J., "Explosive Metal Working of Metals," The Macmillian Company, New York, 1963.

[7] Sharp, W.F., "The Explosion Cladding Process,"Engineering Designer, September/October 1979.

[8] Explosive Fabricators Inc., "Explosion Clad Metals," Brochure.

[9] Coffey, J.M. and Whittle, M.J.,"Non-destructive Testing: Its Relation to Fracture Mechanics and Component Design," Philosophical Transactions Royal Society London, Volume 299, 1981, pp. 93-110.

[10] Newman, J.C. and Raju, I.S., " An Empirical Stress- Intensity Factor Equation for the Surface Crack," Engineering Fracture Mechanics, Vol. 15, No. 1-2, pp. 185-192, 1981.

[11] Feng, J., Vieira, R., Thome, R.J., and Pelloux, R.M., "Localized Shear Bands in Explosively Bonded Alloy 718 / Copper / Alloy 718 Lamiıates," Superalloy 
718 : Metallurgy and Applications, E.A. Loria ed., The Minerals, Metals \& Materials Society, 1989.

[12] Feng, J., Vieira, R., McClintock, F.A., Pelloux, R.M., "Effect of Copper/Inconel Ratio on Fatigue Life of Inconel/Copper/Inconel Laminate at Room Temperature,", CIT Group, MIT Plasma Fusion Center, Internal Report GRD-41, July 1988 .

[13] Feng, J., McClintock, F.A., Pelloux, R.M., "Application of Fatigue Damage Concepts to Estimate PF Coil Fatigue Life (Inconel-Copper-Inconel Laminate)," CIT Group, MIT Plasma Fusion Center, Internal Report GRD-32, January 1988.

[14] Vieira, R., Feng, J., Pelloux, R. M., "Evaluation of the Effects of Ripple Orientation and Ripple Width on Fatigue Life of Copper/Inconel/Copper Laminate Manufacturing Requirements of Interface," CIT Group, MIT Plasma Fusion Center, Internal Report GRD-35, May 1988.

[15] Vieira, R., "Copper C10700 Mechanical Properties," CIT Group, MIT Plasma Fusion Center, Internal Report GRD-21, July 1987.

[16] Feng, J. and Pelloux, R.M., "Failure Analysis of a Fractured Fatigue Specimen for Inconel 718/ Copper/ Inconel 718 Laminate Composite," CIT Group, MIT Plasma Fusion Center, Internal Report TR\#1, March 1987.

[17] Feng, J. and Pelloux, R.M., "Metallurgical Analysis of an Inconel 718 / Copper / Inconel 718 Laminate Composite," CIT Group, MIT Plasma Fusion Center, Internal Report T'R\#2, April 1987.

[18] Feng, J. and Pelloux, R.M., "Failure Analysis of a Fractured Fatigue Specimen of Inconel 718 / Copper / Inconel 718 Laminate Composite," CIT Group; MIT Plasma Fusion Center, Internal Report GRD-13, May 1987.

[19] Feng, J. and Pelloux, R.M., "Failure Analysis of the Fatigue Specimen Fractured at a Hole," CIT Group, MIT Plasma Fusion Center, Internal Report TR\#5, June 1987.

[20] Feng, J. and Pelloux, R.M., "Failure Analysis of a Large LCF Specimen," CIT Group, MIT Plasma Fusion Center, Internal Report TR\#6, August 1987.

[21] Feng, J. and Pelloux, R.M., "Failure Analysis of a Small LCF Specimen with $\mathrm{Cu} / \mathrm{Inc}=50 / 50$ and with Eight Notches in Inconel," CIT Group, MIT Plasma Fusion Center, Internal Report TR\#7, September 1987.

[22] Vieira, R. and Feng, J., "S-N Curves of Inconel / Copper / Inconel Laminates with Inconel / Copper Ratio $=60 / 40$ at Room Temperature," CIT Group, MIT Plasma Fusion Center, Internal Report, September 1987. 
[23] Becker, H., Besen, M., Bobrov, E., Chen, J., Montgomery, D.B., Tognarelli, D., and Walty, R., "Structural Properties of Reinforced Copper," MIT Plasma Fusion Center Report PFC/RR-86-12.

[24] MIT Plasma Fusion Center, "Alcator C-MOD Proposal," Report, PFC/RR85-18, DOE/ET-51013-158, October 1985.

[25] MIT Plasma Fusion Center, "Alcator C-MOD Proposal Addendum," April 1986.

[26] Hutchinson, I.H, et. al. "The Physics and Engineering of Alcator C-MOD,"MIT Plasma Fusion Center Report PFC/RR-88-11, August 1988.

[27] Instron Corporation, "Instron 8500 Series Digital Servohydraulic Testing Instruments," brochure, 1987.

[28] Huntington Alloys, Inc., "Inconel 718," Materials Specification, Third Edition, 1978.

[29] Society of Automotive Engineers, "Aerospace Material Specification AMS 5596E," Revised July 1984.

[30] James, L.A.,"Fatigue-Crack Growth Correlations for Alloy 718," Hanford Engineering Development Laboratory, HEDL-TME 83-7, May 1983.

[31] James, L.A.,"Fatigue Crack Propagation in Alloy 718: A Review," Superalloy 718 : Metallurgy and Applications, E.A. Loria ed., The Minerals, Metals \& Materials Society, 1989.

[32] Mills, W.J., "Fracture Toughness Variations for Alloy 718 Base Metal and Welds," Superalloy 718 : Metallurgy and Applications, E.A. Loria ed., The Minerals, Metals \& Materials Society, 1989.

[33] Tobler,R.L., "Low Temperature Effects on the Fracture Behaviour of a Nickel Base Superalloy," Cryogenics, November 1976.

[34] Mills, W.J. and Blackburn, L.D., "Fracture Toughness Variations in Alloy 718," Transactions of the AMSE, Vol. 110, July 1988.

[35] Smith, H.H. and Michel, D.J.,"Effect of Heat Treatment on Fatigue Crack Propagation and Deformation Mode in Alloy 718 at Elevated Temperatures," Naval Research Laboratory, NRL Memorandum Report 3810, July 1978.

[36] Muzyka, D.R. and Maniar, G.N., "Effects of Solution Treating Temperature and Microstructure on the Properties of Hot Rolled 718 Alloy," Metals Engineering Quarterly, American Society for Metals, November 1969. 
[37] Loier, C., Ottmann, M.C., and Leymonie, C., "Structural Transformations and Mechanical Properties of Two Non-magnetic Alloys (Inconel 718 and ASTM A 286)," Materials Science and Engineering, 63 (1984).

[38] Vieira, R., "Alcator C-MOD Inconel 718 Tensile Test Data," MIT Plasma Fusion Center Internal Memorandurı, September 28, 1987.

[39] American Society for Metals, "Copper," Metals Handbook Ninth Edition Volume 2 Properties and Selection: Nonferrous Alloys and Pure Metals, A.merican Society for Metals, 1986

[40] Revere Copper Products Inc.,"Certificate of Test for CDA 107 Silver Bearing Oxygen Free Copper Plates, Cold-rolled 50\%," Revere No. 833414, June 1987.

[41] Yeske,R.A. and Weertman J., "Fatigue Crack Propagation Under Varied Mean Stress Conditions," Metallurgical Transactions, Volume 5, September 1974.

[42] Alcator Group, MIT Plasma Fusion Center,"C-MOD Core Copper Specification," Attachment No. 1 to FC-A-692111, February 1987.

[43] Alcator Groupg, MIT Plasma Fusion Center, "Inconel 718 Specification," Attachment No. 1 to FC-A-665711, January 1987.

[44] Johnson, H.H., "Calibrating the Electric Potential Method for Studying Slow Crack Growth," Materials Research 60 Standards, Volume 5, Number 9, September 1965, pp. 442-445.

[45] Li,Che-Yu and Wei, R.P., "Calibrating the Electrical Potential Method for Studying Slow Crack Growth," Materials Research \& Standards, Vol. 6, No. 8, August 1966, pp. 392-394.

[46] Andresen, P.L., "Switched DC Potential Drop Technique for Crack Following on Compact Tension Specimens," General Electric Corp. Research and Development, Memo, 1984.

[47] Wei, R.P., and Brazill, R.L., "An Assessment of A-C and D-C Potential Systems for Monitoring Fatigue Crack Growth," Fatigue Crack Growth Measurement and Data Analysis ASTM STP 738, S.J. Hudak, Jr., and R.J. Bucci, Eds., American Society for Testing and Materials, 1981.

[48] Halliday, M.D. and Beevers, C.J., "The d.c. Electrical Potential Method for Crack Length Measuremennt," Measurement of Crack Length and Shape During Fracture and Fatigue, C.J. Beevers Ed., Engineering Materials Advisory Services (EMAS), Cradley Heath, Warley, West Midlands, U.K., 1980. 
[49] Pickard, A.C. and Hicks, M.A., "Crack Length Determination Using the d.c. Electrical P.D. Technique - A Comparison of Calibration Methods," Advances in Crack Length Measurement, C.J. Beevers Ed., Engineering Advisory Services (EMAS), Cradley Heath, Warley, Wes $₫$ Midlands, U.K., 1982.

[50] Ingelbrecht, C.D. and Ward-Close, C.M., "A Computer Programme for the Calibration of the d.c. P.D. Method of Crack Length Measurement," Advances in Crack Length Measurement, C.J. Beevers Ed., Engineering Advisory Services (EMAS), Cradley Heath, Warley, West Midlands, U.K., 1982.

[51] Burgers, A. and Kemper, P.D., "Automatic Crack Length Measurements by the Electrical P.D. Method with Computer Control," Advances in Crack Length Measurement, C.J. Beevers Ed., Engineering Advisory Services (EMAS), Cradley Heath, Warley, West Midlands, U.K., 1982.

[52] Ward-Close, C.M., "A Micro Computer Based Crack Measurement and Test Control System," Advances in Crack Length Measurement, C.J. Beevers Eid., Engineering Advisory Services (EMAS), Cradley Heath, Warley, West Midlands, U.K., 1 Gú2.

[53] Electronic Measurements Inc., "EMHP DC Power Supply Mode EMHP-30600-41224 Operation and Reference Manual," Electronic Measurements, New Jersey, 1983.

[54] Hogg, R.V. and Ledolter, J., Engineering Statistics, Macmillan Publishing Co., New York, 1987.

[55] Ewalds, H.L. and Wanhill, R.J.H., Fracture Mechanics, Edward Arnold and Delftse Uitgevers Maatschappij, Delft, 1986.

[56] Broek, D., Practical Uses of Fracture Mechanics, Kluwer Academic Publishers, Dordrecht, 1989.

[57] Broek, D., Elementary Engineering Fracture Mechanics, Fourth Revised Edition, Martinus Nijhoff Publishers, Dordrecht, 1986.

[58] Dieter, G.E., Mechanical Metallurgy, 3rd edition, McGraw-Hill, New York, 1986.

[59] Collins, J.A., Failure of Materials in Mechanical Design, Analysis, Prediction, Prevention, J. Wiley \& Sons, New York, 1981.

[60] Kanninen, M.F. and Popelar, C.H., Advanced Fracture Mechanics, Oxford Un:versity Press, 1985.

[61] Schijve, J., "Four Lectures on Fatigue Crack Growth," Report LR-254, Delft University of Technology, Delft - The Netherlands, October 1977. 
[62] Elber,W., "The Significance of Fatigue Crack Closure," Damage Tolerance in Aircraft Structures, ASTM STP486, Philidephia, 1971.

[63] Banerjee, S., "A Review of Crack Closure," Air Force Wright Aeronautical Laboratories Technical Report No. AFWAL-TR-84-4031, April 1984.

[64] Paris, P.C. and Erdogan, F., "A Critical Analysis of Crack Propagation Laws," Journal of Basic Engineering Transactions, ASME, Volume 85, December 1963.

[65] Forman,R.G., Kearny,V.F., and Engle, R.M. "Numerical Analysis of Crack Propagation in Cyclic-Loaded Structures," Journal of Basic Engineerin J, ASME Transactions, Series D, Volume 89, 1967.

[66] Feng,J. and Vieira, R., private communication, May 1990.

[67] American Society of Ter"ing and Materials, "Standard Test Method for Measurement of Fatigue Cra. Growth Rates E-647 - 86a", Annual Book of ASTM Standards, Vol. 3.01, 1987.

[68] American Society for Testing and Materials, "Standard Test Method for Tension Testing of Metallic Materials," Designation: E 8-85a, Annual Book of ASTM Standards, Vol. 3.01, 1987.

[69] American Society for Testing and Materials, "Standard Test Methods Determining the Average Grain Size," Designation: E $112-85$, Annual Book of ASTM Standards, Vol. 3.01, 1987.

[70] American Society for Testing and Materials, "Standard Test Method for PlaneStrain Fracture Toughness of Metallic Materials," Designation: E $399-83$, Annual Book of ASTM Standards, Vol. 3.01, 1987.

[71] American Society for Testing and Materials, "Standard Terminology Relating to Fracture Testing," Designation: E $616-82$, Annual Book of ASTM Standards, Vol. 3.01, 1987.

[72] American Society for Testing and Materials, "Standard Definitions of Terms Relating to Fatigue," Designation: E 1150 - 87, Annual Book of ASTM Standards, Vol. 3.01, 1987

[73] American Society for Testing and Materials, "Standard Definitions of Terms Relating to Methods of Mechanical Testing," Designation: E 6-86. Annual Book of ASTM Standards, Vol. 3.01, 1987.

[74] American Society for Metals, "Ductile and Brittle Fractures," Metals Handbook Ninth Edition Volume 11: Failure Analysis and Prevention, American Society for Metals, 1986. 
[75] American Society for Metals, "Fatigue Failures," Metals Handbook Ninth Edition Volume 11 : Failure Analysis and Prevention, American Society for Metals, 1986.

[76] American Society for Metals, "Fatigue Crack Propagation," Merais Handbook Ninth Edition Volume 8: Mechanical Testing, American Societr for Metals, 1985.

[77] Ishida, M., "On the Tension of a Strip with a Central Elliptical Hole," Trans. Jap. Soc. Mech. Eng., 21,1955.

[78] Feddersen, C.E., Discussion, ASTM STP 410, 1967.

[79] Coffin, L.F., "A Review of Fatigue Predictive Methods in the Regime where Inelastic Strains Dominate," ASME International Conference on Advances in Life Prediction Methods, D.A. Woodford and J.R. Whitehead Eds., Anerican Society of Mechanical Engineers, 1983.

[80] El Haddad, M.H., Topper, T.H., and Topper, T.N., "Fatigue Life Predictions of Smooth and Notched Specimens Based on Fracture Mechanics," ASME International Conference on Advances in Life Prediction Methods, D.A. Woodford and J.R. Whitehead Eds., American Society of Mechanical Engineers, 1983.

[81] Leis, B.N., "A Method of Predicting Crack Initiation Fatigue Life of Structural Components," ASME International Conference on Advances in Life Prediction Methods, D.A. Woodford and J.R. Whitehead Eds., American Society of Mechanical Engineers, 1983.

[82] Tomalin, D.S, "Fundamentals of The Past, The Present, and The Future of Wire Technology for EDM Applications Part 1," EDM Digest, Vol. X, No. 4, July/August 1988.

[83] Tomalin, D.S, "Fundamentals of The Past, The Present, and The Future of Wire Technology for EDM Applications Part 2," EDM Digest, Vol. X, No. 5, September/October 1988.

[84] Center for Metals Fabrication, "Electrical Discharge Machining," TechCommentary, Vol. 3, No 1, 1986. 

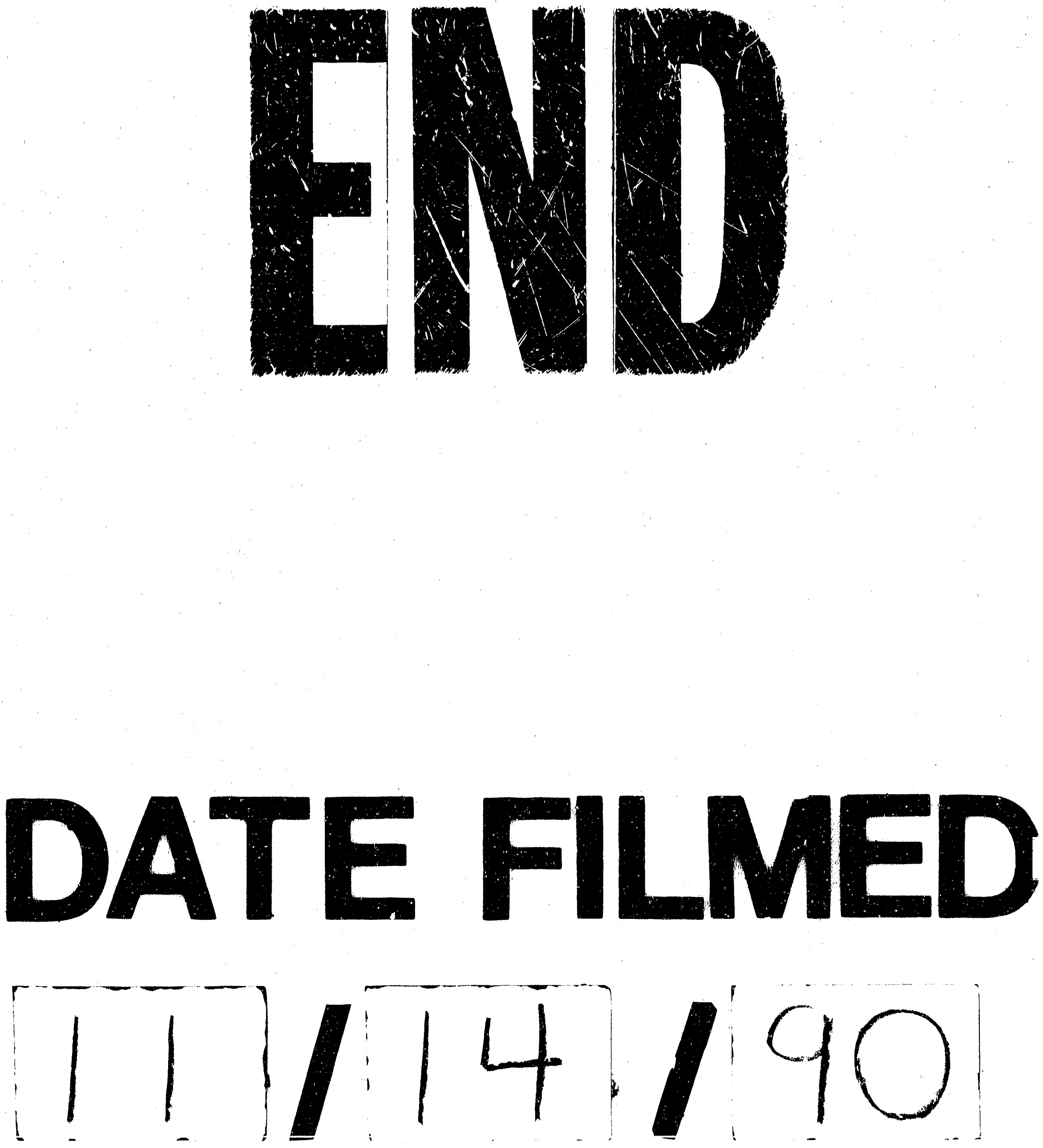
